\title{
Morphology-Governed Performance of Multi-Dimensional Photocatalysts for Hydrogen Generation
}

\author{
Zhishun Wei ${ }^{1, *(\mathbb{C}}$, Tharishinny Raja Mogan ${ }^{2}$, Kunlei Wang ${ }^{2,3}$, , Marcin Janczarek ${ }^{4}$ and Ewa Kowalska ${ }^{2, *(\mathbb{D})}$ \\ 1 Hubei Provincial Key Laboratory of Green Materials for Light Industry, Hubei University of Technology, \\ Wuhan 430068, China \\ 2 Institute for Catalysis, Hokkaido University, Sapporo 001-0021, Japan; rajamogan.t@cat.hokudai.ac.jp (T.R.M.); \\ kunlei@cat.hokudai.ac.jp (K.W.) \\ 3 Northwest Research Institute, Co., Ltd. of C.R.E.C., Lanzhou 730000, China \\ 4 Faculty of Chemical Technology, Institute of Chemical Technology and Engineering, \\ Poznan University of Technology, 60-965 Poznan, Poland; marcin.janczarek@put.poznan.pl \\ * Correspondence: wei.zhishun@hbut.edu.cn (Z.W.); kowalska@cat.hokudai.ac.jp (E.K.)
}

Citation: Wei, Z.; Mogan, T.R.; Wang, K.; Janczarek, M.; Kowalska, E.

Morphology-Governed Performance of Multi-Dimensional Photocatalysts for Hydrogen Generation. Energies 2021, 14, 7223. https://doi.org/ $10.3390 /$ en14217223

Academic Editors: Viviana Cigolotti and Angelo Basile

Received: 25 August 2021

Accepted: 25 October 2021

Published: 2 November 2021

Publisher's Note: MDPI stays neutral with regard to jurisdictional claims in published maps and institutional affiliations.

Copyright: () 2021 by the authors. Licensee MDPI, Basel, Switzerland. This article is an open access article distributed under the terms and conditions of the Creative Commons Attribution (CC BY) license (https:// creativecommons.org/licenses/by/ $4.0 /)$.

\begin{abstract}
In the past few decades, extensive studies have been performed to utilize the solar energy for photocatalytic water splitting; however, up to the present, the overall efficiencies reported in the literature are still unsatisfactory for commercialization. The crucial element of this challenging concept is the proper selection and design of photocatalytic material to enable significant extension of practical application perspectives. One of the important features in describing photocatalysts, although underestimated, is particle morphology. Accordingly, this review presents the advances achieved in the design of photocatalysts that are dedicated to hydrogen generation, with an emphasis on the particle morphology and its potential correlation with the overall reaction performance. The novel concept of this work-with the content presented in a clear and logical way-is based on the division into five parts according to dimensional arrangement groups of $0 \mathrm{D}, 1 \mathrm{D}, 2 \mathrm{D}, 3 \mathrm{D}$, and combined systems. In this regard, it has been shown that the consideration of the discussed aspects, focusing on different types of particle morphology and their correlation with the system's efficiency, could be a promising route for accelerating the development of photocatalytic materials oriented for solar-driven hydrogen generation. Finally, concluding remarks (additionally including the problems connected with experiments) and potential future directions of particle morphology-based design of photocatalysts for hydrogen production systems have been presented.
\end{abstract}

Keywords: water splitting; hydrogen generation; heterogeneous photocatalysis; vis response; nanoparticles; nanotubes; nanosheets; quantum dots

\section{Introduction}

Green and sustainable materials have attracted a lot of interest in the use of renewable energy sources instead of environmentally harmful and nonrenewable fossil fuels [1-3]. The renewable sources (e.g., water, tide, wind, and solar energy) are attractive options in comparison to conventional fuels [4-6]. Hydrogen molecules could be used as a clean and efficient carrier of energy, since they produce only water during combustion $[7,8]$. The other way around-water splitting into hydrogen and oxygen-could be realized by either solar or electrical power $[9,10]$. Commonly, solar-driven water splitting is considered to be a better choice than electrically powered systems, since it is eco-friendly.

Utilization of solar energy to generate hydrogen through water splitting is an ultimate strategy for solving the energy and environmental challenges caused by exhausting fossil fuels; additionally, it is a solution to the emission of greenhouse gases that originate from the combustion of fuels. Accordingly, photocatalysis is a potential method for the efficient use of solar energy, directly through hydrogen production from water. Many photocatalysts, 
such as various oxides [11], nitrides [12], and sulfides [13], have been fabricated and tested for hydrogen generation after the pioneering work of Fujishima and Honda in 1972 [14].

While the term "photocatalysis" might suggest that it is a simple combination of irradiation ("photo") and catalysis (i.e., the acceleration of the reaction rate in the presence of a photocatalyst), it should be pointed out that, usually, the photocatalytic reactions do not proceed in the absence of a photocatalyst nor in the dark. Therefore, the photocatalyst does not only accelerate the reaction rate, but it is necessary for the reaction to happen, as clearly discussed in the review papers by Ohtani $[15,16]$. In the case of heterogeneous photocatalysis, wide bandgap semiconductors are usually used as photocatalytic materials, since they have good redox properties. In brief, under irradiation, the photocatalyst is excited if the energy of photons is equal to or larger than its bandgap, causing electrons to be excited to the conduction band (CB), leaving the holes in the valence band (VB). Accordingly, the photogenerated charge carriers might either migrate to the surface of the photocatalysts, where they initiate the redox reactions, or recombine with each other, which causes activity loss. Obviously, much effort has been taken for the inhibition of charge carriers' recombination to get high quantum yields of photocatalytic reactions. Moreover, the difference between the photocatalytic and photosynthetic processes has also been pointed out by the authors of Refs. [17,18], where the former and the latter deal with thermodynamically downhill $(\Delta G<0)$ and thermodynamically unfavorable $(\Delta G>0)$ processes (e.g., oxidative degradation of organic compounds and water splitting), respectively. Accordingly, water splitting is commonly classified as "artificial photosynthesis" that mimics natural photosynthesis in green plants. However, it must be realized that in the case of natural photosynthesis, there are two main reagents (i.e., water and carbon dioxide); thus, simple water splitting does not solve the problem of $\mathrm{CO}_{2}$ excess in the atmosphere (i.e., its capture and conversion). Accordingly, more advanced systems with simultaneous $\mathrm{CO}_{2}$ reduction (into useful fuels) and $\mathrm{H}_{2} \mathrm{O}$ oxidation have also been proposed that could be named as "artificial photosynthesis", without any doubt [19-23].

Titania $\left(\mathrm{TiO}_{2}\right.$-titanium dioxide) is probably the most broadly investigated semiconductor (SC) photocatalyst because of its low cost, nontoxicity, and abundance. Moreover, many other novel photocatalysts have also been designed and developed with different dimensions and morphologies for high activity in hydrogen production from water splitting. There are huge numbers of research papers on photocatalytic hydrogen evolution and even overall water splitting [24-29], accompanied by comprehensive reviews [30-32]. Many of these papers deal with the challenge how to synthesize novel chemical compounds with new intrinsic properties (i.e., bandgap energy and levels of conduction band (CB) and valence band (VB)) for both water reduction and water oxidation, preferably without the addition of any sacrificial reagent. Although these studies are considered as the most important for future development of solar energy technologies (i.e., vis-responsive materials), the morphology of photocatalytic materials are also very important for possible commercialization. It has been well presented by Liu et al. that photocatalysts' morphology might be a decisive factor for increasing the reaction selectivity and efficiency; additionally, the morphologically oriented studies enable the complex design of photocatalysts dedicated for a specified application, which might increase the chances of their successful commercialization [33]. However, there are only several review papers that deal with morphology, mainly focusing on 1D [34] and 2D materials [35-37], for hydrogen generation. Therefore, in this paper, we would like to present the recent trends in the development of novel photocatalysts with different morphologies, compositions, and performances. In order to make the content clear and logical, the present manuscript has been divided into five parts according to the dimensions of the photocatalysts; i.e., (i) zero-dimension (0D), (ii) one-dimension (1D), (iii) two-dimension (2D), (iv) three-dimension (3D), and also (iv) the composite photocatalysts constructed from two or even more dimensional structures (e.g., $0 \mathrm{D} / 1 \mathrm{D}, 0 \mathrm{D} / 2 \mathrm{D}, 1 \mathrm{D} / 2 \mathrm{D}$ and so on). Of course, in some cases, the classification is not so obvious, but we have tried to organize this review in a reader-friendly matter. 
In general, 0D nanomaterials include nanoclusters, quantum dots (QDs), and nanoparticles (NPs). Nanotubes, nanorods, nanowires, nanorings, nanobelts, and nanofibers belong to $1 \mathrm{D}$ nanomaterials. The 2D nanostructures might be recognized as nanofilms, nanoplates, nanosheets, and nanoflakes, etc.; whereas, 3D nanomaterials usually include meso/macroporous structures, flower-like materials, and honeycomb hierarchical (photonic crystals) composites that are constructed/accumulated by one or more types of $0 \mathrm{D}, 1 \mathrm{D}$, and $2 \mathrm{D}$ nanostructures.

\section{Zero-Dimension (0D) Photocatalysts}

The first group of photocatalytic nanomaterials with the simplest structure is characterized by 0D morphology (i.e., nanoclusters, QDs, and NPs), as summarized in Table 1. Of course, NPs are the most broadly used and investigated for photocatalysis and other applications due to the easiest and fastest preparation methods. Usually, commercial photocatalysts (e.g., famous P25) belong to this group. Although, Fujishima and Honda showed water splitting on irradiated titania [14], the photocatalytic activity was low; thus, various studies have been performed on activity enhancement. One of the first approaches dealt with platinized photocatalysts, as it has been shown that photogenerated electrons in irradiated titania are quickly scavenged by platinum deposits, hindering charge carriers' recombination and working as co-catalysts for hydrogen evolution [38-43]. An interesting study has been performed by Wang et al., who showed that, in the case of commercial photocatalyst P25, platinum is preferably deposited on rutile first, and then on anatase [44]. Moreover, it has been concluded that one platinum deposit on the surface of large aggregates of titania (aggregation caused by thermal treatment) is enough to cause efficient hydrogen evolution under $\mathrm{UV}$ irradiation $\left(\mathrm{CH}_{3} \mathrm{OH}\right.$ as a hole scavenger), thanks to interparticle electron transfer (IPCT) between even the same kinds of titania NPs (anatase-anatase or rutile-rutile) in one aggregate, as shown in Figure 1.

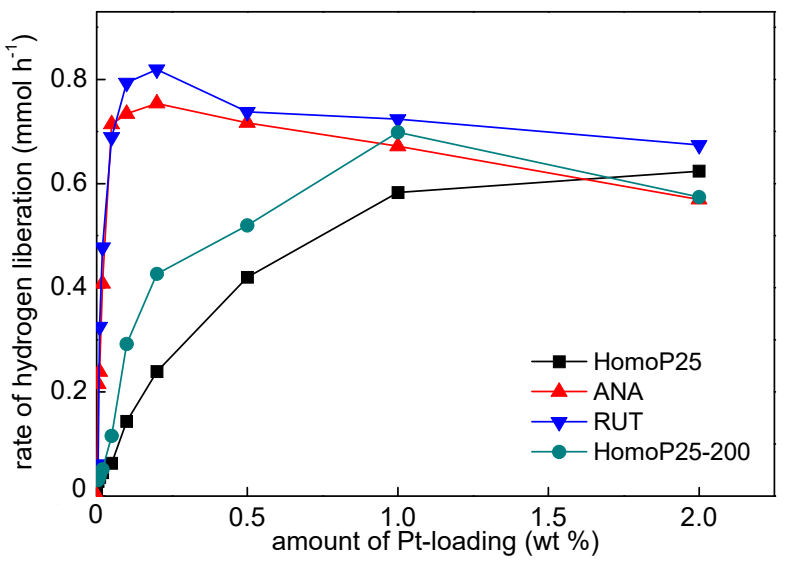

(a)

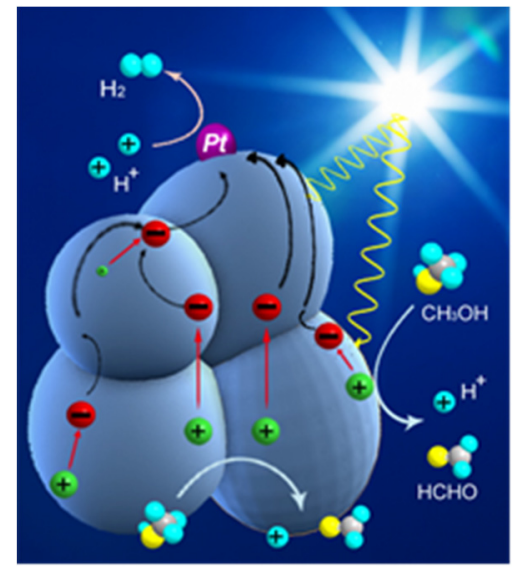

(b)

Figure 1. Hydrogen evolution on titania modified with platinum: (a) Dependence of photocatalytic activity on the amount of Pt loading on homogenized P25 (HomoP25), HomoP25 annealed at $200{ }^{\circ} \mathrm{C}$ (HomoP25-200), and isolated phases from HomoP25 by the chemical dissolution method, followed by purification by thermal treatment: isolated anatase (ANA) and isolated rutile (RUT); (b) Schematic drawing showing IPCT on aggregated single-phase titania particles, e.g., Pt@ANA and Pt@RUT. Copyright 2018 Elsevier.

The importance of platinum localization on different parts of a two semiconductor photocatalyst has also been investigated for polypyrrole (PPy)-titania nanocomposites [45]. It has been found that platinum should be deposited on both semiconductors simultaneously, resulting in high hydrogen evolution rate $\left(\mathrm{CH}_{3} \mathrm{OH}\right.$ as a hole scavenger) (i.e., 125.1 and $3.2 \mathrm{mmol} \mathrm{g}^{-1} \mathrm{~h}^{-1}$ under UV and vis ( $>420 \mathrm{~nm}$ ) irradiation, respectively), which is 
much higher than that when platinum is only deposited on one component (ca. five or ca. seven times lower UV activity for Pt deposited only on titania or only on PPY, respectively), probably due to efficient multiple electron transfer pathways. Similarly, Abe et al. have pointed out that the localization of platinum is also very important for the suppression of a backward reaction for water splitting under vis irradiation $(410 \mathrm{~nm}>$ $\lambda>800 \mathrm{~nm}$; Pt as a co-catalyst), according to two-step photoexcitation: dye-sensitized layered niobate and tungsten oxide photocatalysts in the presence of shuttle redox mediator (triiodide/iodide) [46]. It has been shown that a $\mathrm{Pt}$ co-catalyst loaded inside the interlayer of $\mathrm{H}_{4} \mathrm{Nb}_{6} \mathrm{O}_{17}$ allows the reduction of water in the presence of $\mathrm{I}_{3}{ }^{-}$, because of the inhibited access of $\mathrm{I}_{3}{ }^{-}$to the reduction site (co-catalyst localized inside the structure) by the electrostatic repulsion between the negatively charged $\left(\mathrm{Nb}_{6} \mathrm{O}_{17}\right)^{4-}$ layers and triiodide anions.

Interesting studies have been performed for faceted anatase particles modified with different noble metals (i.e., $\mathrm{Pt}, \mathrm{Au}, \mathrm{Cu}$, and $\mathrm{Ag}$ ) by the photodeposition method in the presence of methanol as a hole scavenger [43]. It has been found that the photodeposition of gold and platinum is very fast ( $>5 \mathrm{~min}$ is sufficient for the complete deposition of $2 \mathrm{wt} \%$ ), as shown in Figure 2a. In contrast, the photodeposition of copper and silver needs a much longer irradiation time ( 8 and $45 \mathrm{~min}$, respectively). The hydrogen evolution rate correlates well with the reduction ability of cations (induction period), i.e., an increase in the induction period correlates with a slower rate of $\mathrm{H}_{2}$ generation. It has been proposed that rates of formation of deposits of noble metals and hydrogen evolution correspond to electron affinity of semiconductors and the work function of metal, i.e., the formed Schottky barrier. Interestingly, slightly different activities have been achieved for metal pre-modified titania samples, i.e., photocatalytic activities measured, not during, but after metal deposition samples were first prepared with in situ hydrogen evolution (as illustrated in Figure 2a), then dried and used as photocatalysts (activities shown in Figure 2b). This difference could be explained by a higher content of oxidized forms of metals (especially lesser noble metals, i.e., silver and copper). For example, the co-catalytic function of $\mathrm{CuO}$ (similar electron scavenging ability to zero-valent copper) has been found for $\mathrm{CuO} / \mathrm{WO}_{3}$, with a multiple-electron reaction on the surface of cupric oxide [47]. Moreover, the participation of mixed oxides, such as cuprous and cupric oxides, in hydrogen evolution must also be considered, since such activity has been confirmed [48].

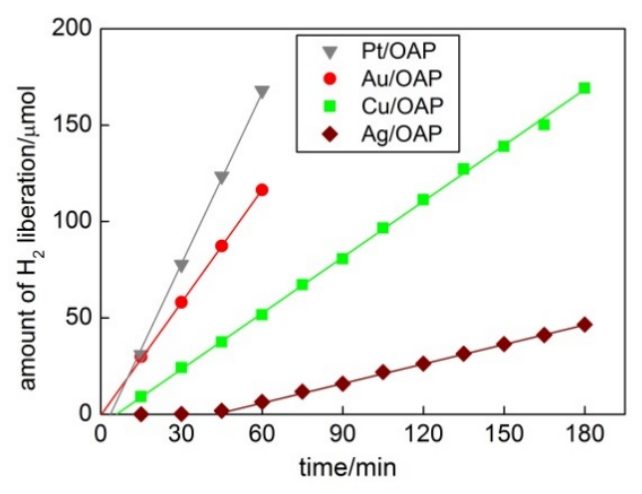

(a)

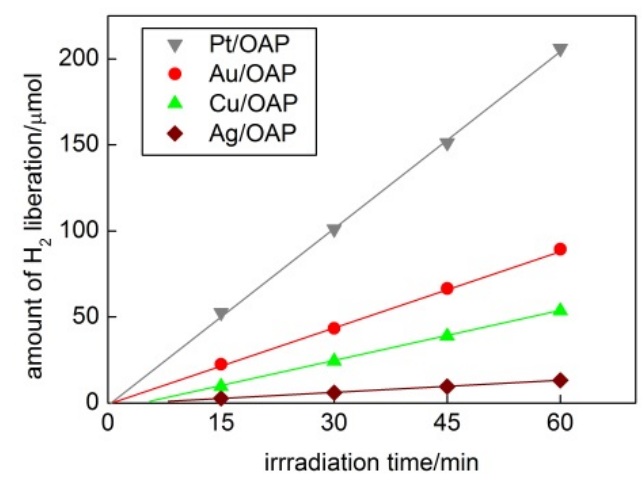

(b)

Figure 2. Hydrogen evolution on octahedral anatase particles (OAP): (a) during metal deposition; (b) after metal deposition. Copyright 2017, Creative Commons Attribution License.

Zero-valent copper has been proposed as a promising co-catalytic material for photocatalysis, since copper has similar electronic properties to silver and gold, and is much cheaper. However, copper is easily oxidized when kept under ambient conditions (as discussed above) $[42,43,49,50]$. Therefore, formed, less active copper species (though probably re-reduced under reductive conditions during hydrogen generation [43]) could seriously 
limit the practical application of copper-based photocatalysts [51]. In order to solve this problem, two approaches have been proposed. First, the stabilization of $\mathrm{Cu}$ NPs by titania when copper is built in titania aerogel structure [52]. Second, in situ encapsulation of copper NPs with N-graphitic carbon layers (N/C-coated $\mathrm{Cu}$ ) [51]. The N/C-coated $\mathrm{Cu}-\mathrm{TiO}_{2}$ composite possesses better photocatalytic properties than the uncoated $\mathrm{Cu}$ NPs, and 27 times higher activity for hydrogen generation than pristine titania. It has been proposed that the coating of $\mathrm{Cu}$ with $\mathrm{N} / \mathrm{C}$ both improves the stability and accelerates the interfacial charge migration. The encapsulation of copper can be easily obtained by using polyethylenimine as a surfactant, where the use of a surfactant with large carbon and nitrogen density favors the formation of $\mathrm{N}$-graphitic carbon coatings. This synthesis approach allows to prepare a cheap, stable, and efficient zero-valent $\mathrm{Cu}$, and it has been proposed that other non-noble metal catalysts could also be fabricated by this method [51].

It should be mentioned, that $\mathrm{H}_{2}$ evolution (or even overall water splitting) was firstly, carried out only under UV irradiation, as pristine titania is inactive under vis irradiation. Then, modified titania (via doping or surface modifications), e.g., with nonmetals [53,54], metals [55,56], and by coupling with other materials [57], has been applied. Interestingly, it has also been found that noble metals could be used for titania activation towards vis response because of plasmonic properties ("plasmonic photocatalysts") [58-61]. However, it should be stressed that, considering the mechanism via charge transfer, the direction of electron transfer is opposite during plasmonic photocatalysis than that during hydrogen evolution, i.e., from noble metal to titania. Therefore, though plasmonic photocatalysts are active under vis irradiation for various reactions, usually there is no (or very low, as compared with that under UV light) activity for hydrogen generation under sole vis irradiation [62-65]. Accordingly, either two kinds of metals (first for plasmonic excitation and second for hydrogen evolution) or more advanced structures (for example, the "advanced superstructure system", i.e., the composite of titania meso-crystals with deposits of noble metals $[66,67]$ (discussed in Section 6)), have been proposed.

For example, $\mathrm{Yu}$ et al. have obtained efficient hydrogen evolution on $\mathrm{TiO}_{2}$-based nanoheterostructures modified with Pt and Ag [68]. The development of metal-semiconductormetal nano-heterostructures for improving photocatalytic activity has been proposed, considering that they are not only the more efficient in harvesting light, but also in the spatial separation of charge carriers, which are important factors for high activity. The semiconductor NPs have been combined with two metals, and the disordered layers have been formed on the titania surface (self-doped (or hydrogenated) titania) to enhance the light harvesting efficiency [69]. Therefore, the $n-n^{+}$junction is obtained at the interface between stoichiometric $\left(\mathrm{n}-\mathrm{TiO}_{2}\right)$ and disordered $\left(\mathrm{n}^{+}-\mathrm{TiO}_{2}\right)$ titania. Additionally, the Schottky diode and Ohmic contact (on $\mathrm{n}-\mathrm{TiO}_{2}$ and $\mathrm{n}^{+}-\mathrm{TiO}_{2}$, respectively) result in multi-junctions ("multiple continuous built-in electric fields"), and thus, significantly improve carriers' separation. The multi-junctions' heterostructure $\left(\mathrm{Pt}-\mathrm{TiO}_{2}-\mathrm{H}-\mathrm{Ag}\right.$; Figure 3) shows highly enhanced photocatalytic activity. The photocatalytic activity for $\mathrm{H}_{2}$ evolution on $\mathrm{Pt}-\mathrm{TiO}_{2}-\mathrm{H}-\mathrm{Ag}$ under solar illumination is 8.3, 9.3, and 1.5 times higher than that on platinized samples P25 (Pt-P25), $\mathrm{TiO}_{2}\left(\mathrm{Pt}-\mathrm{TiO}_{2}\right)$, and hydrogenated $\mathrm{TiO}_{2}\left(\mathrm{Pt}-\mathrm{TiO}_{2}-\mathrm{H}\right)$, respectively. Additionally, the photocatalytic performance under vis irradiation has been improved for $\mathrm{Pt}_{-} \mathrm{TiO}_{2}-\mathrm{H}-\mathrm{Ag}$ in comparison to platinum-modified samples, reaching $2382.7 \mu \mathrm{mol} \mathrm{h}^{-1} \mathrm{~g}^{-1}$, i.e., being about 15.1, 17.2, and 1.4 times higher than that on $\mathrm{Pt}-\mathrm{P} 25, \mathrm{Pt}-\mathrm{TiO}_{2}$, and $\mathrm{Pt}-\mathrm{TiO}_{2}-\mathrm{H}$, respectively. Furthermore, the photocatalyst shows good stability (five re-cycles), suggesting that simultaneous extension of photoabsorption and improvement of the spatial separation of charge carriers could be used also for other wide bandgap metal-oxide semiconductor photocatalysts [68]. 


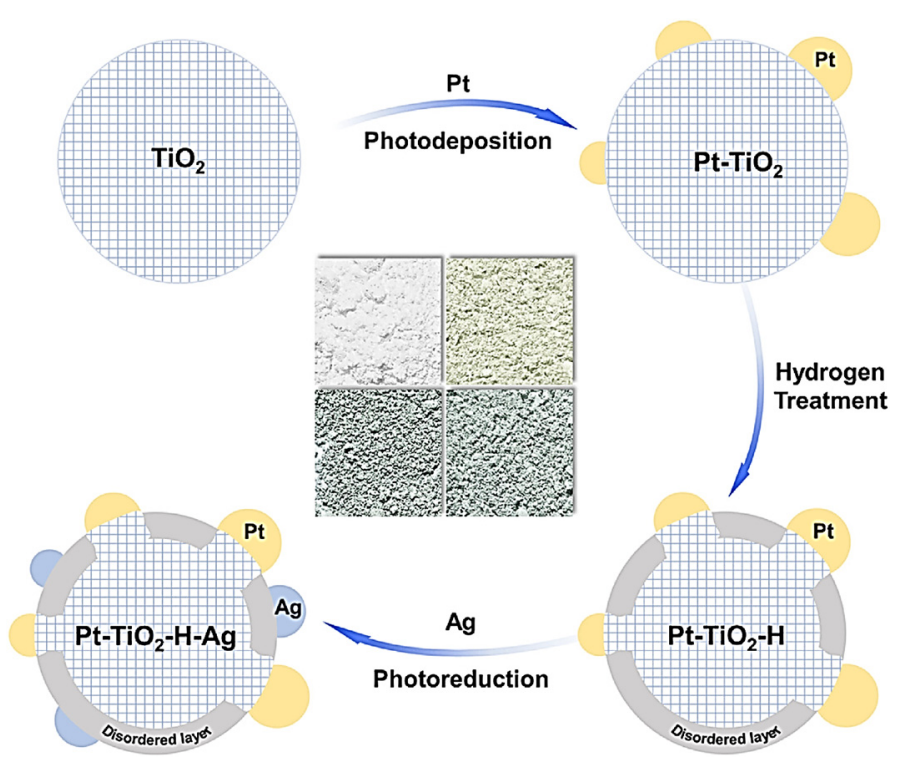

Figure 3. Scheme with photographs for the fabrication of $\mathrm{Pt}-\mathrm{TiO}_{2}-\mathrm{H}-\mathrm{Ag}$ nano heterostructure. Copyrights 2020 Elsevier [68].

It should also be mentioned that other metals have been used for titania modification towards hydrogen evolution. For instance, Luna et al. have modified titania NPs with two types of metals, i.e., noble and non-noble (Pd and Ni [70], and $\mathrm{Au}$ and Ni [56]). In both cases, the synergistic effect has been observed between both metals (Ni existing in both zero-valent and oxidized forms), and based on the investigation on the light absorption, the charge-carrier dynamics (time-resolved microwave conductivity; TRMC) and the photocatalytic performance (action spectra), it has been concluded that the main role of metal NPs is to act as catalytic sites for the recombination of atomic hydrogen. Unfortunately, hydrogen has been mainly generated at the UV range of solar spectrum, and only slight vis response has been noticed $(\lambda<420 \mathrm{~nm})$.

Huang et al. have synthesized titania co-modified with two non-noble metals ( $\mathrm{Sn}$ and $\mathrm{Ni}$ ) by surface organometallic chemistry [71]. The photocatalytic activities of the prepared photocatalysts have been evaluated by photocatalytic $\mathrm{H}_{2}$ evolution in the presence of ethylenediaminetetraacetic acid disodium salt (EDTA). The synergistic effect between the atomically separated centers of $\mathrm{Ni}$ and $\mathrm{Sn}$ has been noticed for solar-to-hydrogen conversion, and about one order improvement of hydrogen generation has been achieved for optimal photocatalysts $\left(\mathrm{Sn}_{1.12} / \mathrm{Ni}_{0.98} / \mathrm{TiO}_{2}\right)$, in comparison with a pristine titania sample under solar light illumination. It has been proposed that the synergistic effect relates to the heteroatomic clusters with the cyclic structure of eight members, i.e., [ $-\mathrm{O}-\mathrm{Ti}-$ $\mathrm{O}-\mathrm{Sn}-\mathrm{O}-\mathrm{Ni}-\mathrm{O}-\mathrm{Ti}-\mathrm{]}$ (Figure 4). Accordingly, efficient separation of charges and excitons are caused by an electron delocalization loop generated in $\mathrm{Ni}-\mathrm{O}-\mathrm{Ti}$ molecular linkages (Figure 5). 


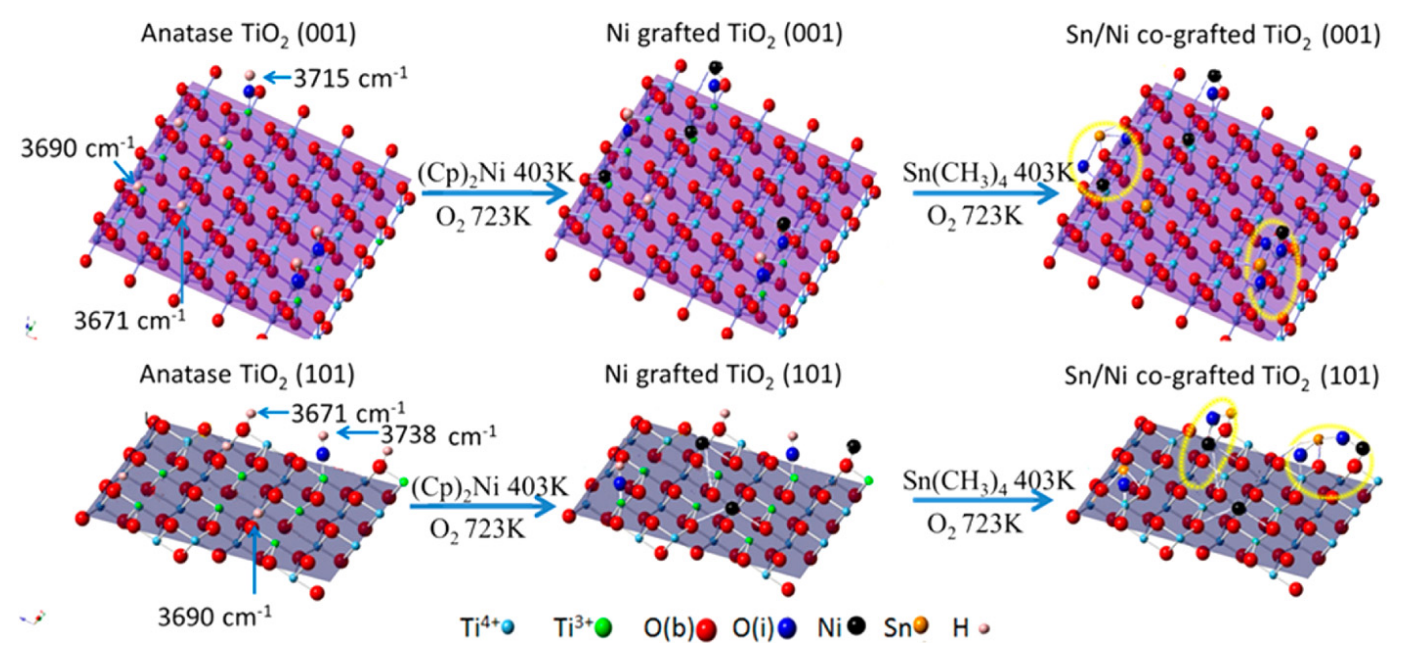

Figure 4. The schematic mechanism for the proposed formation of titania modified with Sn/Ni. Copyrights 2015 ACS. [71].

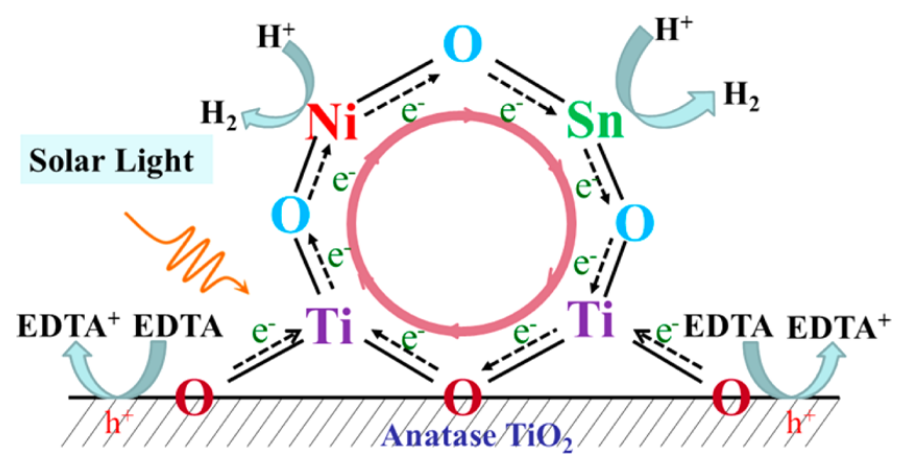

Figure 5. The scheme of the ring mechanism for electron delocalization. Copyrights 2015 ACS [71].

It should be pointed out that the experiments under solar (simulated or natural) radiation are very important for possible applications, but they do not lead to fruitful conclusions on the mechanism for titania-based photocatalysts, since titania is also excited due to the presence of UV light in the solar spectrum.

As already mentioned, faceted nanocrystals might be a promising base for efficient hydrogen generation. Both octahedral anatase particles with only $\{101\}$ facets [72,73] and decahedral anatase particles with eight $\{101\}$ and two $\{001\}$ facets [74,75] (i.e., OAPs and DAPs, respectively) show very high activity for hydrogen generation under UV irradiation, when modified with NPs of noble metals. In contrast, though noble metal-modified faceted samples are also active under vis irradiation, due to plasmonic photocatalysis for oxidative decomposition of organic compounds $[42,43,50,76,77]$, the negligible activity for hydrogen evolution has only been observed (electron-deficient metal after "hot" electron transfer from noble metals). However, faceted titania nanocrystals modified with nanoclusters of indium oxide $\left(\mathrm{In}_{2} \mathrm{O}_{3}\right)$ have shown to be good candidates for hydrogen generation in the absence of a noble metal co-catalyst under solar irradiation [78]. Development of a new type of nanoheterostructure, consisting of fine nanoclusters of $\operatorname{In}_{2} \mathrm{O}_{3}$ (i.e., alike to fine species "doped" on the surface of $\mathrm{TiO}_{2}$ nanocrystals with $\{101\}$ and $\{001\}$ exposed facets), developed through a facile hydrothermal method, has resulted in remarkable hydrogen production under visible light (LED source) and solar simulated light (AM 1.5G). It has been proposed that photogenerated electrons migrate from the $\mathrm{CB}$ of indium oxide to the $\mathrm{CB}$ of titania, what is responsible for the observed vis response. Additionally, it has been found that $\mathrm{In}_{2} \mathrm{O}_{3}$-modified titania single crystals with two kinds of facets $(\{101\}$ and $\{001\})$ exhibit higher $(1.3 \times) \mathrm{H}_{2}$ generation under vis irradiation than nanocrystals with only one type of facets $(\{101\})$. It has been proposed that high photocatalytic activity is caused by 
the synergism between indium oxide and titania, the enhanced absorption of visible light, a unique morphology and high crystallinity [78].

Core-shell NPs are also considered as another 0D morphology with interesting properties due to the formation of a functional system from the integration of individual components, improving chemical and physical properties, such as dispersibility, functionality, and stability, that might not be obtained for sole components $[79,80]$. The core-shell titania-structured materials are considered as highly wanted, not only due to enhanced stability and activity, but also because of improved recycling ability when a magnetic component is used in the composite [81,82]. Indeed, Bielan et al. have found that the modification of magnetic core-shell particles $\left(\mathrm{Fe}_{3} \mathrm{O}_{4} @ \mathrm{SiO}_{2} / \mathrm{TiO}_{2}\right)$ with NPs of platinum and/or copper has resulted in a high enhancement of hydrogen evolution (methanol as a hole scavenger) even by two orders of magnitude under UV/vis irradiation [83]. Unfortunately, similar to other plasmonic photocatalysts, though vis activity has been observed for oxidative decomposition of phenol, negligible evolution of hydrogen has been noticed under vis irradiation. An interesting approach has been designed by Wang et al. for coreshell $\mathrm{Cu}_{\mathrm{x}} \mathrm{O} @ \mathrm{TiO}_{2}$ formation by microemulsion method [57]. It is well known that coupled oxides, such as titania and copper/silver oxides-despite their enhanced activity under UV irradiation due to the inhibition of charge recombination (either via heterojunction type II or Z-scheme mechanism [84]) - are often not stable under irradiation in contrast to titania, as these oxides with a narrower bandgap suffer from photocorrosion [85-87]. However, obtained core-shell $\mathrm{Cu}_{\mathrm{x}} \mathrm{O} @ \mathrm{TiO}_{2}$ photocatalysts have exhibited high photocatalytic activity under long $(6 \mathrm{~h})$ and repeated ( 3 cycles) UV irradiation [57]. Additionally, based on XPS analysis showing the reduction of copper species, it has been concluded that enhanced activity is caused by Z-scheme mechanisms both for hydrogen generation (methanol as a hole scavenger) and oxidative degradation of acetic acid. Unfortunately, core-shell structures with vis-responsive material as a core usually means vis inactivity, due to the lack of electron donor inside the core-shell structure. In contrast, Zubair et al. have shown enhanced activity of core-shell $\mathrm{TiO}_{2} @ \mathrm{CdS}$ photocatalysts, fabricated by a hydrothermal process (two steps) [88]. However, activity has been measured under simulated solar radiation, and thus it is difficult to estimate the reason for this enhancement (UV or vis range). Authors have optimized the shell thickness of titania by adjusting the amount of $\mathrm{TiO}_{2}$ precursor, and the optimized $\mathrm{TiO}_{2} @ \mathrm{CdS}$ sample exhibits much higher photocatalytic activity for hydrogen generation than pristine $\mathrm{TiO}_{2}$ and $\mathrm{CdS}$ samples.

The QDs-semiconductor composites have been intensively investigated because of the specific optical, electronic, and structural properties that result from the quantum confinement effect and large surface-to-volume ratios. There are various types of QDs with unique physicochemical properties. Recently, carbon QDs (CQDs) have been proposed for the modification of semiconductors [89], since they are non-expensive, non-toxic, and soluble in water. For hydrogen generation under vis irradiation (LED of $420 \mathrm{~nm}$ ), Dong et al. have prepared an efficient and stable ternary photocatalyst- $\mathrm{Ni}_{4} \mathrm{P}_{2}$-CQDs@CdS, produced by chemical precipitation and photoreaction process [90]. Photocatalytic hydrogen generation $\left(145 \mu \mathrm{mol} \mathrm{g}^{-1} \mathrm{~h}^{-1}\right)$ from pure water without any sacrificial reagents has been achieved by employing CdS, CQDs, and $\mathrm{Ni}_{4} \mathrm{P}_{2}$ as a light harvester, an electron acceptor (and a donor), and a catalyst, respectively. The experimental results demonstrate the electrons transfer from CdS via CQDs to $\mathrm{Ni}_{4} \mathrm{P}_{2}$ (catalyst), upon which, accumulated electrons facilitate hydrogen generation. An interesting study on overall water splitting has been performed with plasmonic excitation of CuNi bimetal NPs modified with CQDs [91]. Here, under plasmonic excitation, "hot" electrons were transferred to CQDs, working as a co-catalyst for hydrogen evolution, as shown in Figure 6. 


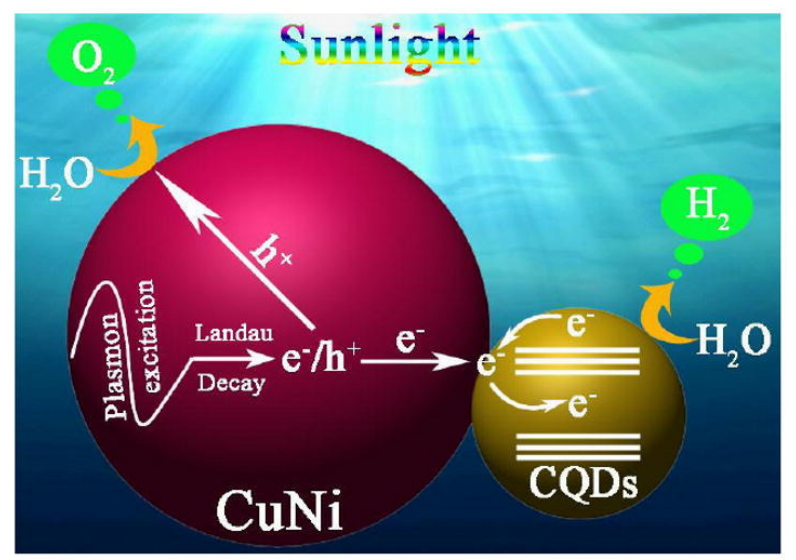

Figure 6. A scheme showing the mechanism of water splitting on CuNi/CQDs photocatalyst. Copyrights 2019 Elsevier [91].

Additionally, more advanced carbon structures (i.e., graphene QDs (GQDs)), have also been used because of the large content of active sites, high photostability, low toxicity, high biocompatibility, and chemical inertness [92,93]. It is known that graphene could enhance the photocatalytic activity of semiconductors, hindering charge carriers recombination, and also working as a co-catalyst for hydrogen evolution [94]. Indeed, GQDs have successfully been applied for solar water splitting [91,95,96]. For example, ternary photocatalyst nitrogen-doped GQDs (NGQDs) $-\mathrm{ZnNb}_{2} \mathrm{O}_{6} / \mathrm{g}-\mathrm{C}_{3} \mathrm{~N}_{4}$ exhibits visible light hydrogen generation $(\lambda>420 \mathrm{~nm})$ [96]. It has been shown that the mole ratio of $\mathrm{ZnNb}_{2} \mathrm{O}_{6} / \mathrm{g}-\mathrm{C}_{3} \mathrm{~N}_{4}(\mathrm{Zn} / \mathrm{CN})$ and the amount of NGQDs influence the efficiency of hydrogen generation. Accordingly, the highest hydrogen evolution rate of $0.34 \mathrm{mmol} \mathrm{h}^{-1} \mathrm{~g}^{-1}$ has been obtained on optimized photocatalyst, i.e., $\mathrm{Zn} / \mathrm{CN}$ with a mole ratio of $1 / 7$ and $5 \%$ NGQDs. It has been proposed that the best photocatalytic activity could be caused by the cooperative effects of heterojunction and NGQDs, resulting in the formation of a large number of charge carriers and the acceleration of their separation.

Moreover, other types of QDs have been applied for hydrogen generation. An interesting study has been carried out by Qian et al. on the application of $\mathrm{CeO}_{2}-\mathrm{CuO}$ QDs for efficient solar-driven hydrogen evolution [97]. The p-type $\mathrm{CuO} /$ n-type $\mathrm{CeO}_{2}$ heterojunction has been synthesized by the hypha assistance process on graphene. The filamentous fungus (Geotrichum candidum) has been used for the preparation of the hyphal structure of graphene microtubules, embedded with $\mathrm{CeO}_{2}-\mathrm{CuO}$ QDs. The prepared material exhibits high efficiency of hydrogen generation in the presence of a low amount of a sacrificial agent and without noble metals. The observed $\mathrm{H}_{2}$ evolution rate has reached $2481 \mu \mathrm{mol} \cdot \mathrm{h}^{-1} \cdot \mathrm{g}^{-1}$, being constant during four cycles of reaction. Another approach with QDs has been proposed by Lee at al., in which CdSe QDs have been covered with an amorphous titania layer $\left(\mathrm{a}-\mathrm{TiO}_{2}\right)$ and applied for hydrogen generation from water [98]. Although a- $\mathrm{TiO}_{2}$ is often considered as an ineffective photocatalyst, due to its rich crystalline disorder and defects [99], the improved photocatalytic activity of CdSe QDs-when covered with a- $\mathrm{TiO}_{2}$-also indicates that amorphous titania might enhance the photocatalytic activity when it is in the form of a thin layer. It has been proposed that an electron transfer to a- $\mathrm{TiO}_{2}$ depends on the position of the $\mathrm{CB}$ edge of $\mathrm{CdSe} \mathrm{NCs}$ (The dependence on the size indicates that improved electron injection is expected for the energy level offset between $\mathrm{CdSe}$ and $\mathrm{TiO}_{2}$.). It has been concluded that both charge mobility and absorption ability should be considered for the development of highly active QD-based photocatalysts for water splitting.

As summarized in Table 1, the exceptional photocatalytic properties have been reported in the case of titania 0D systems modified with copper or Ni/Sn. Furthermore, noble metal particles significantly improve the photocatalytic activity of such photocatalysts under both UV and vis irradiation. Interestingly, it has been found that even amor- 
phous titania might improve photocatalytic activity if applied in the form of monolayer. Unfortunately, most experiments are performed in the presence of scavengers, mainly alcohols, and also other compounds, such as EDTA and $\mathrm{Na}_{2} \mathrm{~S} / \mathrm{Na}_{2} \mathrm{SO}_{3}$. Therefore, in some papers the "alcohol dehydrogenation" term is clearly stated rather than "water reduction/splitting" [42,43,50,57]. Obviously, water reduction in the absence of any hole scavenger is most recommended, but it is hardly succeeded, due to positive change in Gibbs free energy (as already pointed in the Introduction), i.e., "photosynthetic process". Generally, it might be summarized that photocatalysts with 0D morphology have various advantages, such as a large specific surface area, a large number of active sites and fast charge carrier migration. However, they might aggregate easily, losing these profits. Additionally, their nano-sized dimensions result in serious difficulty for the recovery/recycling process, and also causes environmental threats, as they can be considered as secondary pollutants.

Table 1. Examples of 0D photocatalysts for photocatalytic hydrogen evolution.

\begin{tabular}{|c|c|c|c|c|c|}
\hline SCs & $\begin{array}{l}\text { Modification on } \\
\text { SCs }\end{array}$ & Irradiation Source & Scavenger & Findings & Ref. \\
\hline $\mathrm{TiO}_{2}$ & $\mathrm{Cu}$ loading & Xe lamp & $\mathrm{CH}_{3} \mathrm{OH}$ & $18 \times$ enhancement & [55] \\
\hline $\mathrm{TiO}_{2}$ & Pt-H-Ag deposition & Xe lamp (>420 nm) & $\mathrm{CH}_{3} \mathrm{OH}$ & $17.2 \times$ enhancement & [68] \\
\hline $\mathrm{TiO}_{2}$ & $\mathrm{Ni} / \mathrm{Sn}$ loading & Xe lamp (>200 nm) & EDTA & $20 \times$ enhancement & [71] \\
\hline $\mathrm{TiO}_{2}$ & octahedral & Hg lamp $(290 \mathrm{~nm})$ & $\mathrm{CH}_{3} \mathrm{OH}$ & $1.5 \times$ enhancement & [73] \\
\hline $\mathrm{TiO}_{2}$ & Ag loading & Xe lamp & $\mathrm{CH}_{3} \mathrm{CHOHCH}_{3}$ & improved activity & {$[76]$} \\
\hline $\mathrm{TiO}_{2}$ & Au loading & Xe lamp (>420 nm) & $\mathrm{CH}_{3} \mathrm{OH}$ & $8.3 \times$ enhancement & [77] \\
\hline $\mathrm{TiO}_{2}$ & $\mathrm{In}_{2} \mathrm{O}_{3}$ loading & LED lamp/solar simulator & $\mathrm{CH}_{3} \mathrm{OH}$ & high activity & [78] \\
\hline $\mathrm{TiO}_{2}-\mathrm{CdS}$ & core-shell & Xe lamp & $\mathrm{Na}_{2} \mathrm{~S} / \mathrm{Na}_{2} \mathrm{SO}_{3}$ & $1.4 \times$ enhancement & [88] \\
\hline graphene & $\begin{array}{l}\mathrm{CeO}_{2}-\mathrm{CuO} \mathrm{QDs} \\
\text { loading }\end{array}$ & Xe lamp & $\mathrm{CH}_{3} \mathrm{OH}$ & $2481 \mu \mathrm{mol} \mathrm{g}-1 \cdot \mathrm{h}^{-1}$ & [97] \\
\hline CdSe & $\mathrm{TiO}_{2}$ coating & AM 1.5 light & $\mathrm{Na}_{2} \mathrm{~S} / \mathrm{Na}_{2} \mathrm{SO}_{3}$ & $2.7 \times$ enhancement & [98] \\
\hline
\end{tabular}

\section{One-Dimension (1D) Photocatalysts}

Nanotubes, nanowires, nanofibers, nanorings and nanobelts belong to 1D-structured materials. It is thought that nanotubes have been the most frequently studied among them for various photo-electrocatalytic reactions. In the case of titania nanotubes (TNTs), Grimes [100] and Schmuki [101] were probably first to investigate them, and they have popularized the global study of TNTs. Their research groups have performed various studies on: (i) synthesis optimization (mainly the anodization of titanium foil), (ii) characterization, (iii) growth mechanism, (iv) modification with different components (e.g., for vis activity), and (v) possible applications [102-107]. Subsequently, study of TNTs has been extensively performed by many research groups for both environmental purification [108-110] and solar energy conversion, including hydrogen generation, as shown in Table 2 [111].

For example, Chun et al. prepared a $\mathrm{TiO}_{2} / \mathrm{Ti}_{2} \mathrm{O}_{3}$ photocatalyst consisting of TNTs (in situ grown; mixed anatase/rutile) on the bulk $\mathrm{Ti}_{2} \mathrm{O}_{3}$ support, as shown in Figure 7 [112]. Under sunlight irradiation (and without any co-catalyst), high rates of hydrogen evolution $\left(1440 \mu \mathrm{mol} \mathrm{g}^{-1} \mathrm{~h}^{-1}\right)$ have been observed. It has been proposed that the photogenerated electrons from anatase could migrate via rutile to $\mathrm{Ti}_{2} \mathrm{O}_{3}$; of course, this also means that titania must be excited, and thus, only the UV part of the solar spectrum is used. Moreover, it has been suggested that the synergism between bandgap alignments, improved light harvesting ability, and enhanced density of charge carriers generated by the heterojunctions between the $\mathrm{Ti}_{2} \mathrm{O}_{3}$ and $\mathrm{TiO}_{2}$ are responsible for the high efficiency of hydrogen generation. 


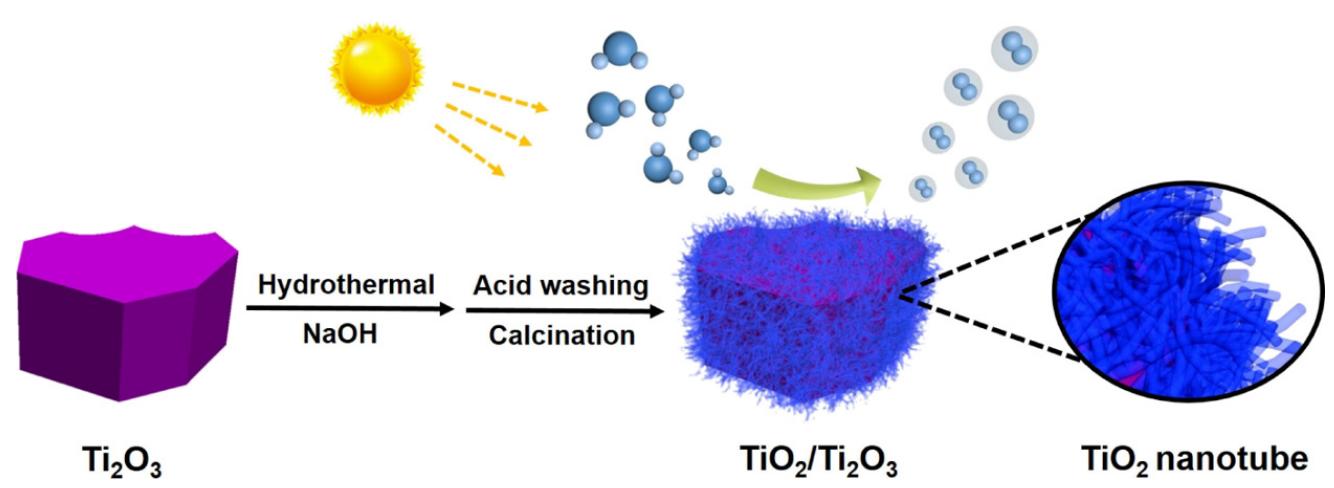

Figure 7. Scheme of $\mathrm{TiO}_{2} / \mathrm{Ti}_{2} \mathrm{O}_{3}$ synthesis via hydrothermal treatment, acid washing, and calcination of bulk $\mathrm{Ti}_{2} \mathrm{O}_{3}$. Copyright ACS [112].

Another approach that emphasizes the role of nanotubular structures was designed by Yang et al. [113]. The 1D mesoporous anatase TNTs with engineered surface defects were successfully synthesized via a combination of the solvothermal method and the high temperature surface hydrogenation process. It has been found that high temperature surface hydrogenation results in the formation of surface oxygen vacancies, which efficiently enhances the light absorption and spatial charge separation. The optimized sample $\left(\mathrm{H} 400-\mathrm{TiO}_{2}\right)$ shows a high rate of photocatalytic hydrogen generation of $9.8 \mathrm{mmol} \mathrm{h}^{-1} \mathrm{~g}^{-1}$, which is ca. 2.5 times higher than that of TNTs without defects. It has been suggested that noticeably high photocatalytic activity might be due to more efficient photoabsorption because of the presence of surface defects; additionally, the special one-dimensional mesoporous nanotube structure contributes to the efficient spatial charge separation on the horizontal-vertical dimension (Figure 8).

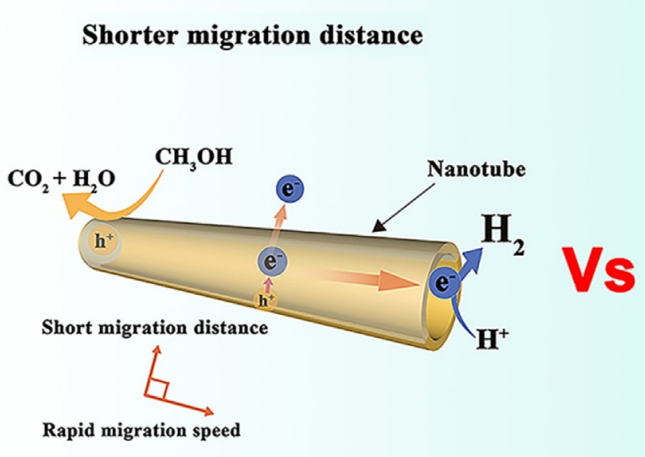

Adequate surface active sites

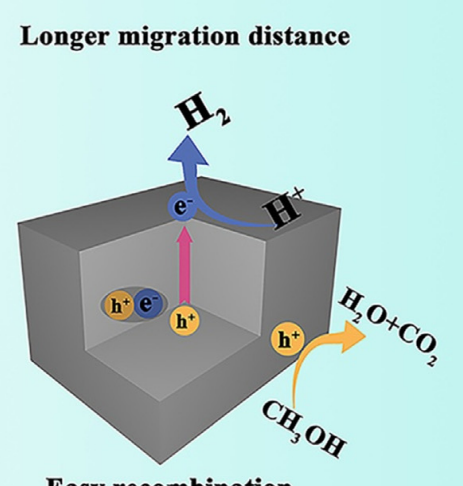

Easy recombination

Figure 8. The schematic mechanisms of charge transfers in anatase TNTs under solar light irradiation (left) and charge recombination in the case of bulk titania (right). Copyrights 2021 Elsevier [113].

Highly defective TNTs have also been investigated by Liu et al. who have prepared black TNTs, composed of anatase, with high contents of $\mathrm{Ti}^{3+}$, by a high pressure $\mathrm{H}_{2}$ treatment [114]. It has been proposed that a high rate of open-circuit photocatalytic generation of hydrogen (under UV excitation), without the presence of a co-catalyst, is caused by a stable and isolated $\mathrm{Ti}^{3+}$ defect structure acting as a co-catalytic center for hydrogen generation.

For vis response, TNTs have also been modified and/or doped with various elements. For example, $\mathrm{N}$-doped TNTs have been prepared by treatment with $\mathrm{NH}_{4} \mathrm{~F}$ during the TNT synthesis by electrochemical anodization [115]. It has been found that the quantity of $\mathrm{NH}_{4} \mathrm{~F}$ significantly influences the $\mathrm{N}$-doping level and the tube length; thus, influencing 
the optical and photocatalytic properties. It has been proposed that a "suitable" N-doping level accelerates the electrons/holes separation, improving the photocatalytic activity for hydrogen evolution and RhB degradation under UV/vis irradiation (Xe lamp with a VisREF filter; $350 \mathrm{~nm}>\lambda>780 \mathrm{~nm}$ ).

Nanorods are another type of 1D structure applied for $\mathrm{H}_{2}$ evolution processes. For example, anatase nanorods have been successfully prepared by thermal treatment of $\mathrm{H}_{2} \mathrm{Ti}_{3} \mathrm{O}_{7}$ nanotubes [116]. It has been found that nanorods with different properties (such as crystallite sizes, aspect ratios, and specific surface areas) might be prepared by adjusting the calcination parameters. Optimized calcination conditions $\left(600^{\circ} \mathrm{C}\right.$ for $20-180 \mathrm{~min}$ or $700{ }^{\circ} \mathrm{C}$ for $10 \mathrm{~min}$ ) results in the preparation of anatase nanorods with large specific surface areas, high crystallinity, and the best photocatalytic performances towards methylene blue photodegradation and $\mathrm{H}_{2}$ evolution in alcohol-water systems by modification with metallic co-catalysts $(\mathrm{Au}, \mathrm{Pd}$ or $\mathrm{Au} / \mathrm{Pd})$ under $\mathrm{UV}$ irradiation $\left(365 \mathrm{~nm}, 6.5 \mathrm{~mW} \mathrm{~cm}^{-2}\right)$. The best sample $\left(\mathrm{Pd}-\mathrm{Au} / 600 \mathrm{TiO}_{2}(20)\right)$ has reached $\mathrm{H}_{2}$ generation rates of $37.2,44.0$, and $45.6 \mathrm{mmol} \mathrm{g}^{-1} \mathrm{~h}^{-1}$ in $10 \%$ vol. ethanol-water, ethylene glycol-water, and glycerol-water systems, respectively. In the other work, Galdamez-Martinez et al. have prepared $\mathrm{ZnO}$ nanowires via a vapor-liquid-solid (VLS) process, using Au as a catalyst [117]. Different morphologies, e.g., homogeneously grown vertically orientated nanowires, nanowires with random orientation (grown also at a tilted angle of ca. $65^{\circ}$, i.e., less homogenous), heterogeneously grown nanowires (a lack of the anisotropic crystallization), and highly heterogeneous nanostructure (disorder), have been obtained by adjusting the growth conditions during the VLS process. It has been found that nanowires with random orientations and optimal diameters exhibit the best photocatalytic activity under UV/vis for hydrogen generation from water; whereas, the sample with a disorder structure shows the worst activity.

Next, nanowires with vis responses have also been designed. For example, self-doped $\mathrm{Ta}_{2} \mathrm{O}_{5}$ nanorods with efficient light harvesting ability (absorption from 400 to $800 \mathrm{~nm}$ ), prepared by a simple hydrolysis method, could generate hydrogen under vis irradiation $\left(23.35 \mu \mathrm{mol} \mathrm{g}^{-1} \mathrm{~h}^{-1}\right)$ in contrast with an inactive commercial $\mathrm{Ta}_{2} \mathrm{O}_{5}$ sample [118]. Selfdoping results in the significant narrowing of the bandgap from $3.88 \mathrm{eV}$ to $2.93,2.83,2.75$, and $2.53 \mathrm{eV}$ for samples prepared at different temperatures of $180,200,220$, and $240{ }^{\circ} \mathrm{C}$, respectively. Moreover, the specific surface area of self-doped samples (the mesoporous structure) has reached up to $237.89 \mathrm{~m}^{2} \mathrm{~g}^{-1}$. It has been proposed that the formation of $\mathrm{Ta}^{4+}$ species, high crystallinity, large specific surface area and mesopores are responsible for high photocatalytic activity. The proposed mechanism of vis-induced hydrogen generation (Figure 9) considers that a new energy level (between the VB maximum and CB minimum) is formed (due to $\mathrm{Ta}^{4+}$ species localized near oxygen vacancies), effectively narrowing the bandgap. Therefore, under vis irradiation the photogenerated electrons from the VB are excited to the new energy level, and then transferred to the $\mathrm{CB}$ (no discussion on the reason of their transfer to $\mathrm{CB}$ ).
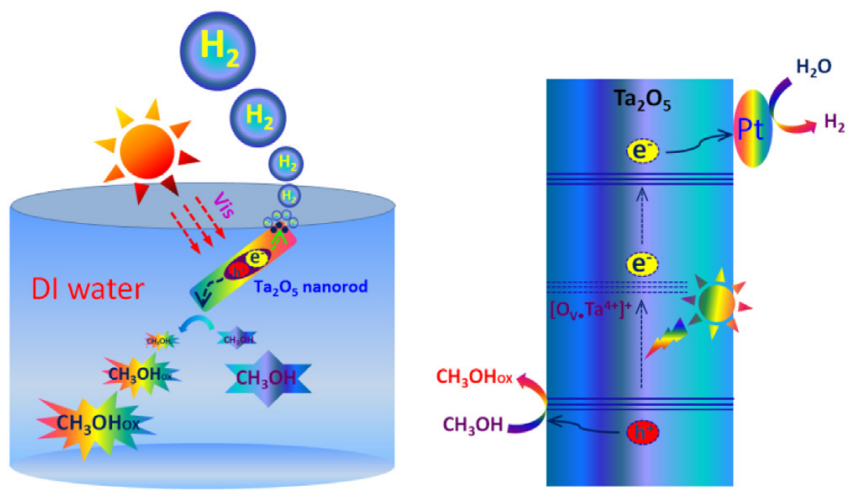

Figure 9. The schemes showing the proposed mechanism of visible light hydrogen generation on self-doped $\mathrm{Ta}_{2} \mathrm{O}_{5}$ nanorod. Copyrights 2017 Elsevier [118]. 
Furthermore, nanowire-based composites have also been proposed for photocatalytic hydrogen generation processes. An interesting approach has been presented for $\mathrm{TiO}_{2} / \mathrm{ZnO}$ nanowire arrays, prepared by a two-step hydrothermal route on stainless steel mesh, in which a combination of solar $(50 \mathrm{~W})$ and ultrasonic $(50 \mathrm{~W})$ energy accelerates hydrogen generation [119]. It has been found that the co-utilization of solar and mechanical energy results in high activity (hydrogen-generation rate reaching $3.052 \mu \mathrm{mol} \cdot \mathrm{g}^{-1} \cdot \mathrm{h}^{-1}, \sim 1.6$ times that under only solar radiation) and also good recyclability and stability. Moreover, nanowires in the core-shell arrangement have also been adopted for hydrogen evolution. For example, $\mathrm{CdS}-\mathrm{ZnO}$ core-shell nanowires show high photocatalytic activity, and it has been proposed that the $\mathrm{ZnO}$ shell does not only prevent photocorrosion of cadmium sulfide but also improves the charge carriers' separation [120]. The CdS-ZnO nanowires exhibit better stability in acid solution and in the enhancement of photocatalytic hydrogen generation rates by more than two orders in magnitude under UV/vis than sole CdS nanowires. Nanorods in core-shell configuration have also been prepared by sulfidation of $\mathrm{ZnO}$ nanorods on stainless steel wire mesh by Hsu et al. [121]. It has been suggested that photogenerated charges carriers, generated in $\mathrm{ZnS}$ under vis irradiation, might be effectively separated by the migration of electrons to $\mathrm{CB}$ of $\mathrm{Ag}_{2} \mathrm{~S}$, or to steel wire mesh (Figure 10). It has been found that, besides the enlargement of the specific surface area, the core-shell structure has also changed the surface character from hydrophobic to superhydrophilic. The high photocatalytic activity for hydrogen generation, reaching 5870 and $168 \mu \mathrm{mol} \mathrm{g}^{-1} \mathrm{~h}^{-1}$ under UV and visible light irradiation, respectively, is probably caused by the formation of an $\mathrm{Ag}_{2} \mathrm{~S}$ coupled $\mathrm{ZnO}-\mathrm{ZnS}$ heterojunction on a conductive support (metal mesh) that improves the following: (i) the light absorption, (ii) the separation efficiency of photogenerated charge carriers, and (iii) the contact with the reactants.

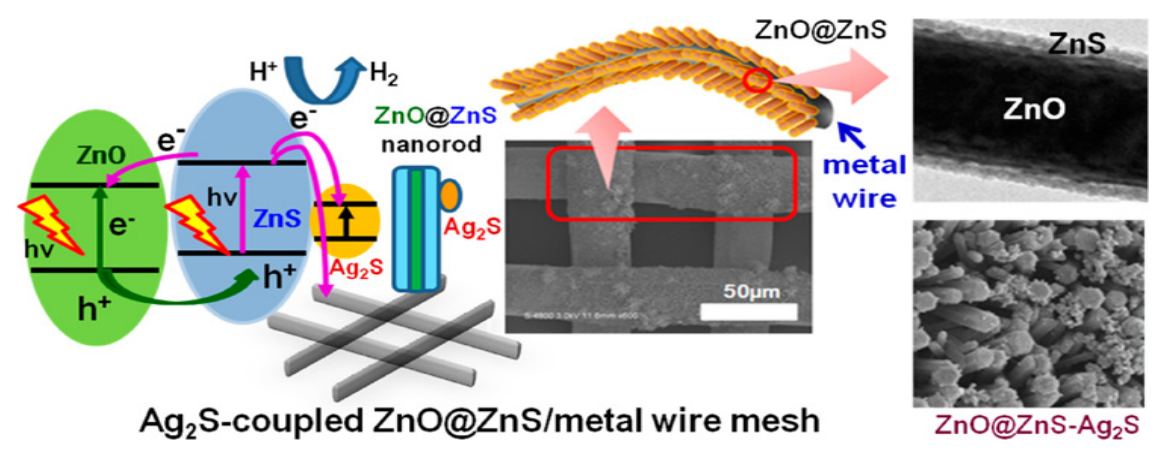

Figure 10. Schematic mechanism of hydrogen evolution on $\mathrm{Ag}_{2} \mathrm{~S}-\mathrm{ZnO@ZnS/mesh} \mathrm{photocatalyst.}$ Copyrights 2016 ACS [121].

Table 2, with summarized examples of 1D photocatalysts dedicated for hydrogen generation, shows the potential of heterojunction structures such as CdS-ZnO core-shell nanowires. For vis photocatalytic activity, a very promising performance has been found for self-doped $\mathrm{Ta}_{2} \mathrm{O}_{5}$ nanorods, but without detailed mechanism clarification.

In summary, there are the following advantages of 1D morphology: high aspect ratio, directed migration of electrons (spatial separation of charge carriers), and large specific surface area. However, the size-controllable synthesis and efficient dispersion are remaining challenges. Similar to $0 \mathrm{D}$ photocatalysts, hole scavengers are commonly applied; that is, mainly methanol, but also other organic (ascorbic acid) and inorganic $\left(\mathrm{Na}_{2} \mathrm{~S} / \mathrm{Na}_{2} \mathrm{SO}_{3} / \mathrm{NaCl}\right)$ compounds are used. Unfortunately, it is difficult to compare the photocatalytic activity of different photocatalysts, since significantly different experimental conditions have been used, including the most important factor of irradiation conditions (i.e., lamp type, wavelengths' range, irradiation intensity, irradiation distance, etc.), as well as the type and concentration of scavengers, and the photoreactor type (light distribution, mass transport, diffusion/kinetic-control, with or without hydrogen uptake, etc.), which all differ between research groups. However, it is clear that modifications and new structures 
proposed by authors have exhibited promising activities for possible commercialization. Obviously, the change in the synthesis conditions influences the properties of the final structure. For example: (i) N-doping does not only change the photoabsorption properties, but also the length of TNTs; (ii) the calcination conditions affect the properties (specific surface area, crystallinity, etc.), and thus, the photocatalytic activity of titania nanowires. It should be pointed out that $1 \mathrm{D}$ as well as $2 \mathrm{D}$ morphologies could be easily used as (photo)electrode materials; thus, these also apply for (photo)electrocatalytic purposes.

Table 2. Examples of 1D photocatalysts for photocatalytic hydrogen evolution.

\begin{tabular}{|c|c|c|c|c|c|}
\hline SCs & Modification on SCs & Irradiation Source & Scavenger & Findings & Ref. \\
\hline $\mathrm{TiO}_{2} \mathrm{NTs}$ & $\mathrm{TiO}_{2} / \mathrm{Ti}_{2} \mathrm{O}_{3}$ & $\begin{array}{l}\text { Xe lamp (full-sunlight } \\
\text { filter) }\end{array}$ & $\mathrm{CH}_{3} \mathrm{OH}$ & $1440 \mu \mathrm{mol} \mathrm{g}^{-1} \mathrm{~h}^{-1}$ & [112] \\
\hline $\mathrm{TiO}_{2} \mathrm{NTs}$ & Pt loading & Xe lamp(AM 1.5 G) & $\mathrm{CH}_{3} \mathrm{OH}$ & $\begin{array}{l}9.8 \mathrm{mmol} \mathrm{h}^{-1} \mathrm{~g}^{-1}, \\
2.5 \times \text { enhancement }\end{array}$ & [113] \\
\hline $\mathrm{TiO}_{2}$ & $\mathrm{Ti}^{3+}$ & solar simulator (AM 1.5) & $\mathrm{CH}_{3} \mathrm{OH}$ & enhanced $\mathrm{H}_{2}$ rate & [114] \\
\hline $\mathrm{TiO}_{2} \mathrm{NTs}$ & N-doped & $\begin{array}{c}\text { halogen lamp (5\% UV } \\
\text { light) }\end{array}$ & $\mathrm{CH}_{3} \mathrm{OH}$ & $3.77 \mathrm{mmol} \mathrm{cm}^{-2} \mathrm{~h}^{-1}$ & [115] \\
\hline $\mathrm{TiO}_{2}$ nanorod & $\mathrm{Pd} / \mathrm{Au} / \mathrm{Pd}-\mathrm{Au}$ & 100 P / F lamp (365 nm) & alcohols & $45.6 \mathrm{mmol} \mathrm{g}^{-1} \mathrm{~h}^{-1}$ & [116] \\
\hline $\mathrm{Ta}_{2} \mathrm{O}_{5}$ & $\mathrm{Ta}^{4+}$ & Xe lamp (>400 nm) & $\mathrm{CH}_{3} \mathrm{OH}$ & $23.35 \mathrm{mmol} \mathrm{g}^{-1} \mathrm{~h}^{-1}$ & [118] \\
\hline $\mathrm{TiO}_{2} / \mathrm{ZnO}$ & nanowires & Xe lamp (200-2500 nm) & $\mathrm{CH}_{3} \mathrm{OH}$ & $1.985 \mu \mathrm{mol} \cdot \mathrm{g}^{-1} \cdot \mathrm{h}^{-1}$ & [119] \\
\hline $\mathrm{CdS}-\mathrm{ZnO}$ & Core-shell nanowires & Xe lamp & ascorbic acid & $\begin{array}{l}\text { more than } 1200 \\
\mu \mathrm{mol} \cdot \mathrm{g}^{-1} \cdot \mathrm{h}^{-1}\end{array}$ & [120] \\
\hline $\mathrm{ZnO}$ & $\begin{array}{c}\mathrm{Ag}_{2} \mathrm{~S}-\mathrm{ZnO@ZnS} \\
\text { core-shell nanorods }\end{array}$ & visible light & $\mathrm{Na}_{2} \mathrm{~S} / \mathrm{Na}_{2} \mathrm{SO}_{3} / \mathrm{NaCl}$ & $168 \mu \mathrm{mol} \mathrm{lg} \mathrm{g}^{-1} \mathrm{~h}^{-1}$ & [121] \\
\hline
\end{tabular}

\section{Two-Dimension (2D) Photocatalysts}

Among various 2D nanostructures (nanofilms, nanoplates, nanosheets, nanoflakes), one might conclude that nanosheets have been the most popular in the investigation of hydrogen evolution. For example, hydrogenation combined with gas-assisted liquid exfoliation has been proposed for the fabrication of ultrathin $\mathrm{TiO}_{2}$ nanosheet assembly (Figure 11 and Table 3) [122]. It has been proposed that hydrogenation is responsible for the formation of surface-point defects (e.g., oxygen vacancy), while keeping the ultrathin 2D structure without any damage. It has been found that 2D structures have large specific surface areas and high contents of low-coordinated surface atoms. Additionally, surface lattice distortion (oxygen vacancies and low-coordinated surface atoms) results in a reduction of bandgap and an upshift of the CB minimum. Accordingly, the structure exhibits narrow bandgap and its significant content of surface reactive sites, and thus, its efficient solar-light utilization, which causes high photocatalytic activity for hydrogen generation $\left(540.7 \mu \mathrm{mol} \cdot \mathrm{h}^{-1}\right)$ and good stability during recycling under simulated solar radiation.
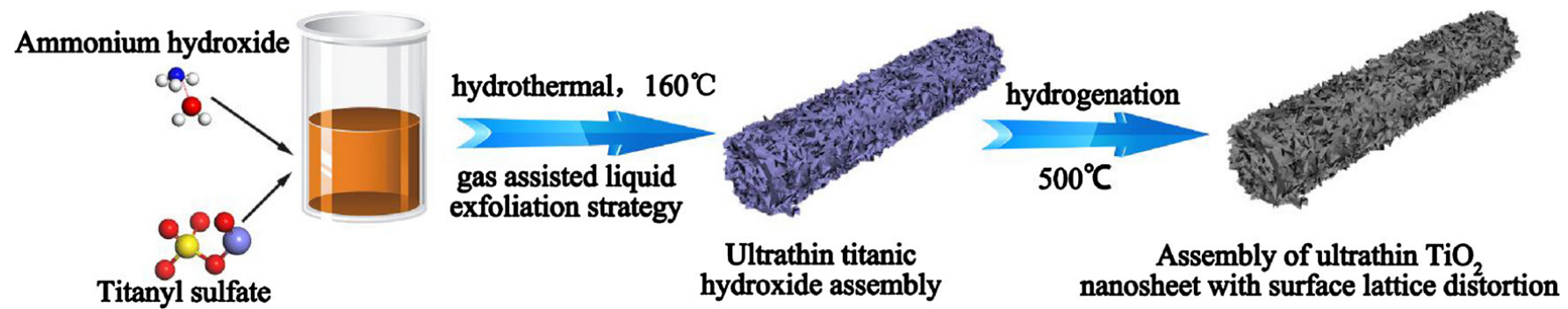

Figure 11. The schematic mechanism of assembly formation of titania ultrathin nanosheets. Copyright 2018 Elsevier [122].

The defective nanosheets have also been proposed by Liu et al. [123]. Herein, anatase nanosheets with defects at different locations (i.e., either on the surface or in the bulk) have been successfully fabricated by the adjustment of temperature and HF contents during hydrothermal process. It has been found that surface defects are preferable for efficient 
hydrogen generation (simulated solar radiation), because of their dual functions: (i) trapping of photogenerated charges; and (ii) adsorption of reagents. Similarly, Liu et al. have investigated defective titania nanosheets [124]. Titania nanosheets were prepared by a solvothermal method and treated with $\mathrm{N}_{2}$ plasma at atmospheric pressure to generate defects, i.e., oxygen vacancy and $\mathrm{Ti}^{3+}$ ions. The photocatalytic hydrogen formation (under $\mathrm{UV} / \mathrm{vis})$ in the defective titania $\left(8.1 \mathrm{mmol} \mathrm{g}^{-1} \mathrm{~h}^{-1}\right)$ was 14.85 times higher than that in bare titania nanosheets. Advantageous action of defective titania has also been shown for a single-atomic Pt site photocatalyst, constructed using defective titania nanosheets as a photocatalytic support for hydrogen production from water splitting [125]. It has been suggested that the oxygen vacancy on the surface of titania could effectively stabilize the atomic platinum by constructing the Ti-Pt-Ti structure. Accordingly, stabilized platinum sites by a three-center structure could promote the separation and migration of photogenerated charges, enhancing the hydrogen production. This photocatalyst has shown the improved performance under UV/vis irradiation, where the hydrogen evolution rate is up to $13460.7 \mu \mathrm{mol} \cdot \mathrm{h}^{-1} \cdot \mathrm{g}^{-1}$, i.e., ca. 29.0 and 4.7 times higher than that on titania nanosheets and titania modified with $\mathrm{Pt}$ NPs, respectively. Platinum and defects have also been applied in bimetallic $(\mathrm{Pd}-\mathrm{Pt}) /$ mesocrystalline $\mathrm{Ta}_{2} \mathrm{O}_{5}$ nanosheets with high vis absorption abilities, mainly because of the creation of oxygen vacancies [126]. The highest photocatalytic activity for hydrogen formation on Pd-Pt/mesocrystalline $\mathrm{Ta}_{2} \mathrm{O}_{5}$ nanosheets reaches $21529.52 \mathrm{~g}^{-1} \mathrm{~h}^{-1}$ (being ca. 21.2 times higher than that on the commercial $\mathrm{Ta}_{2} \mathrm{O}_{5}$ ) with apparent quantum efficiency of ca. $16.5 \%$ at $254 \mathrm{~nm}$. It has been proposed that highly improved activity is mainly caused by the significant roles of $\mathrm{Pd}-\mathrm{Pt}$ NPs for increasing the charge separation and transport. Similar to single-atomic Pt site photocatalyst, isolated Co atoms grafted on the titania nanosheet (with the thickness of $6 \mathrm{~nm}$ ) surface via Co-O electronic coupling, have been proposed for hydrogen formation [127]. Indeed, this photocatalyst shows efficient hydrogen generation under UV/vis irradiation, exceeding the activity of bare titania nanosheets by 12 times. Based on the theoretical and experimental results, it has been confirmed that Co atoms work as reactive sites, and also that the electron transfer and hydrogen adsorption/desorption processes might be significantly enhanced via the effective $\mathrm{Co}-\mathrm{O}$ electronic coupling in atomic scale, causing an acceleration in hydrogen production. A unique nanosheet-based system for simultaneous degradation of pollutants and water splitting has been proposed by $\mathrm{Wu}$ et al. [128]. The $\mathrm{Co}_{3} \mathrm{O}_{4}-\{001\} /\{101\}-\mathrm{TiO}_{2}$ nanosheets with unique $\mathrm{p}-\mathrm{n} /$ facet heterojunction structure have been used for treating pharmaceutical-contaminated water. Under UV/vis irradiation, a strong internal electric field (well known for decahedral anatase) forced electron transfer and hole transfer to $\{101\}$ facets and $\mathrm{Co}_{3} \mathrm{O}_{4} \mathrm{NPs}$, respectively. Accordingly, the dual ( $\mathrm{p}-\mathrm{n} /$ surface) heterojunction structure enables the spatial separation of charges. The holes, primarily accumulated on $\mathrm{Co}_{3} \mathrm{O}_{4} \mathrm{NPs}$, might efficiently oxidize the pharmaceutical pollutants (enrofloxacin, ciprofloxacin, and ibuprofen); whereas, the electrons accumulated on $\{101\}$ facets of titania nanosheets might simultaneously reduce water molecules to hydrogen.

The second important group of 2D structures is based on nanoplates. Feng et al. have prepared cadmium sulfide nanoplates with rough surfaces through an ionic exchange process, and then modified them with in situ photo-deposited Pt NPs [129]. The rate of photocatalytic hydrogen generation on $\mathrm{Pt} / \mathrm{CdS}$ reached $3.75 \mathrm{mmol} \mathrm{h}^{-1} \mathrm{~g}^{-1}$, which was much higher than that on pristine CdS. Additionally, the $\mathrm{Pt} / \mathrm{CdS}$ has shown a good stability in continuous solar hydrogen production, even after 16 days. It has been proposed that the rough structure (plate-like) and the presence of platinum as a co-catalyst could efficiently improve the photoabsorption ability and the charge carrier separation (providing reactive sites), respectively. Application of a pyroelectric material $\left(\mathrm{BiOIO}_{3}\right.$ nanoplates) to separate charge carriers by internal polar field, and thus, to enhance the efficiency of photocatalysis, has been proposed by Su et al. [130]. The thickness of nanoplates has been shown to be decisive for the efficiency of photocatalytic hydrogen production, i.e., seven times enhancement has been achieved for $150 \mathrm{~nm}$-thick nanoplates in comparison to $25 \mathrm{~nm}$-thick 
ones. It was concluded that the enhanced internal polar field resulting from the increased thickness of the $\mathrm{BiOIO}_{3}$ nanoplates ensures a tightly bound layer of the adsorbed ions on the surface of nanoplates, and also acts as an accelerator to separate the photoexcited carriers.

A very popular material for vis photocatalysis, $g-\mathrm{C}_{3} \mathrm{~N}_{4}$, has also been used for water splitting. For example, ultrathin $\mathrm{g}-\mathrm{C}_{3} \mathrm{~N}_{4}$ nanosheets with large specific surface areas have been fabricated by a liquid exfoliation process from bulk $\mathrm{g}-\mathrm{C}_{3} \mathrm{~N}_{4}$ in isopropanol [131]. The g- $\mathrm{C}_{3} \mathrm{~N}_{4}$ nanosheets are shown to be more efficient for hydrogen generation than the bulk sample under solar radiation, probably due to their more efficient photoabsorption and larger specific surface area. Additionally, modification of $\mathrm{g}-\mathrm{C}_{3} \mathrm{~N}_{4}$ with $\mathrm{CuS}$ nanoplates (hexagonal) by a hydrothermal process has an enhanced charge separation efficiency, and g- $\mathrm{C}_{3} \mathrm{~N}_{4}-\mathrm{CuS}$ exhibits a much higher hydrogen generation rate $\left(126.5 \mu \mathrm{mol} \mathrm{h}{ }^{-1}\right)$ than the bare $\mathrm{g}-\mathrm{C}_{3} \mathrm{~N}_{4}$ nanosheets.

An interesting approach, using a new type of $\mathrm{WS}_{2} / \mathrm{WO}_{3}$ photocatalyst with layered structure to mimic photosynthesis (i.e., Z-scheme heterostructure), has been proposed by Zhang et al. [132]. The composite-monoclinic $\mathrm{WO}_{3}$ nanoplates $\left(\mathrm{m}-\mathrm{WO}_{3}\right)$, with a few layers of hexagonal $\mathrm{WS}_{2}$ with semiconducting $2 \mathrm{H}\left(2 \mathrm{H}-\mathrm{WS}_{2}\right)$, has been fabricated via a sulfurization (in situ) of hydrous nanoplates of $\mathrm{WO}_{3}$, prepared by a hydrothermal process. It has been proposed that the electronic interaction between two components follows a direct Z-scheme mechanism; thus, it decreases the recombination of charge carriers, while keeping the redox ability of both components. Moreover, the formation of the transition layer ("S-W-O"), due to the contact between $2 \mathrm{H}-\mathrm{WS}_{2}$ and $\mathrm{m}-\mathrm{WO}_{3}$, could further shorten the migration path of charges, smoothing their interfacial transfer. Accordingly, about five times higher activity has been achieved with a photocatalyst with optimized properties for hydrogen generation under $\mathrm{UV} /$ vis irradiation than the few-layered $2 \mathrm{H}-\mathrm{WS}_{2}$ alone.

The highlighted examples of 2D-ordered photocatalytic materials (Table 3) show that defective Pt-loaded titania nanosheets have exceptional photocatalytic properties under solar-simulated light, similar to bimetallic $\mathrm{Pd}-\mathrm{Pt} /$ mesocrystalline $\mathrm{Ta}_{2} \mathrm{O}_{5}$ nanosheets. Similar to $0 \mathrm{D}$ and 1D photocatalysts, various scavengers (methanol, triethanolamine, ENR, CIP, IBU, lactic acid, and so on) are commonly used for photocatalytic hydrogen evolution; however, an interesting approach to the use of wastes (pharmaceutical wastewater) as a hole scavenger has also been proposed. Moreover, it has been confirmed that the structure and the morphology are decisive for the overall activity. For example, the localization of defects (on the surface or in the bulk), the thickness of the nanosheets $(5 \times$ broader causing $7 \times$ higher activity for $\mathrm{BiOIO}_{3}$, probably a product of the increased interpolar field, and thus, the enhanced charge carrier separation), the superiority of organized structure (nanosheet) above the bulk (e.g., for $\mathrm{g}-\mathrm{C}_{3} \mathrm{~N}_{4}$ ), and the isolated atomic metals (Ti-Pt-Ti and $\mathrm{Co}-\mathrm{O}$ ) and nonmetals ( $\mathrm{S}-\mathrm{W}-\mathrm{O}$ ) resulting in an efficient charge-carrier transfer and hydrogen generation, have been found for 2D nanostructures.

Table 3. Examples of 2D photocatalysts for photocatalytic hydrogen evolution.

\begin{tabular}{|c|c|c|c|c|c|}
\hline SCs & Modification on SCs & Irradiation Source & Scavenger & Findings & Ref. \\
\hline $\mathrm{TiO}_{2}$ & ultrathin nanosheets & AM1.5 & $\mathrm{CH}_{3} \mathrm{OH}$ & $540.7 \mu \mathrm{mol} \mathrm{g}^{-1} \mathrm{~h}^{-1}$ & [122] \\
\hline $\mathrm{TiO}_{2}$ & $\mathrm{Ti}^{3+}$ & simulated solar light & $\mathrm{CH}_{3} \mathrm{OH}$ & $28.8 \mu \mathrm{mol} \mathrm{g}^{-1} \mathrm{~h}^{-1}$ & [123] \\
\hline $\mathrm{TiO}_{2}$ & N-doping & simulated solar light & TEA & $14.85 \times$ enhancement & [124] \\
\hline $\mathrm{TiO}_{2}$ & Pt loading & Xe lamp (solar simulator) & $\mathrm{CH}_{3} \mathrm{OH}$ & $13,460.7 \mu \mathrm{mol} \mathrm{g}{ }^{-1} \mathrm{~h}^{-1}$ & [125] \\
\hline $\mathrm{Ta}_{2} \mathrm{O}_{5}$ & Pd-Pt loading & Xe lamp & $\mathrm{CH}_{3} \mathrm{OH}$ & $21,529.52 \mu \mathrm{mol} \mathrm{g}^{-1} \mathrm{~h}^{-1}$ & [126] \\
\hline $\mathrm{TiO}_{2}$ & Co loading & Xe lamp & $\mathrm{CH}_{3} \mathrm{OH}$ & $12 \times$ enhancement & [127] \\
\hline $\mathrm{TiO}_{2}$ & $\mathrm{Co}_{3} \mathrm{O}_{4}$ loading & Xe lamp (400 nm) & ENR/CIP/IBU & $3.75 \mathrm{mmol} \mathrm{h}^{-1} \mathrm{~g}^{-1}$ & [128] \\
\hline $\mathrm{CdS}$ & Pt loading & Xe lamp (435 nm) & $\mathrm{Na}_{2} \mathrm{~S} / \mathrm{Na}_{2} \mathrm{SO}_{3}$ & improved activity & [129] \\
\hline $\mathrm{BiOIO}_{3}$ & nanoplates & UV-vis & $\mathrm{CH}_{3} \mathrm{OH}$ & $7 \times$ enhancement & [130] \\
\hline $\mathrm{g}-\mathrm{C}_{3} \mathrm{~N}_{4}$ & CuS loading & simulated solar light & TEA & $126.5 \mu \mathrm{mol} \mathrm{g}^{-1} \mathrm{~h}^{-1}$ & [131] \\
\hline $\mathrm{WO}_{3}$ & $\mathrm{WS}_{2}$ & Xe lamp & lactic acid & $673 \mu \mathrm{mol} \mathrm{g}{ }^{-1} \mathrm{~h}^{-1}$ & [132] \\
\hline
\end{tabular}




\section{Three-Dimension (3D) Photocatalysts}

In this group, one can distinguish meso/macro-porous structures, flower-like composites, and honeycomb-like hierarchical materials that have been constructed/accumulated from one or more kinds of $0 \mathrm{D}, 1 \mathrm{D}$, and $2 \mathrm{D}$ nanostructures. For example, titania with a 3D urchin-like structure has been synthesized by a single-step process (to control both the crystal phase and morphology of titania) via a surfactant-free solvothermal method [133]. The best-performing mixed-phase (anatase/rutile) photocatalyst exhibits remarkable durability up to $25 \mathrm{~h}$ and an ability to generate hydrogen at the rate of $3522 \mu \mathrm{mol} \mathrm{g}^{-1}$ under natural sunlight (with $\mathrm{Na}_{2} \mathrm{~S} / \mathrm{Na}_{2} \mathrm{SO}_{3}$ as sacrificial reagents). Moreover, titania coupled with other materials has also been investigated, e.g., flower-like nanostructures of $\mathrm{TiO}_{2} @ \mathrm{Ni}(\mathrm{OH})_{2}$ core-shell microspheres [134]. The 3D nanostructure, composed of well-arranged $\mathrm{Ni}(\mathrm{OH})_{2}$ nanoflakes on the titania microspheres, has resulted in six-fold improvement of hydrogen production (simulated solar radiation, with EDTA-Na ${ }_{2}$ as a sacrificial reagent), than that by pristine titania. It has been proposed that $p-n$ type heterostructures facilitate the separation and the transfer of charge carriers, and provide large quantities of active sites for photocatalytic hydrogen evolution. Titania has also been used to construct unique, black, flower-like nanostructures with solar-driven photocatalytic activity for hydrogen evolution [135]. In this study, a mild method has been developed for the preparation of a black 3D N-TiO 2 -x@MoS 2 core-shell structured photocatalyst (Figure 12). Titania has been co-doped with $\mathrm{Ti}^{3+}$ and $\mathrm{N}$ and additionally coupled with $\mathrm{MoS}_{2}$, forming a core-shell nanostructure. It has been proposed that successful doping results in vis light absorption; whereas, type II heterojunction hinders charge carriers' recombination. The decomposition of methyl orange (vis) and the hydrogen-production rate (solar simulator, with $\mathrm{CH}_{3} \mathrm{OH}$ as a sacrificial reagent) have reached $91.8 \%$ and $1.882 \mathrm{mmol} \mathrm{h}^{-1} \mathrm{~g}^{-1}$, respectively.

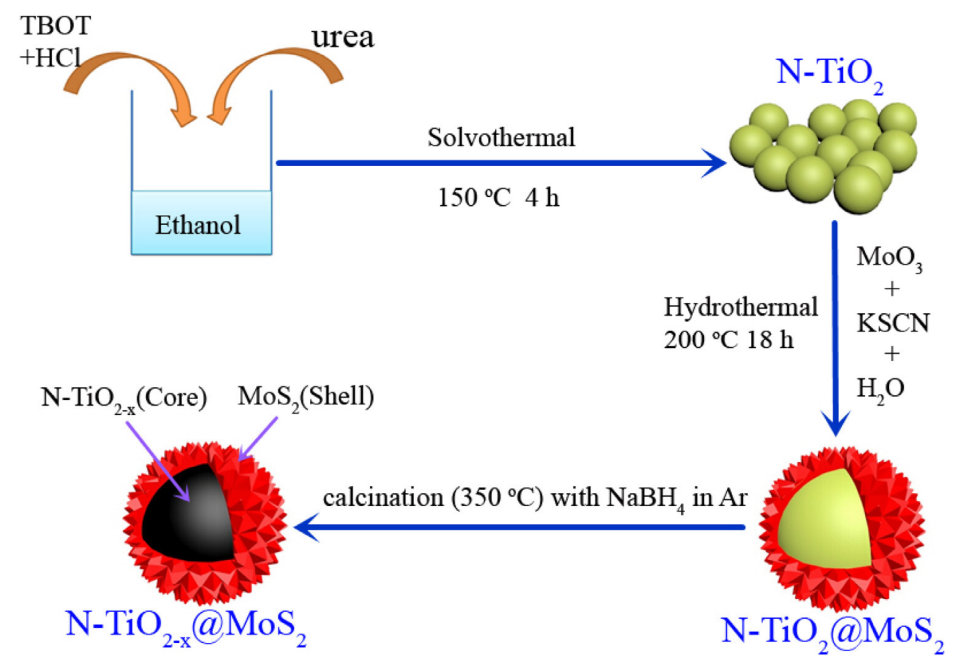

Figure 12. Schematic diagram for the formation of the $\mathrm{N}-\mathrm{TiO}_{2}-\mathrm{x} @ \mathrm{MoS}_{2}$ nanocomposites. Copyrights 2017 Elsevier [135].

The unique combination of flower-like structures and sheets has been studied by $\mathrm{Lv}$ et al. [136]. The perovskite NPs and graphene oxide (GO) have formed the 3D nest-like $\mathrm{LaCO}_{3} \mathrm{OH} / \mathrm{Ni}(\mathrm{OH})_{2} @$ graphene (RGO) hierarchical composite, as shown in Figure 13. GO has been used as both carbon source (self-sacrificial) and morphology-control agent. The photocatalytic performance has been significantly improved, thanks to this morphology, benefiting from the fast electron transfer on the uniform nanosheets of $\mathrm{Ni}(\mathrm{OH})_{2} @ \mathrm{RGO}$ and the efficient light harvesting of the 3D nest- and flower-like structure of $\mathrm{LaCO}_{3} \mathrm{OH}-$ $\mathrm{Ni}(\mathrm{OH})_{2} @ \mathrm{RGO}$. The photocatalytic activity for hydrogen generation achieves ca. $1.38 \mathrm{mmol} \cdot \mathrm{h}^{-1} \cdot \mathrm{g}^{-1}$, being 13 -fold higher than that for bare $\mathrm{LaCO}_{3} \mathrm{OH}$. Unfortunately, the experiments have been performed under strong UV irradiation (Hg lamp; $250 \mathrm{~nm}>\lambda>$ 
$650 \mathrm{~nm}$ ); thus, it is impossible to conclude if this photocatalyst might be active under sole vis irradiation.

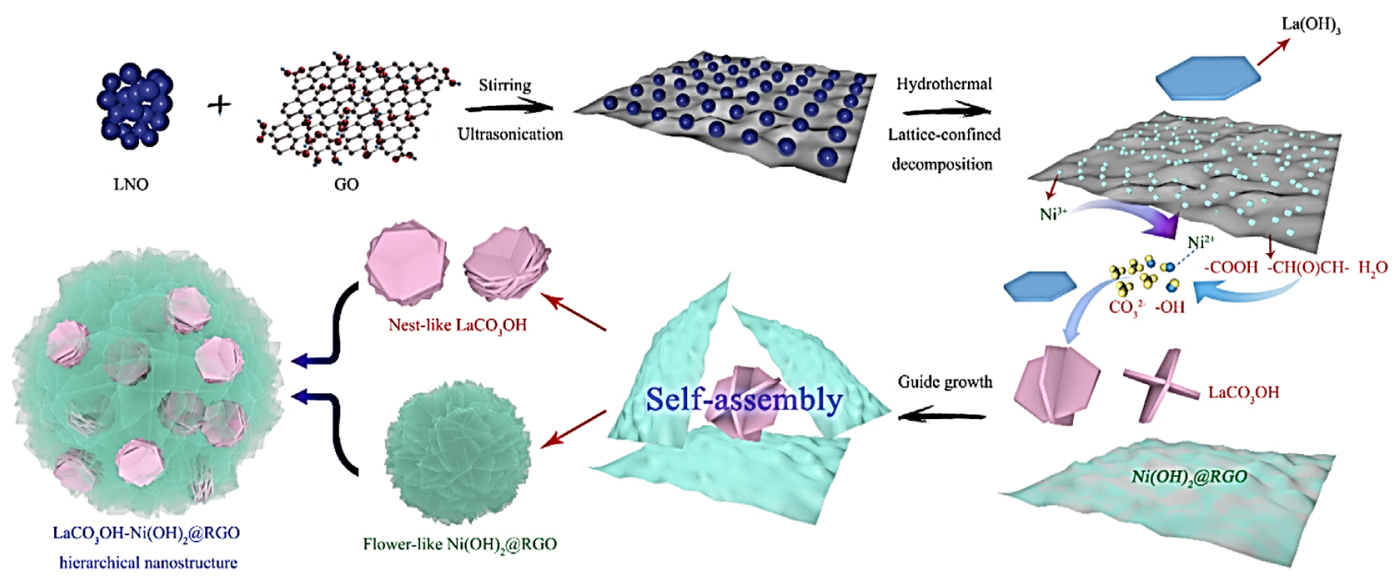

Figure 13. Scheme showing the fabrication of $\mathrm{LaCO}_{3} \mathrm{OH}-\mathrm{Ni}(\mathrm{OH})_{2} @ \mathrm{RGO}$ composite. Copyrights 2020 Elsevier [136].

Furthermore, flower-like $\mathrm{Bi}_{2} \mathrm{WO}_{6}-\mathrm{Bi}_{2} \mathrm{O}_{3}$ structures have been prepared by a twostep process, including an ionic liquid-assisted solvothermal step and calcination [137]. The addition of ionic liquids during the preparation of $\mathrm{Bi}_{2} \mathrm{WO}_{6}$ based-materials causes an increase in photocatalyst size and the creation of more petal sheets in the flowerlike microspheres. The $\mathrm{Bi}_{2} \mathrm{WO}_{6}-\mathrm{Bi}_{2} \mathrm{O}_{3}$ flower-like photocatalyst shows higher activity for $\mathrm{H}_{2}$ generation under $\mathrm{UV} / \mathrm{vis}$ (Xe lamp) irradiation than the $\mathrm{Bi}_{2} \mathrm{WO}_{6}$ photocatalyst, probably due to improved light absorption, enlarged specific surface area, and matched band structure (type II heterojunction), and thus, inhibited charge carriers' recombination. Finally, a flower-like nanostructure has also been tested for hydrogen evolution under vis $(\lambda>420 \mathrm{~nm})$ irradiation. The $\mathrm{Sn}_{3} \mathrm{O}_{4}$ has been prepared in the form of a flower by a hydrothermal method without templates or surfactants [138]. It has been found that a platinized flower-like nanostructure is much more efficient $(85 \%)$ than platinized sheets, reaching $184 \mu \mathrm{mol} \cdot \mathrm{h}^{-1} \cdot \mathrm{g}^{-1}$ hydrogen evolution $\left(\mathrm{CH}_{3} \mathrm{OH}\right.$ as a sacrificial reagent). Moreover, another flower-like nanostructure, composed of $\mathrm{Ag}_{2} \mathrm{~S}$ and $\mathrm{CdS}$, has also exhibited vis activity for hydrogen evolution $(\lambda>420 \mathrm{~nm}$; TEOA) [139]. Cadmium sulfide consisting of self-assembled nanosheets $(4.7 \cdot \mathrm{nm}$-thick) has been prepared via solvothermal method assisted with microwaves, and an in situ ion exchange method has been used to deposit $\mathrm{Ag}_{2} \mathrm{~S}$ NPs on the nanosheets' edges (Figure 14. The photocatalyst has shown high activity for $\mathrm{H}_{2}$ evolution, reaching $375.6 \mu \mathrm{mol} \cdot \mathrm{h}^{-1} \cdot \mathrm{g}^{-1}$, which is 11.5 -fold higher than that of pristine CdS. It has been proposed that the effective separation of charge carriers, the low overpotential of $\mathrm{Ag}_{2} \mathrm{~S}$, and the utilization of the near-infrared (NIR) light by $\mathrm{Ag}_{2} \mathrm{~S}$ are responsible for the improved performance in photocatalytic hydrogen generation [41].

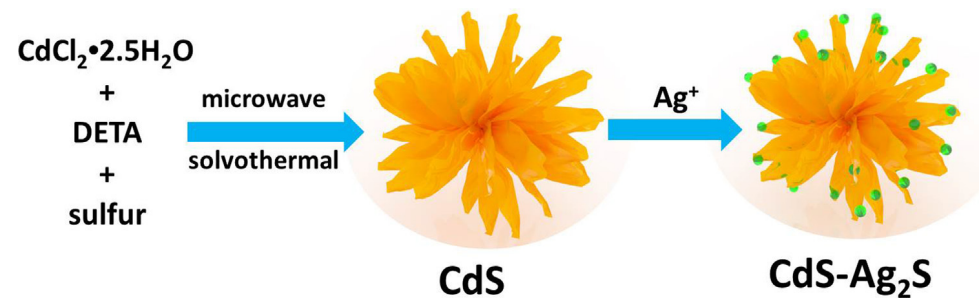

Figure 14. Schematic illustration of synthesis procedure for hierarchically structured $\mathrm{CdS}-\mathrm{Ag}_{2} \mathrm{~S}$ nanocomposites. Copyrights 2019 Elsevier [139].

Mesoporous structures also play an important role in the 3D group. Zhang et al. have utilized the concept of defect engineering for the preparation of defective mesoporous 
titania microspheres, where defects are formed by $\mathrm{NaBH}_{4}$ in the mesopore space [140]. Interestingly, it has been found that through changing the temperature of reduction, the migration of defects occurs, from the nanocrystalline-exposed surfaces to the interfaces between phase junction (Figure 15), which enables a well-tuned localization of defects. It has been reported that the reaction rates of hydrogen evolution $\left(\mathrm{CH}_{3} \mathrm{OH}\right.$ as a sacrificial reagent and $\mathrm{Pt}$ as a co-catalyst) under simulated solar radiation (AM 1.5G) and vis $(\lambda>420 \mathrm{~nm})$ irradiation reach $1065 \cdot \mu \mathrm{mol} \cdot \mathrm{h}^{-1}$ and $42.6 \cdot \mu \mathrm{mol} \cdot \mathrm{h}^{-1}$, respectively.

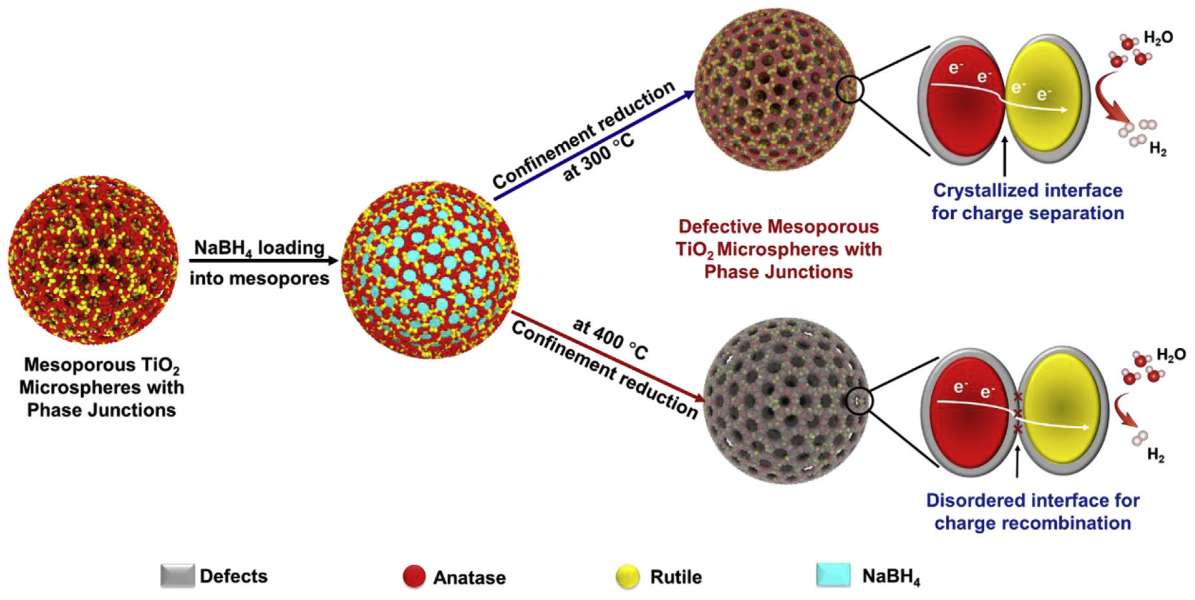

Figure 15. Schematic illustration of the synthesis of defective mesoporous titania microspheres with phase junctions via a facile confinement reduction method. Copyrights 2019 Elsevier [140].

Titania has also been used in another mesoporous structure, considering the famous P25; thus, a uniformly ordered mesoporous titania microsphere, with a tuned ratio of anatase to rutile, and radially oriented meso-channels, has been constructed, through a coordination-mediated self-assembly method [141]. The obtained microspheres have a similar anatase/rutile ratio to that in P25, but larger specific surface area $\left(78.6 \mathrm{~m}^{2} \mathrm{~g}^{-1}\right)$ and larger pore volume $\left(0.39 \mathrm{~cm}^{3} \mathrm{~g}^{-1}\right)$. It has been found that mesoporous microspheres exhibit a much higher solar-driven hydrogen generation rate (with $\mathrm{Pt}$ and $\mathrm{CH}_{3} \mathrm{OH}$ as a co-catalyst and a hole scavenger, respectively) than commercial P25 (simulated solar radiation). Moreover, microspheres could also generate hydrogen under vis irradiation (420 $\mathrm{nm}$ and $520 \mathrm{~nm}$ ) in contrast to inactive P25.

Next, the composites of titania with other compounds were investigated, e.g., $\mathrm{TiO}_{2} /$ $\mathrm{Cu}_{2} \mathrm{O}$ [142], $\mathrm{TiO}_{2} / \mathrm{g}-\mathrm{C}_{3} \mathrm{~N}_{4}$ [143], $\mathrm{TiO}_{2} / \mathrm{CdS}$ [144], and $\mathrm{NH}_{4} \mathrm{TiOF}_{3} / \mathrm{TiO}_{2} / \mathrm{g}-\mathrm{C}_{3} \mathrm{~N}_{4}$. [145]. The $\mathrm{Cu}_{2} \mathrm{O} / \mathrm{TiO}_{2}$ photocatalysts with oxygen vacancies have been prepared through a adsorption-reduction strategy of $\mathrm{Cu}^{2+}$ ions with $\mathrm{Cu}_{2} \mathrm{O}$ NPs, decorated on/within mesoporous titania microspheres [142]. It has been proposed that high activity for hydrogen evolution $\left(\mathrm{CH}_{3} \mathrm{OH}\right.$ as a hole scavenger) under UV/vis irradiation (Xe lamp) is due to allsolid, direct Z-scheme mechanisms between defective titania and cuprous oxide. Moreover, it has been shown that hydrogen can also be evolved from sea water, with reaction rates of $5.1 \mathrm{mmol} \mathrm{h}^{-1} \mathrm{~g}^{-1}$ and $11 \mathrm{mmol} \mathrm{h}^{-1} \mathrm{~g}^{-1}$ for seawater and water, respectively. It was concluded that (i) the Z-scheme mechanism, (ii) a high specific surface area (more photocatalytic active sites for both $\mathrm{Cu}_{2} \mathrm{O}$ and $\mathrm{TiO}_{2}$ ), and (iii) improved stability (consumption of holes from $\mathrm{Cu}_{2} \mathrm{O}$ by the oxygen vacancy), result in high photocatalytic performance of these microspheres. Another titania-based composite $\left(\mathrm{TiO}_{2} / \mathrm{CdS}\right)$ has been designed by Meng et al., in which a hierarchical structure, consisting of titania spiny nanosheet microspheres with CdS NPs, has been synthesized by a SILAR method (successive ionic layer adsorption and reaction), as shown in Figure 16 [144]. The hybrid photocatalyst has shown a significantly enhanced photocatalytic hydrogen evolution rate of $51.4 \mu \mathrm{mol} \mathrm{h}^{-1}$ under UV/vis (Xe lamp; $\mathrm{CH}_{3} \mathrm{OH}$ as a hole scavenger), in comparison to almost inactive components. It 
has been proposed that the Z-scheme mechanism, hierarchical structures, and efficient charge carriers' separation and migration are responsible for high photocatalytic activity.

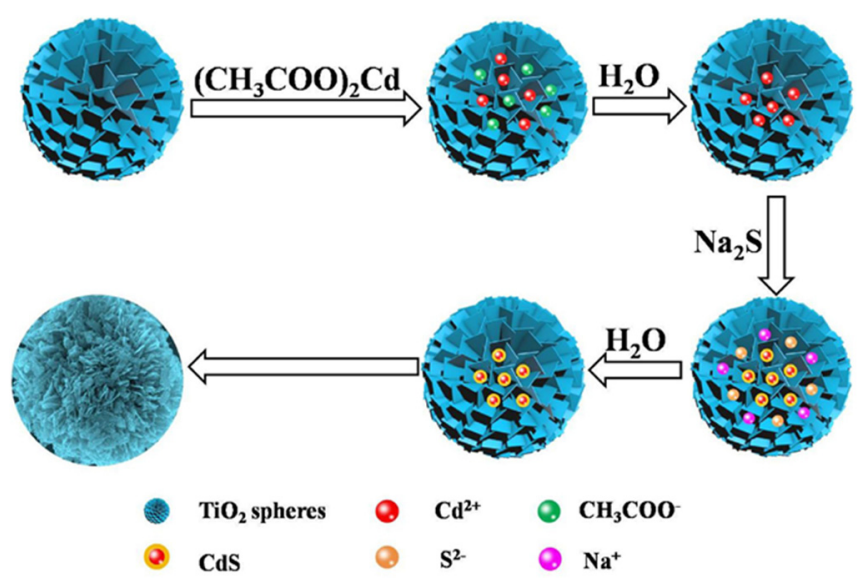

Figure 16. Schematic illustration for the fabrication of $\mathrm{TiO}_{2} / \mathrm{CdS}$ photocatalyst. Copyrights 2017 Elsevier [144].

Similarly, it has been shown that hierarchical titania/graphitic carbon nitride nanofibers (meso/macro-porous), constructed by combined electrospinning and calcination, exhibit enhanced hydrogen evolution under simulated solar irradiation [143]. The hierarchical composite shows much higher activity than reference samples (non-hierarchical composites and porous titania nanofibers) for hydrogen evolution $\left(\mathrm{CH}_{3} \mathrm{OH}\right.$ as a hole scavenger) under solar radiation. Moreover, only composites with g- $\mathrm{C}_{3} \mathrm{~N}_{4}$ (hierarchical and non-hierarchical) show vis response ( $\lambda>420 \mathrm{~nm}$; no details on the irradiation setup). Therefore, it has been proposed that hierarchical meso/macro-porous structures might increase the migration of charge carriers and the diffusion rate of product molecules, while supplying a large specific surface area and plentiful reactive sites. Graphitic carbon nitride and titania have also been combined with $\mathrm{NH}_{4} \mathrm{TiOF}_{3}$, forming 3D camellia-like structures [145]. It has been proposed that the 3D hierarchical structure enables multiple refractions and reflections of light within the material, which significantly enhances the sunlight harvesting efficiency. The photocatalytic hydrogen generation under UV/vis (Xe lamp; TEOA and Pt as a hole scavenger and a co-catalyst, respectively) irradiation at the rate of $3.6 \mathrm{mmol} \mathrm{g}^{-1} \mathrm{~h}^{-1}$ exceeds that by pure $\mathrm{g}-\mathrm{C}_{3} \mathrm{~N}_{4}$ by ca. four times. It has been proposed that high photocatalytic activity is due to the $\mathrm{Z}$-scheme mechanism between g- $\mathrm{C}_{3} \mathrm{~N}_{4}$ and titania; additionally, $\mathrm{NH}_{4} \mathrm{TiOF}_{3}$, evenly dispersed on titania, improves the interface performance of both main components by hindering the rapid recombination of charge carriers.

The sole $3 \mathrm{D} \mathrm{g}-\mathrm{C}_{3} \mathrm{~N}_{4}$, in the form of a multi-hole hexagon with nitrogen defects and a high specific surface area, has been synthesized by thermal polymerization via addition of EDTA into hydrothermal-treated dicyandiamide, as shown in Figure 17 [146]. The photocatalytic activity for hydrogen generation under vis irradiation $(\lambda>420 \mathrm{~nm}$; Xe lamp with cut-off filter; TEOA and Pt) for the optimal photocatalyst reaches $5839 \mu \mathrm{mol} \cdot \mathrm{g}^{-1} \cdot \mathrm{h}^{-1}$, which is 102 -fold higher than that of bulk g- $\mathrm{C}_{3} \mathrm{~N}_{4}$. It has been proposed that the combined effects of enhanced light harvesting, enlarged specific surface area $\left(129 \mathrm{~m}^{2} / \mathrm{g}\right)$, hindered recombination of charge carriers, negatively shifted $\mathrm{CB}$ position, and an efficient exposure of active sites, are responsible for high photocatalytic activity (Figure 18). 


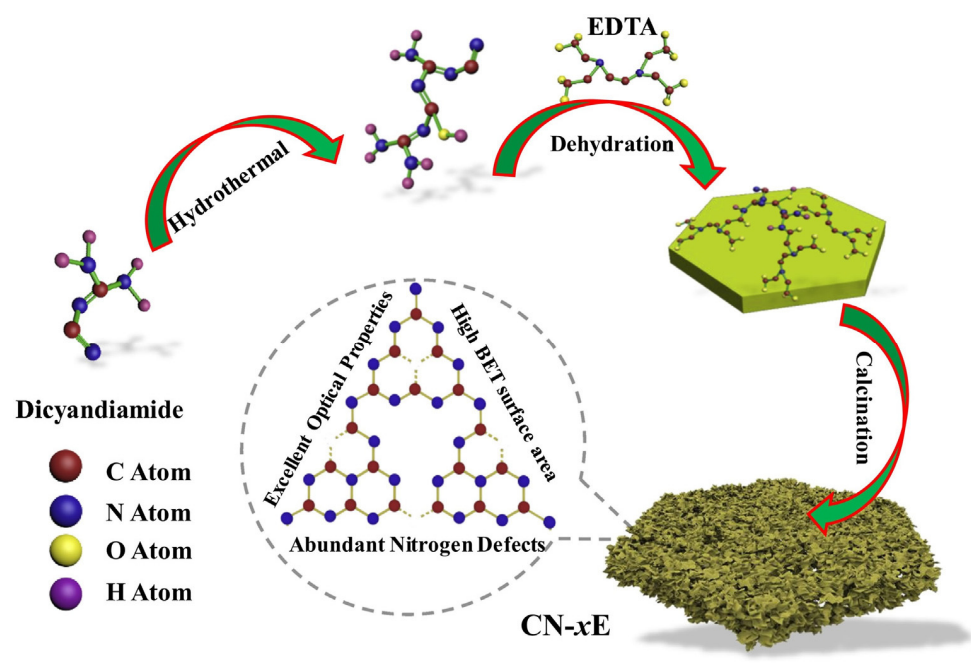

Figure 17. Scheme of the synthesis for multi-hole hexagon of $g-C_{3} N_{4}$. Copyrights 2020 Elsevier [146].

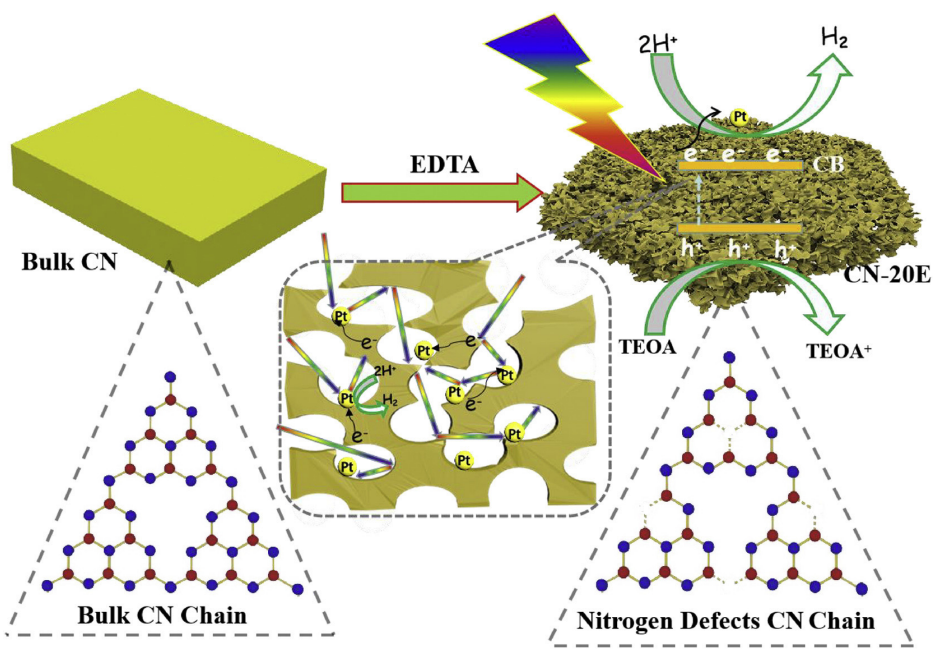

Figure 18. Scheme of the morphology superiority for the photocatalytic $\mathrm{H}_{2}$ production for defective hexagon of $\mathrm{g}-\mathrm{C}_{3} \mathrm{~N}_{4}$ under vis irradiation. Copyrights 2020 Elsevier [146].

Another specific 3D structure has been presented by Gultom et al.; a nanodiode of $\mathrm{Ag}_{2} \mathrm{O}$ and $\mathrm{Zn}(\mathrm{O}, \mathrm{S})$, deposited on the surface of mesoporous silica to form the p-n heterojunction $\mathrm{SiO}_{2} / \mathrm{Ag}_{2} \mathrm{O} / \mathrm{Zn}(\mathrm{O}, \mathrm{S})$, as illustrated in Figure 19 [147]. It was found that the photocatalytic hydrogen generation has been obviously enhanced for the composite of $\mathrm{n}-\mathrm{Zn}(\mathrm{O}, \mathrm{S})$ with $\mathrm{p}-\mathrm{Ag}_{2} \mathrm{O}$ (outward for improvement of reduction reactions, and inward for modulating the built-in electrical nanofield). The best hydrogen generation rate (under UV irradiation) of $9.2 \mathrm{mmol} \cdot \mathrm{g}^{-1} \cdot \mathrm{h}^{-1}$, corresponding to an apparent quantum yield of $10.3 \%$, has been achieved by the optimization of the $\mathrm{Zn}(\mathrm{O}, \mathrm{S})$ content and $\mathrm{p}-\mathrm{Ag}_{2} \mathrm{O}$ localization, which was about 2.7 times higher than that by pristine $\mathrm{Zn}(\mathrm{O}, \mathrm{S})$. The remarkable enhancement of activity has been ascribed to the synergy between components via the following: (i) three-dimensional multi-bandgap quantum-well (3D MQW) band structure, (ii) improved photoabsorption, (iii) activity of surface oxygen, (iv) separation of charge carriers, (v) longer lifetime of charges, (vi) low charge transfer resistance, and (vii) the p-n heterojunction in the photocatalyst. 


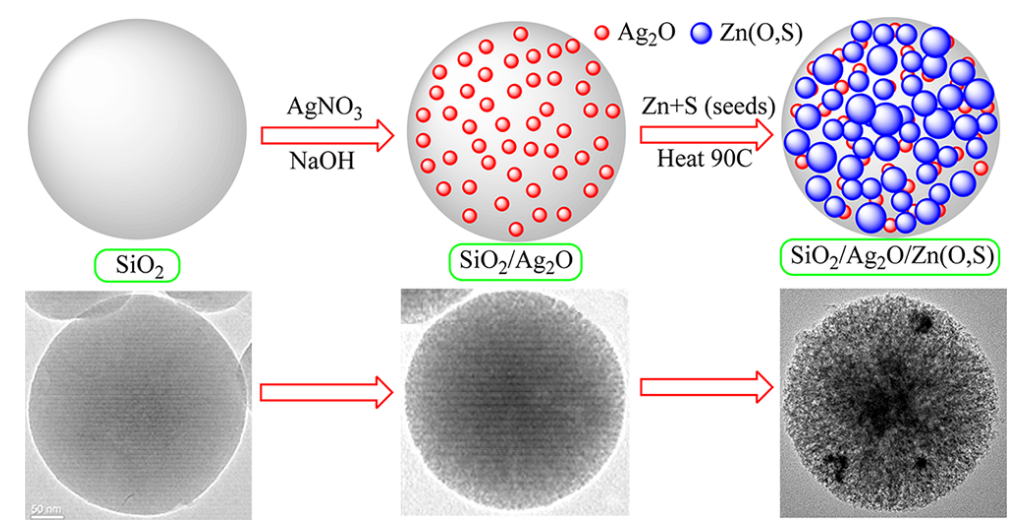

Figure 19. Schematic illustration for the synthesis of $\mathrm{SiO}_{2} / \mathrm{Ag}_{2} \mathrm{O} / \mathrm{Zn}(\mathrm{O}, \mathrm{S})$. Copyrights 2019 ACS [147].

Hierarchical honeycomb structures of anatase, co-doped with $\mathrm{Br}-$ and N- (HC-Br,N/Ana), have been proposed by Zhang et al. [148]. It was found that $\mathrm{HC}-\mathrm{Br}, \mathrm{N} /$ Ana exhibits a high efficiency of hydrogen-generation rate under vis $(\lambda>420 \mathrm{~nm})$ of $2247 \mu \mathrm{mol} \mathrm{h}^{-1} \mathrm{~g}^{-1}$, which is much higher than that by single doped titania $\left(\mathrm{Br}-\right.$ or $\mathrm{N}$ - of 0 or $63 \mu \mathrm{mol} \mathrm{h} \mathrm{h}^{-1} \mathrm{~g}^{-1}$, respectively); thus, synergy between $\mathrm{Br}$ and $\mathrm{N}$ was suggested. It has been proposed that the co-doping of titania with $\mathrm{Br}$ and $\mathrm{N}$ reduces its bandgap (to $2.88 \mathrm{eV}$ ), and that the holes on $\mathrm{N}$ acceptor level could passivate the electrons on $\mathrm{Br}$ donor level; thus, hindering the charge carriers' recombination.

Finally, probably the most prospective structure for efficient light harvesting is presented: photonic crystals (PCs) - a periodic optical nanostructure that affects the motion of photons. Although various types of structures could be considered (1D, 2D, and 3D), they are presented here together (considering honeycomb structures as the most typical) for clarity of presentation. The uniqueness of PCs is the formation of photonic bandgap (PBG), where light at certain frequencies is forbidden from propagation, due to refractive periodicity of the material [149]. An occurrence of PBG causes multiple scatterings of light at the edges, resulting in a decrease in photons' group velocity-known as slow photons - that could be efficiently utilized with photo-absorbing materials for amplified light harvesting [150]. It should be pointed out that the PBG effect is dependent on the angle of the irradiation [151,152], the diameter of the void spaces or inner spaces [153,154], the distance between tubes (nanotubes), and the thickness of the periodic nanostructure's wall [155].

In recent years, several studies have been reported on the correlation between the PBG effect of PCs and their photocatalytic activity for hydrogen production. Accordingly, Chiarello et al. have shown that the total amount of generated $\mathrm{H}_{2}$ increases linearly with the enlargement of the inner diameter of titania, indicating the confinement and manipulation of light that entered within the material. In contrast, enhanced photoelectrochemical hydrogen evolution has been reported for quantum dots-sensitized $\mathrm{TiO}_{2}$ inverse opal PCs with the smallest void spaces [156]. Moreover, an enhanced "energy production" from water/biomass could depend not only on the nanovoid spaces of the designed PCs, but also other factors, such as co-modifications performed on the periodic nanostructure, as summarized in Table 4.

The overlapping of the slow photons region (PBG effect) and the absorption edge of the backbone PC material, has emerged as a successful technique for promoting light harvesting; thus, they can amplify the photocatalytic performance. Liu et al. have shown the enhanced hydrogen evolution for Pt-loaded titania inverse opal (IO) with a nanovoid diameter of $133 \mathrm{~nm}$, which allows more precise overlapping between slow photons and a titania electronic absorption at approximately $360 \mathrm{~nm}$, in comparison with smaller/larger nanovoids with a slow photons effect at shorter/longer wavelengths [157]. Similarly, Waterhouse et al. have succeeded in matching the wavelengths of the PBG effect and titania 
absorption edge through precise tuning for $\mathrm{Au} / \mathrm{TiO}_{2} \mathrm{PC}$, with a stopband position located at $357 \mathrm{~nm}$, which has exhibited efficient hydrogen generation from photoelectrochemical water splitting [158].

Apart from that, an increase in overall activity could be evident by the overlapping of the slow photons at either blue or red edges with any photo-absorbing material, such as noble metals (plasmonic effect) [159] and dye sensitized molecules. Accordingly, enhanced hydrogen evolution has been observed by tuning the arise of slow photons at ca. $518 \mathrm{~nm}$ that overlapped precisely with the localized surface plasmon resonance (LSPR) effect from Au NPs, deposited on titania nanorod PCs [160]. Similarly, the amplified photoelectrochemical water splitting has been achieved after matching the wavelengths of LSPR and PBG (at $513 \mathrm{~nm}$ ), owning to the noble metal incorporated within the material and slow photons from the bismuth vanadium-based photoelectrode, respectively [161]. However, it should be highlighted that the precise matching between slow photons and plasmon effect could not be proven by polychromatic source of irradiation, as PCs material such as titania could also absorb light under vis range up to $450 \mathrm{~nm}$ (due to defects and impurities), as shown in a recent study [162].

Fabrication of well-ordered multi-array PCs is identified as one of the important aspects in governing the overall photocatalytic performance, as the trapping and multiscattering of photons is more evident in such materials. Accordingly, Cui et al. have reported much higher hydrogen evolution during water oxidation in the presence of the $\mathrm{CdS}-\mathrm{Au}-\mathrm{WO}_{3}$ heterostructure PCs in comparison with the crushed ones, highlighting the reduced slow photons enhancement in the latter sample [163]. A similar observation has been highlighted in a study performed for the photodegradation of organic pollutants, where the grounded PCs sample exhibits much lower activity in comparison with the undestroyed ones [164], indicating the importance of the well-ordered multi-array PC structures in the overall photocatalytic activity.

In summary, 3D photocatalysts have been usually constructed from one or more kinds of $0 \mathrm{D}, 1 \mathrm{D}$, and 2D morphologies, and thus, the 3D morphologies could accumulate their various advantages. Undoubtedly, the morphology-governed activity has been confirmed in various studies. For example, $3 \mathrm{D}$ organized structures, such as hierarchical $\mathrm{TiO}_{2} / \mathrm{g}-$ $\mathrm{C}_{3} \mathrm{~N}_{4}, 3 \mathrm{D} \mathrm{TiO}$ with oriented radially meso-channels, and $3 \mathrm{D}$ g- $\mathrm{C}_{3} \mathrm{~N}_{4}$ multihole hexagon, were shown to be much more active than respective materials with irregular morphologies. Moreover, photocatalysts with 3D morphology exhibit higher activity than 2D ones, e.g., platinized flower-like $\mathrm{Sn}_{3} \mathrm{O}_{4}$ compared with platinized sheets of $\mathrm{Sn}_{3} \mathrm{O}_{4}$. Additionally, a uniform dispersion of one component on another might also improve the photocatalytic performance, e.g., $\mathrm{NH}_{4} \mathrm{TiOF}_{3}$ dispersed on the titania surface in a $\mathrm{TiO}_{2} / \mathrm{g}-\mathrm{C}_{3} \mathrm{~N}_{4}$ composite. Usually, it is proposed that an organized morphology results in an efficient charge carriers migration, and thus, in higher photocatalytic activity. Moreover, 3D structures have also been proposed as profitable materials for an efficient light harvesting, e.g., the camelia-like structure of $\mathrm{TiO}_{2} / \mathrm{g}-\mathrm{C}_{3} \mathrm{~N}_{4} / \mathrm{NH}_{4} \mathrm{TiOF}_{3}$ and all PCs. The light harvesting ability of PCs is their main advantage, and thus, is commonly used for various applications. The most recommended option is to overlap the photonic bandgap edge position (slow photon effect) with the absorption ability of SCs, which results in a significant enhancement of photocatalytic activity. Moreover, an addition of modifiers with the ability of vis absorption, and the subsequent tuning the position of PBG edge (by void/sphere diameter) to overlap with the absorption of modifiers, results in significant enhancement of activity, even in the visible range of the solar spectrum. The important morphology is probably the most evident for PCs, since even slight destruction of their structure causes a significant decrease in the activity.

Table 4 presents the examples of different types of PCs applied for hydrogen generation. Similar to other structures hole scavengers, i.e., alcohols (methanol, ethanol, ethylene glycol), triethanolamine, and $\mathrm{Na}_{2} \mathrm{~S} / \mathrm{Na}_{2} \mathrm{SO}_{3}$, etc., are commonly used for the hydrogen evolution process. Notwithstanding the scavengers' use, the presented enhancements in 
the photocatalytic activity confirm that significant developments of new efficient materials based on PCs is highly recommended.

Table 4. Examples of photonic crystals applied for photocatalytic hydrogen evolution.

\begin{tabular}{|c|c|c|c|c|c|}
\hline PCs & Modification on PCs & Irradiation Source & Scavenger & Findings & Ref. \\
\hline TNTs & - & Xe lamp & - & improved activity & [154] \\
\hline $\mathrm{TiO}_{2}$ & Pt loading & Xe lamp & $\mathrm{CH}_{3} \mathrm{OH}$ & $2 \times$ enhancement * & [157] \\
\hline IOT & Au loading & $\begin{array}{l}\text { UV lamp (>365 nm) } \\
\text { and solar }\end{array}$ & $\mathrm{C}_{2} \mathrm{H}_{5} \mathrm{OH}$ & high activity & [158] \\
\hline $\mathrm{TiO}_{2}$ nanorods & Au NP loading & Xe lamp (>420 nm) & - & improved activity & [160] \\
\hline $\mathrm{Mo:BiVO}_{4} \mathrm{IO}$ & Au NP deposition & solar light stimulator & - & $4 \times$ enhancement & [161] \\
\hline $\mathrm{WO}_{3}$ & $\mathrm{Au} / \mathrm{CdS}$ loading & Xe lamp (>420 nm) & $\mathrm{Na}_{2} \mathrm{~S} / \mathrm{Na}_{2} \mathrm{SO}_{3}$ & high activity * & [163] \\
\hline $\mathrm{TiO}_{2}$ & $\mathrm{Au} / \mathrm{CdS}$ loading & Xe lamp (>420 nm) & $\mathrm{Na}_{2} \mathrm{~S} / \mathrm{Na}_{2} \mathrm{SO}_{3}$ & high activity & [165] \\
\hline TNTs & Cu NP loading & Xe lamp (>420 nm) & ethylene glycol & high activity & [166] \\
\hline IOT & F_IOT/Au infilt. & $\mathrm{Hg} /$ Xe lamp & $\mathrm{C}_{2} \mathrm{H}_{5} \mathrm{OH}$ & high activity & [167] \\
\hline IOT & $\mathrm{CuO} / \mathrm{BiVO}_{4}$ loading & Hg lamp (365 nm) & $\mathrm{C}_{2} \mathrm{H}_{5} \mathrm{OH}$ & enh. Activity ** & [168] \\
\hline IOT & $\mathrm{Ti}^{3+} / \mathrm{Au}-\mathrm{Pt}$ NPs load. & UV lamp (<400 nm) & $\mathrm{C}_{2} \mathrm{H}_{5} \mathrm{OH}$ & high activity & [169] \\
\hline $\mathrm{CdS} \mathrm{IO}$ & - & $\lambda \geq 420 \mathrm{~nm}$ & $\mathrm{Na}_{2} \mathrm{~S} / \mathrm{Na}_{2} \mathrm{SO}_{3}$ & $2 \times$ enhancement * & [170] \\
\hline TNTs & $\mathrm{Ti}^{3+}$ & $\bar{X}$ lamp & - & $10 \times$ enhancement $*$ & [171] \\
\hline $\mathrm{g}-\mathrm{C}_{3} \mathrm{~N}_{4} \mathrm{IO}$ & - & Xe lamp & TEA & $6 \times$ enhancement $*$ & [172] \\
\hline IOT & Ag NP loading & Xe lamp & - & high activity & [173] \\
\hline
\end{tabular}

* - compared to reference; **-enhanced activity dependent on $\mathrm{BiVO}_{4}$ and $\mathrm{CuO}$ amount; infilt.—infiltration; IO—inverse opal; IOT—inverse opal titania; F_IOT—fluorination of IOT; $\mathrm{Ti}^{3+}$ - self-doping.

\section{Composite-Structure (Multi-Dimensional) Photocatalysts}

Multi-composite photocatalysts, constructed from two (or even more) dimensions structured together (e.g., 0D/1D, 0D/2D, 1D/2D), have also been proposed for photocatalytic hydrogen evolution. Obviously, application of fine deposits (0D: QDs, NPs, nanoclusters) on the surface of more complex structures is the most popular. Although QDs have shown remarkable merits (e.g., large specific surface area, efficient light harvesting ability, and adjustable bandgap), which are beneficial for vis photocatalysis, the utilization of QDs is also connected to serious issues of charge recombination and possible aggregation. Accordingly, the stabilization of QDs on the support should be beneficial for the overall performance. Indeed, stable and highly active photocatalysts have been prepared when 0D Zn-AgIn ${ }_{5} \mathrm{~S}_{8}$ (ZAIS) QDs are deposited onto $2 \mathrm{D} \alpha-\mathrm{Fe}_{2} \mathrm{O}_{3}$ nanosheets through electrostatic attractions, i.e., a difference in Zeta potential results in a uniform dispersion of ZAIS QDs on nanosheets, as shown in Figure 20 (Table 5) [174]. It has been confirmed that the introduction of $\alpha-\mathrm{Fe}_{2} \mathrm{O}_{3}$ nanosheets enhances the mobility and separation of charge carriers. Additionally, high conductivity of $\alpha-\mathrm{Fe}_{2} \mathrm{O}_{3}$ can lead out the photogenerated charge carriers, and thus, hindering their recombination. It has been proven that appropriate band alignment is beneficial for the construction of Z-scheme heterostructures (as confirmed by EPR), which improves the redox properties and prevents the charge carriers' recombination. The best nanocomposite, with $3 \mathrm{wt} \% \alpha-\mathrm{Fe}_{2} \mathrm{O}_{3}$, causes hydrogen evolution under vis irradiation ( $>420 \mathrm{~nm}$; ascorbic acid as a hole scavenger) at the rate of $1.7 \mathrm{mmol} \cdot \mathrm{g}^{-1} \mathrm{~h}^{-1}$, that is 3.5 times higher than that on pristine QDs, with an apparent quantum efficiency of $7.48 \%$ at $450 \cdot \mathrm{nm}$. 


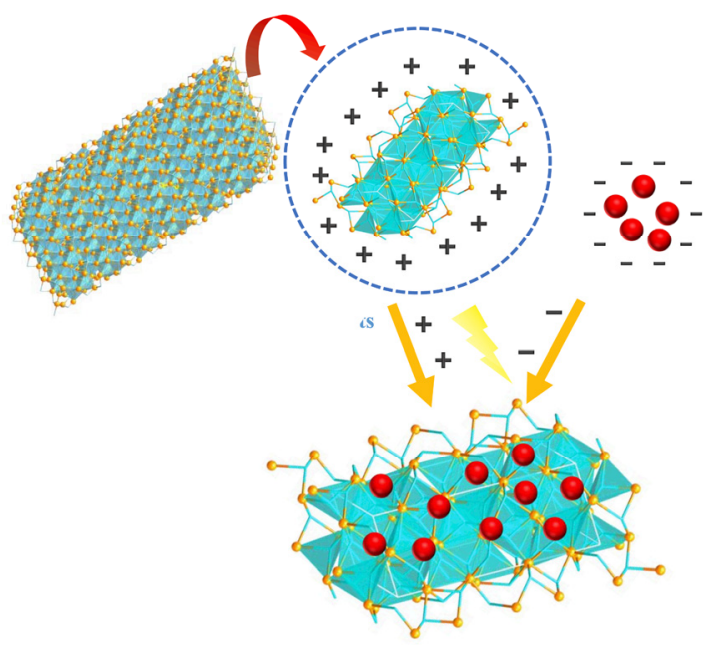

Figure 20. Schematic illustration for synthesis of ZAIS $/ \alpha-\mathrm{Fe}_{2} \mathrm{O}_{3}$ via electrostatic adsorption of the ZAIS QDs on $\alpha-\mathrm{Fe}_{2} \mathrm{O}_{3}$ nanosheets. Copyrights 2021 Elsevier [174].

NPs are probably more popular than QDs for the modification of other structures due to their usually easier and cheaper synthesis methods. For example, Liu et al. have prepared a $0 \mathrm{D} / 2 \mathrm{D} \mathrm{TiO}_{2} / \mathrm{CoP}$ photocatalyst via in situ growing of titania NPs on the CoP nanosheets by hydrothermal process [175]. It has been found that the optimized composite ( $1 \mathrm{wt} \% \mathrm{CoP})$ exhibits the best activity for $\mathrm{H}_{2}$ generation under $\mathrm{UV} /$ vis $\left(\mathrm{Xe}\right.$ lamp; $\left.\mathrm{CH}_{3} \mathrm{OH}\right)$, which is ten times higher than that by pristine titania. It has been proposed that small work function and high conductivity of nanosheets causes the formation of an Ohmic-junction with titania, which can efficiently enhance the charge carriers' separation, thus increasing the photocatalytic activity. In contrast, Bian et al. have used 2D titania structures (mesocrystals) modified with $0 \mathrm{D}$ deposits of noble metals as plasmonic photocatalyst $[66,67]$. It has been proposed that the position of noble metals is detrimental for the overall activity; thus, gold should be deposited on the basal rather than the lateral surface, resulting in electrons migration via titania mesocrystals. In the case of hydrogen evolution under vis irradiation (460 nm > $\lambda>700 \mathrm{~nm}$; 2-propanol), a second metal should be deposited as a co-catalyst for hydrogen generation (electron transfer from first metal via plasmonic excitation to titania and then to second metal). Therefore, it has been proposed that gold should be deposited on the basal surface, with platinum on the lateral one, causing efficient hydrogen evolution even under vis irradiation.

Furthermore, a more complex structure has also been proposed: 3D titania microflowers (prepared by the hydrothermal method) deposited on $\mathrm{g}-\mathrm{C}_{3} \mathrm{~N}_{4}$ sheets (prepared by calcination) via solution-mediated self-assembly, as shown in Figure 21 [176]. The photocatalytic activity of the optimized ( $50 \mathrm{w} \% \mathrm{~g}-\mathrm{C}_{3} \mathrm{~N}_{4}$ ) composite for hydrogen evolution under $\mathrm{UV} /$ vis (Xe lamp; TEOA and Pt) is 7.7 and 1.9 times higher than that on bare $\mathrm{g}-\mathrm{C}_{3} \mathrm{~N}_{4}$ and $\mathrm{TiO}_{2}$, respectively. Accordingly, it has been suggested that the photo-induced electron/hole pairs in this $3 \mathrm{D} / 2 \mathrm{D}$ could be separated efficiently via a direct Z-scheme mechanism. 


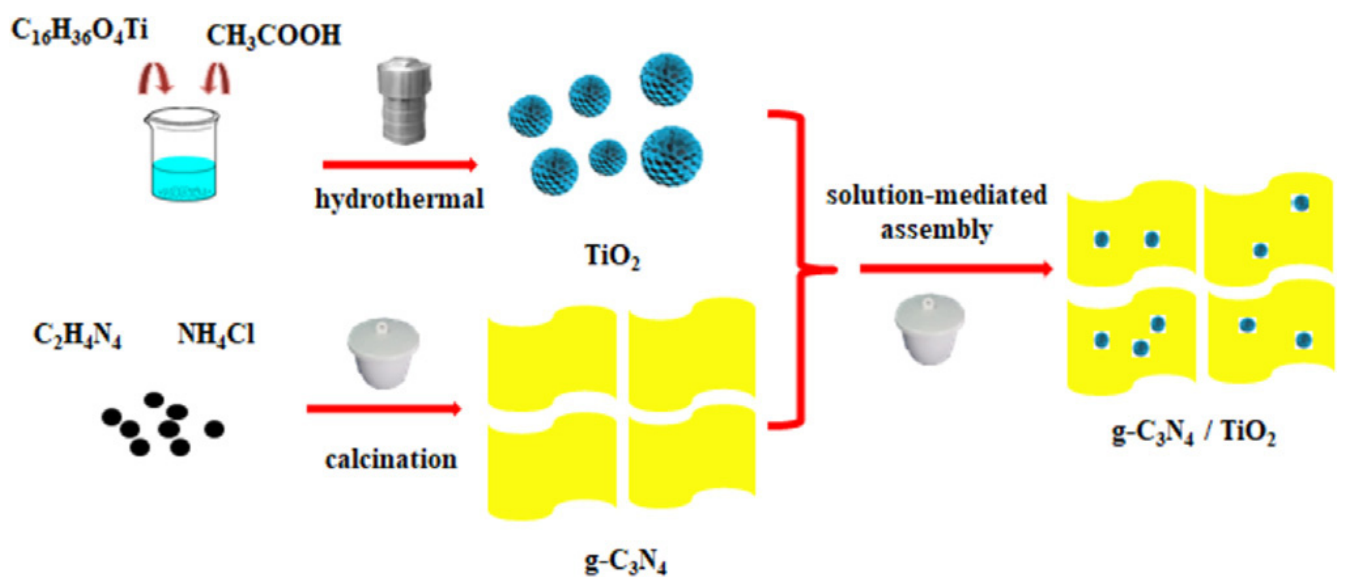

Figure 21. Schematic representation for the fabrication of $3 \mathrm{D} \mathrm{TiO} 2 / 2 \mathrm{D} \mathrm{g}-\mathrm{C}_{3} \mathrm{~N}_{4}$ composites. Copyrights 2019 Elsevier [176].

Well-known sulfides are highly attractive for photocatalysis under vis irradiation due to a narrower bandgap than oxides, but their practical application is limited due to photocorrosion. Accordingly, modification of sulfides with other materials has been proposed to improve their stability and the overall performance of the composite materials [177-179]. For example, cadmium sulfide has been widely used for the formation of coupled materials with advanced morphology, forming efficient and stable photocatalysts, e.g., CdS $/ \mathrm{Co}_{9} \mathrm{~S}_{8}(3 \mathrm{D} / 0 \mathrm{D})$ [180], $\mathrm{CdS} / \mathrm{TiO}_{2}$ (1D/2D) [181], and $\mathrm{CdS} / \mathrm{MoS}_{2}(1 \mathrm{D} / 2 \mathrm{D})$ [182]. Although CdS, in the form of QDs (0D), is commonly applied in photocatalysis [183-185], other organized structures have also been proposed. For example, 3D hierarchical CdS supporting 0D $\mathrm{Co}_{9} \mathrm{~S}_{8} \mathrm{NPs}$ has been prepared via a facile solvothermal method [180]. It has been found that the photocatalytic activity $\left(>420 \mathrm{~nm} ; \mathrm{Na}_{2} \mathrm{~S} / \mathrm{Na}_{2} \mathrm{SO}_{3}\right)$ of the optimized material exceeds $\mathrm{H}_{2}$-generation rate of reference samples, i.e., $\mathrm{CdS}$ and $\mathrm{Co}_{9} \mathrm{~S}_{8}$, by ca. 7 and 258 times, respectively. Accordingly, it has been proposed that a synergistic effect, including enhanced light absorption capacity, accelerated separation, and migration of charge carriers, as well as much stronger reduction ability of electrons in the $\mathrm{CB}$ of $\mathrm{Co}_{9} \mathrm{~S}_{8}$ (Z-scheme mechanism), are responsible for activity enhancement. Another form of CdS that has been used for composite structures are nanowires (1D). For example, 2D titania with exposed \{001\} facets (nanosheets), pre-modified with Pt NPs (as a co-catalyst for $\mathrm{H}_{2}$ evolution), has been modified with CdS by reflux method [181]. It has been confirmed that the morphology controls the photocatalytic performance as $\mathrm{Pt} / \mathrm{TiO}_{2}(2 \mathrm{D}) / \mathrm{CdS}(1 \mathrm{D})$ exhibits 3.7 times higher hydrogen generation rate ( $>400 \mathrm{~nm}$; lactic acid) than that of the $\mathrm{Pt} / \mathrm{P} 25 / \mathrm{CdS}$ composite.

Similar 1D structures of CdS (nanorods) have been used by Chava et al. for synthesis (by a two-step facile hydrothermal process; Figure 22) of 1D/3D CdS/ $\mathrm{MoS}_{2}$ heteronanostructures (HNSs) [182]. It has been found that the hydrogen evolution rate under vis irradiation ( $>420 \mathrm{~nm}$; lactic acid) is 11 times higher than that on pure CdS nanorods. Accordingly, it has been proposed that a synergistic effect between components, due to matched energy band levels causing the inhibition of charges' recombination, is responsible for this enhanced activity, as shown in Figure 23. 


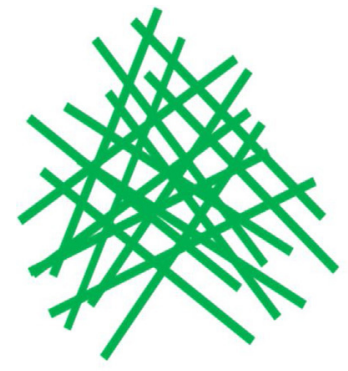

CdS NRs

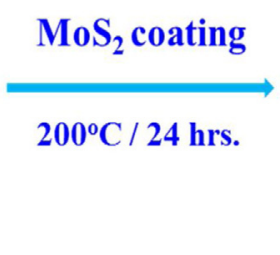

Figure 22. Schematic illustration of synthesis protocol for the fabrication of $1 \mathrm{D} \mathrm{CdS} / 2 \mathrm{D} \mathrm{MoS}_{2}$. Copyrights 2018 Elsevier [182].

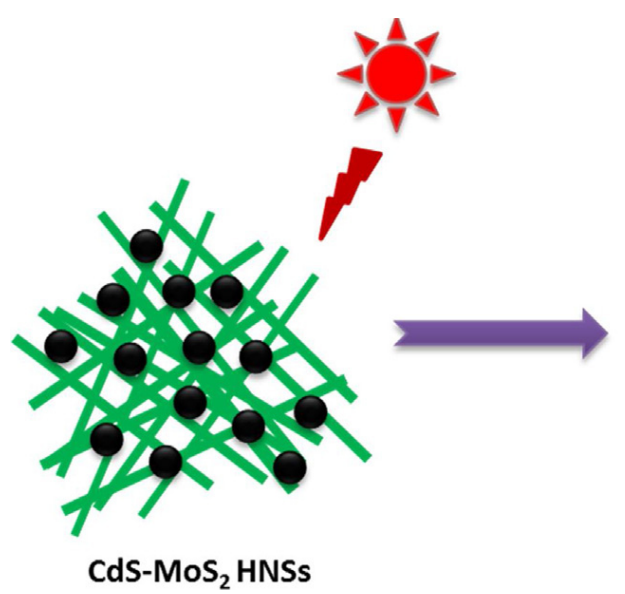

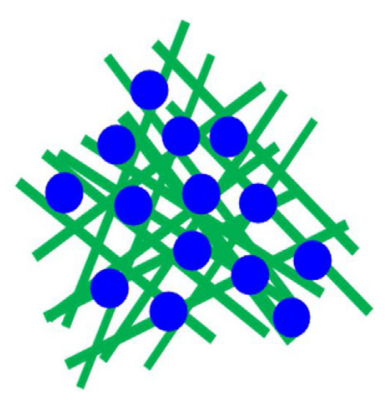

CdS-MoS ${ }_{2}$ HNSs

Figure 23. Schematic illustration of the proposed mechanism for enhanced photocatalytic activity during $\mathrm{H}_{2}$ evolution. Copyrights 2018 Elsevier [182].

Although the majority of studies compare the novel photocatalysts (with well-organized morphology) with either bulk materials or commercial samples, some reports have discussed how slight changes in the morphology (e.g., of one component) might influence the photocatalytic performance. For example, an interesting study has been performed for a porous titania structure modified with CdSe (a sol-gel method with calcination and hydrothermal process) of different morphology, i.e., nanoplates, nanoprisms and nanopyramids [186]. It has been found that the composites with nanoplate-shaped CdS exhibit the highest rate for hydrogen evolution of $3.6 \mathrm{mmol} \mathrm{h}^{-1} \mathrm{~g}^{-1}\left(>400 \mathrm{~nm} ; \mathrm{Na}_{2} \mathrm{~S} / \mathrm{Na}_{2} \mathrm{SO}_{3}\right.$ ), then nanoprisms $\left(3.1 \mathrm{mmol} \mathrm{h}^{-1} \mathrm{~g}^{-1}\right)$ and nanopiramids $\left(2.5 \mathrm{mmol} \mathrm{h}^{-1} \mathrm{~g}^{-1}\right)$, which additionally is much higher than the activity of bare samples, i.e., $0.5 \mathrm{mmol} \mathrm{h}^{-1} \mathrm{~g}^{-1}$ for pristine CdSe and inactive titania.

As summarized in Table 5, the formation of coupled semiconductors' materials, especially CdS-based systems, is a desired direction for the development of efficient photocatalysts for $\mathrm{H}_{2}$ evolution. Various scavengers (L-ascorbic acid, methanol, triethanolamine, $\mathrm{Na}_{2} \mathrm{~S} / \mathrm{Na}_{2} \mathrm{SO}_{3}$, and lactic acid, etc.) have also been applied for multi-dimensional photocatalysts. Despite this, the effective optimization of multi-dimensional morphologies could combine advantages of mono-dimensional materials and avoid disadvantages of other morphologies, significantly improving the properties and photocatalytic activities. It is clear that organized and well-controlled morphology results in much higher photocatalytic activity also for multi-dimensional photocatalysts. Similar to other dimension structures, the localization of a co-catalyst could be decisive for the overall performance of photocatalysts. 
Table 5. Examples of multi-dimensional photocatalysts applied for photocatalytic hydrogen evolution.

\begin{tabular}{|c|c|c|c|c|c|}
\hline SCs & $\begin{array}{l}\text { Modification on } \\
\text { SCs }\end{array}$ & Irradiation Source & Scavenger & Findings & Ref. \\
\hline$\alpha-\mathrm{Fe}_{2} \mathrm{O}_{3}$ & $\mathrm{Zn}-\mathrm{AgIn}_{5} \mathrm{~S}_{8}$ QDs & Xe lamp $(\lambda \geq 420 \mathrm{~nm})$ & L-ascorbic acid & $1.7 \mathrm{mmol} \mathrm{g}^{-1} \mathrm{~h}^{-1}$ & [173] \\
\hline $\mathrm{CoP}$ & $\mathrm{TiO}_{2}$ & Xe lamp & $\mathrm{CH}_{3} \mathrm{OH}$ & $0.06 \mathrm{mmol} \mathrm{g}^{-1} \mathrm{~h}^{-1}$ & [174] \\
\hline $\mathrm{g}-\mathrm{C}_{3} \mathrm{~N}_{4}$ & $\mathrm{TiO}_{2}$ & Xe lamp & TEA & $7.7 \times$ enhancement & [175] \\
\hline $\mathrm{CdS}$ & $\begin{array}{c}\mathrm{Cog}_{8} \mathrm{~S}_{8} \\
\text { nanoparticles }\end{array}$ & halogen light (5\% UV light) & $\mathrm{Na}_{2} \mathrm{~S} / \mathrm{Na}_{2} \mathrm{SO}_{3}$ & $\begin{array}{l}5.15 \mathrm{mmol} \mathrm{h}^{-1} \mathrm{~g}^{-1} \\
6.8 \times \text { enhancement }\end{array}$ & [179] \\
\hline $\mathrm{TiO}_{2} / \mathrm{CdS}$ & Xe lamp (>400 nm) & Xe lamp (>400 nm) & lactic acid & $35.3 \mu \mathrm{mol} \mathrm{g}-1 \mathrm{~h}^{-1}$ & [180] \\
\hline $\mathrm{CdS}$ & $\mathrm{MoS}_{2}$ & Xe lamp & lactic acid & $\begin{array}{l}11.85 \mathrm{mmol} \mathrm{g}^{-1} \mathrm{~h}^{-1} \\
11 \times \text { enhancement }\end{array}$ & [181] \\
\hline $\mathrm{TiO}_{2}$ & CdSe & UV cut-off filter $(\lambda \geq 400 \mathrm{~nm})$ & $\mathrm{Na}_{2} \mathrm{~S} / \mathrm{Na}_{2} \mathrm{SO}_{3}$ & $3650 \mu \mathrm{mol} \mathrm{g}^{-1} \mathrm{~h}^{-1}$ & [185] \\
\hline
\end{tabular}

\section{Conclusions}

The photocatalytic generation of hydrogen remains a challenge when it comes to practical applications. One might conclude that the overall efficiencies of this process, reported in the literature, are unsatisfactory. The problems relate, firstly, to the use of sacrificial reagents (electron donors). Considering the fast charge carriers' recombination and backward reactions, with the continuous addition of those substances which are indispensable to allow the reaction to proceed efficiently (half of the water splitting reaction to perform water reduction to hydrogen). Another problematic issue is connected with the nature of these sacrificial reagents, especially in the context of their costs vs. photocatalytic hydrogen generation total costs. Accordingly, the proposed application of wastewater as a hole scavenger is a very attractive possibility; potentially resulting in complete water purification and fuel generation. The crucial element of the considered photocatalytic system is the photocatalyst itself. The proper selection and design of photocatalytic materials can significantly improve the perspective applications of this process. The most often investigated issues determining the efficiency of photocatalysts are the band structure of semiconductor, crystallinity, crystal type and structure, and particle size. However, a photocatalyst morphology is quite rarely taken into consideration in the photocatalysts design procedures, so far, despite it being known that, in some cases, even a slight change in the morphology could result in significant change in the photocatalytic performance (as also shown in this review). The various morphological configurations belonging to the main dimensional arrangement groups of $0 \mathrm{D}, 1 \mathrm{D}, 2 \mathrm{D}$, and 3D, presented in this review, show that their utilization in the photocatalytic hydrogen production systems can provide a promising direction for significant enhancement of the efficiency of hydrogen generation.

One can expect that, probably, all structures of nanomaterials with any capacity to be active under irradiation have already been tested and likely recommended for hydrogen generation. Unfortunately, it is quite hard to compare different structures, as experiments are performed under significantly differing conditions. Additionally, there are some confusing reports, e.g., those suggesting solar water splitting (title or/and abstract) when water reduction in the presence of sacrificial reagents has been only performed under $\mathrm{UV} / \mathrm{vis}$ irradiation. It should be remembered that bare titania is also active under solar radiation due to the UV part of the solar spectrum, and thus, vis activity for modified titania could not be proven under solar (or simulated solar) radiation. In some cases, authors do not write at all how photocatalytic experiments have been performed. Moreover, sometimes vis, solar, simulated solar, and UV/vis (Xe lamp) irradiation are used interchangeably. Another issue that could cause concern relates to unproven conclusions. It is thought that, in some cases when the study is focused on the morphology, the mechanism is little neglected (no need to answer the question: "why?"). Moreover, many photocatalytic materials are described as "excellent". Accordingly, it is hard to conclude which material is the best and the most highly recommended. Therefore, in general, after consideration of both the pros and cons of various structures (Table 6), it is thought that the composite nanostructure photocatalysts (formed from 0D, 1D, 2D, and 3D) might be the most highly 
recommended by this review, since they usually retain the advantages of single components while simultaneously limiting their respective disadvantages.

Table 6. Advantages and disadvantages of different morphologies.

\begin{tabular}{|c|c|c|c|}
\hline D & Advantages & Disadvantages & Ref. \\
\hline $0 \mathrm{D}$ & large SSA, many AS, fast CCM from bulk to surface & $\begin{array}{c}\text { aggl.; AS inactivation (easily and } \\
\text { uncontrollable), difficult recyc., secondary } \\
\text { pollutants }\end{array}$ & [187-189] \\
\hline $1 \mathrm{D}$ & $\begin{array}{l}\text { directivity and conductivity, large SSA, high aspect } \\
\text { ratio, fast CCM along the axial direction-low E-HR } \\
\text { and high PA }\end{array}$ & E-T-B uneven in size, poor dispersion & {$[190,191]$} \\
\hline $2 \mathrm{D}$ & $\begin{array}{l}\text { large SSA, high stability, used to stabilize 0D (poor } \\
\text { stability/aggl.) by loading 0D on 2D }\end{array}$ & $\begin{array}{l}\text { E-T-B re-stacked due to the hydrophobicity } \\
\text { and van der Waals force - reduces SSA }\end{array}$ & {$[192,193]$} \\
\hline $3 \mathrm{D}$ & $\begin{array}{c}\text { easily recy., high stability, overcome shortcomings of } \\
\text { OD, 1D and 2D aggl., AS of each component, large } \\
\text { SSA, high porosity and AS, improved CCM and } \\
\text { absorbability }\end{array}$ & $\begin{array}{l}\text { req. surfactants or template (secondary } \\
\text { pollutant), a problem of subsequent removal } \\
\text { (affecting integrity of the structure) }\end{array}$ & [194-196] \\
\hline
\end{tabular}

aggl.—agglomeration; AS—active sites; CCM—charge carriers' migration; D—dimension; E-HR—electron-hole recombination; E-T-B—easy to be; PA—-photocatalytic activity; SSA—specific surface area; req.-mostly require; recy.-recycle/reuse.

To summarize, although there are many examples of efficient hydrogen evolution methods (even under vis irradiation) on novel photocatalytic materials, there is still insufficient discussion on the influence of the morphology on the photocatalytic activity, while also considering the mechanism clarification. It is thought that further studies should be performed via systematic investigation in this field, in order to understand key factors of photocatalytic activity and to propose commercially acceptable photocatalysts. This should be done while taking into consideration proper reactor design. As a result of further study, practical application of this method can be made possible.

Author Contributions: Conceptualization, Z.W. and E.K.; writing-original draft preparation, Z.W., T.R.M., K.W., M.J. and E.K.; writing-review and editing, Z.W., K.W., M.J. and E.K. All authors have read and agreed to the published version of manuscript.

Funding: This research was funded by the National Natural Science Foundation of China (NSFC) (51802087), the Natural Science Foundation of the Hubei province of China (2019CFB524), the Ministry of Education and Science of Poland and "Yugo-Sohatsu Kenkyu" for an Integrated Research Consortium on Chemical Sciences (IRCCS) project from the Ministry of Education and Culture, Sport, Science and Technology-Japan (MEXT).

Institutional Review Board Statement: Not applicable.

Informed Consent Statement: Not applicable.

Data Availability Statement: Not applicable.

Conflicts of Interest: The authors declare no conflict of interest.

\section{References}

1. Tsang, C.H.A.; Huang, H.B.; Xuan, J.; Wang, H.Z.; Leung, D.Y.C. Graphene materials in green energy applications: Recent development and future perspective. Renew. Sustain. Energy Rev. 2020, 120, 109656. [CrossRef]

2. Rana, A.; Yadav, K.; Jagadevan, S. A comprehensive review on green synthesis of nature-inspired metal nanoparticles: Mechanism, application and toxicity. J. Clean. Prod. 2020, 272, 122880. [CrossRef]

3. Xie, Z.J.; Peng, Y.P.; Yu, L.; Xing, C.Y.; Qiu, M.; Hu, J.Q.; Zhang, H. Solar-Inspired Water Purification Based on Emerging 2D Materials: Status and Challenges. Sol. RRL 2020, 4, 1900400. [CrossRef]

4. Saidur, R.; Rahim, N.A.; Islam, M.R.; Solangi, K.H. Environmental impact of wind energy. Renew. Sustain. Energy Rev. 2011, 15, 2423-2430. [CrossRef]

5. Pickering, M.D.; Horsburgh, K.J.; Blundell, J.R.; Hirschi, J.J.M.; Nicholls, R.J.; Verlaan, M.; Wells, N.C. The impact of future sea-level rise on the global tides. Cont. Shelf Res. 2017, 142, 50-68. [CrossRef] 
6. Kuriqi, A.; Pinheiro, A.N.; Sordo-Ward, A.; Garrote, L. Water-energy-ecosystem nexus: Balancing competing interests at a run-of-river hydropower plant coupling a hydrologic-ecohydraulic approach. Energy Convers. Manag. 2020, $223,113267$. [CrossRef]

7. Dawood, F.; Anda, M.; Shafiullah, G.M. Hydrogen production for energy: An overview. Int. J. Hydrogen Energy 2020, 45, 3847-3869. [CrossRef]

8. Hirscher, M.; Yartys, V.A.; Baricco, M.; von Colbe, J.B.; Blanchard, D.; Bowman, R.C.; Broom, D.P.; Buckley, C.E.; Chang, F.; Chen, P.; et al. Materials for hydrogen-based energy storage-Past, recent progress and future outlook. J. Alloys Compd. 2020, 827, 153548. [CrossRef]

9. Cobo, S.; Heidkamp, J.; Jacques, P.A.; Fize, J.; Fourmond, V.; Guetaz, L.; Jousselme, B.; Ivanova, V.; Dau, H.; Palacin, S.; et al. A Janus cobalt-based catalytic material for electro-splitting of water. Nat. Mater. 2012, 11, 802-807. [CrossRef]

10. Yilmaz, C.; Tan, C.F.; Lim, Y.F.; Ho, C.W. Pseudomorphic Transformation of Interpenetrated Prussian Blue Analogs into Defective Nickel Iron Selenides for Enhanced Electrochemical and Photo-Electrochemical Water Splitting. Adv. Energy Mater. 2019, 9, 1802983. [CrossRef]

11. Khan, S.U.M.; Al-Shahry, M.; Ingler, W.B., Jr. Efficient photochemical water splitting by a chemically modified n-TiO 2 . Science 2002, 297, 2243-2245. [CrossRef]

12. Lu, D.L.; Hitoki, G.; Katou, E.; Kondo, J.N.; Hara, M.; Domen, K. Porous single-crystalline TaON and Ta $3 \mathrm{~N}_{5}$ particles. Chem. Mater. 2004, 16, 1603-1605. [CrossRef]

13. Park, H.; Ou, H.H.; Kim, M.; Kang, U.; Han, D.S.; Hoffmann, M.R. Photocatalytic $\mathrm{H}_{2}$ production on trititanate nanotubes coupled with CdS and platinum nanoparticles under visible light: Revisiting $\mathrm{H}_{2}$ production and material durability. Faraday Discuss. 2017, 198, 419-431. [CrossRef] [PubMed]

14. Fujishima, A.; Honda, K. Electrochemical photolysis of water at a semiconductor electrode. Nature 1972, 238, 37-38. [CrossRef] [PubMed]

15. Ohtani, B. Photocatalysis A to Z-What we know and what we do not know in a scientific sense. J. Photochem. Photobiol. C Photochem. Rev. 2010, 11, 157-178. [CrossRef]

16. Ohtani, B. Preparing articles on photocatalysis-beyond the illusions, misconceptions, and speculation. Chem. Lett. 2008, 37, 217-229. [CrossRef]

17. Osterloh, F.E. Photocatalysis versus Photosynthesis: A Sensitivity Analysis of Devices for Solar Energy Conversion and Chemical Transformations. ACS Energy Lett. 2017, 2, 445-453. [CrossRef]

18. Takanabe, K. Photocatalytic Water Splitting: Quantitative Approaches toward Photocatalyst by Design. ACS Catal. 2017, 7, 8006-8022. [CrossRef]

19. Wang, C.; Sun, Z.; Zheng, Y.; Hu, Y.H. Recent progress in visible light photocatalytic conversion of carbon dioxide. J. Mat. Chem. A 2019, 7, 865-887. [CrossRef]

20. Pan, H.; Heagy, M.D. Photons to Formate: A Review on Photocatalytic Reduction of $\mathrm{CO}_{2}$ to Formic Acid. Nanomaterials 2020, 10, 2422. [CrossRef]

21. White, J.L.; Baruch, M.F.; Pander, J.E.; Hu, Y.; Fortmeyer, I.C.; Park, J.E.; Zhang, T.; Liao, K.; Gu, J.; Yan, Y.; et al. Light-Driven Heterogeneous Reduction of Carbon Dioxide: Photocatalysts and Photoelectrodes. Chem. Rev. 2015, 115, 12888-12935. [CrossRef] [PubMed]

22. Roy, N.; Suzuki, N.; Terashima, C.; Fujishima, A. Recent Improvements in the Production of Solar Fuels: From $\mathrm{CO}_{2}$ Reduction to Water Splitting and Artificial Photosynthesis. Bull. Chem. Soc. Jpn. 2019, 92, 178-192. [CrossRef]

23. Li, K.; Teng, C.; Wang, S.; Min, Q. Recent Advances in $\mathrm{TiO}_{2}$-Based Heterojunctions for Photocatalytic $\mathrm{CO}_{2}$ Reduction With Water Oxidation: A Review. Front. Chem. 2021, 9, 637501. [CrossRef]

24. Takata, T.; Tanaka, A.; Hara, M.; Kondo, J.N.; Domen, K. Recent progress of photocatalysts for overall water splitting. Catal. Today 1998, 44, 17-26. [CrossRef]

25. Maeda, K.; Teramura, K.; Lu, D.; Takata, T.; Saito, N.; Inoue, Y.; Domen, K. Photocatalyst releasing hydrogen from water. Nature 2006, 440, 295. [CrossRef] [PubMed]

26. Yamasita, D.; Takata, T.; Hara, M.; Kondo, J.N.; Domen, K. Recent progress of visible-light-driven heterogeneous photocatalysts for overall water splitting. Solid State Ion. 2004, 172, 591-595. [CrossRef]

27. Sasaki, Y.; Nemoto, H.; Saito, K.; Kudo, A. Solar Water Splitting Using Powdered Photocatalysts Driven by Z-Schematic Interparticle Electron Transfer without an Electron Mediator. J. Phys. Chem. C 2009, 113, 17536-17542. [CrossRef]

28. Maeda, K.; Higashi, M.; Lu, D.L.; Abe, R.; Domen, K. Efficient Nonsacrificial Water Splitting through Two-Step Photoexcitation by Visible Light using a Modified Oxynitride as a Hydrogen Evolution Photocatalyst. J. Am. Chem. Soc. 2010, 132, 5858-5868. [CrossRef]

29. Abe, R.; Higashi, M.; Domen, K. Overall Water Splitting under Visible Light through a Two-Step Photoexcitation between TaON and WO3 in the Presence of an Iodate-Iodide Shuttle Redox Mediator. ChemSusChem 2011, 4, 228-237. [CrossRef]

30. Abe, R. Recent progress on photocatalytic and photoelectrochemical water splitting under visible light irradiation. J. Photoch. Photobio. C 2010, 11, 179-209. [CrossRef]

31. Kudo, A. Recent progress in the development of visible light-driven powdered photocatalysts for water splitting. Int. J. Hydrogen Energy 2007, 32, 2673-2678. [CrossRef] 
32. Kudo, A.; Kato, H.; Tsuji, I. Strategies for the development of visible-light-driven photocatalysts for water splitting. Chem. Lett. 2004, 33, 1534-1539. [CrossRef]

33. Liu, G.; Yu, J.C.; Lu, G.Q.; Cheng, H.M. Crystal facet engineering of semiconductor photocatalysts: Motivations, advances and unique properties. Chem. Commun. 2011, 47, 6763-6783. [CrossRef] [PubMed]

34. Babu, V.J.; Vempati, S.; Uyar, T.; Ramakrishna, S. Review of one-dimensional and two-dimensional nanostructured materials for hydrogen generation. Phys. Chem. Chem. Phys. 2015, 17, 2960-2986. [CrossRef] [PubMed]

35. Ganguly, P.; Harb, M.; Cao, Z.; Cavallo, L.; Breen, A.; Dervin, S.; Dionysiou, D.D.; Pillai, S.C. 2D Nanomaterials for Photocatalytic Hydrogen Production. ACS Energy Lett. 2019, 4, 1687-1709. [CrossRef]

36. Faraji, M.; Yousefi, M.; Yousefzadeh, S.; Zirak, M.; Naseri, N.; Jeon, T.H.; Choi, W.; Moshfegh, A.Z. Two-dimensional materials in semiconductor photoelectrocatalytic systems for water splitting. Energy Environ. Sci. 2019, 12, 59-95. [CrossRef]

37. Tong, R.; Ng, K.W.; Wang, X.; Wang, S.; Wang, X.; Pan, H. Two-dimensional materials as novel co-catalysts for efficient solar-driven hydrogen production. J. Mat. Chem. A 2020, 8, 23202-23230. [CrossRef]

38. Kraeutler, B.; Bard, A.J. Heterogeneous photocatalytic preparation of supported catalysts. Photodeposition of platinum on $\mathrm{TiO}_{2}$ powder and other substrates. J. Am. Chem. Soc. 1978, 100, 4317-4318. [CrossRef]

39. Herrmann, J.-M.; Disdier, J.; Pichat, P. Photoassisted platinum deposition on $\mathrm{TiO}_{2}$ powder using various platinum complexes. J. Phys. Chem. 1986, 90, 6028-6034. [CrossRef]

40. Ohtani, B.; Osaki, H.; Nishimoto, S.; Kagiya, T. A novel photocatalytic process of amine N-alkylation by platinized semiconductor particles suspended in alcohols. J. Am. Chem. Soc. 1986, 108, 308-310. [CrossRef]

41. Kowalska, E.; Remita, H.; Colbeau-Justin, C.; Hupka, J.; Belloni, J. Modification of titanium dioxide with platinum ions and clusters: Application in photocatalysis. J. Phys. Chem. C 2008, 112, 1124-1131. [CrossRef]

42. Wei, Z.; Janczarek, M.; Endo, M.; Wang, K.L.; Balcytis, A.; Nitta, A.; Mendez-Medrano, M.G.; Colbeau-Justin, C.; Juodkazis, S.; Ohtani, B.; et al. Noble metal-modified faceted anatase titania photocatalysts: Octahedron versus decahedron. Appl. Catal. B Environ. 2018, 237, 574-587. [CrossRef]

43. Wei, Z.; Endo, M.; Wang, K.; Charbit, E.; Markowska-Szczupak, A.; Ohtani, B.; Kowalska, E. Noble metal-modified octahedral anatase titania particles with enhanced activity for decomposition of chemical and microbiological pollutants. Chem. Eng. J. 2017, 318, 121-134. [CrossRef] [PubMed]

44. Wang, K.L.; Wei, Z.S.; Ohtani, B.; Kowalska, E. Interparticle electron transfer in methanol dehydrogenation on platinum-loaded titania particles prepared from P25. Catal. Today 2018, 303, 327-333. [CrossRef]

45. Yuan, X.; Wang, C.; Dragoe, D.; Beaunier, P.; Colbeau-Justin, C.; Remita, H. Highly Promoted Photocatalytic Hydrogen Generation by Multiple Electron Transfer Pathways. Appl. Catal. B Environ. 2021, 281, 119457. [CrossRef]

46. Abe, R.; Shinmei, K.; Koumura, N.; Hara, K.; Ohtani, B. Visible-Light-Induced Water Splitting Based on Two-Step Photoexcitation between Dye-Sensitized Layered Niobate and Tungsten Oxide Photocatalysts in the Presence of a Triiodide/Iodide Shuttle Redox Mediator. J. Am. Chem. Soc. 2013, 135, 16872-16884. [CrossRef]

47. Muniz-Miranda, M.; Gellini, C.; Simonelli, A.; Tiberi, M.; Giammanco, F.; Giorgetti, E. Characterization of Copper nanoparticles obtained by laser ablation in liquids. Appl. Phys. A 2013, 110, 829-833. [CrossRef]

48. Nilius, N.; Ernst, N.; Freund, H. On energy transfer processes at cluster-oxide interfaces: Silver on titania. Chem. Phys. Lett. 2001, 349, 351-357. [CrossRef]

49. Endo-Kimura, M.; Karabiyik, B.; Wang, K.; Wei, Z.; Ohtani, B.; Markowska-Szczupak, A.; Kowalska, E. Vis-responsive coppermodified titania for decomposition of organic compounds and microorganisms. Catalysts 2020, 10, 1194. [CrossRef]

50. Janczarek, M.; Wei, Z.; Endo, M.; Ohtani, B.; Kowalska, E. Silver- and copper-modified decahedral anatase tiania particles as visible light-responsive plasmonic photocatalyst. J. Photon. Energy 2017, 7, 012008. [CrossRef]

51. Ombaka, L.M.; Curti, M.; McGettrick, J.D.; Davies, M.L.; Bahnemann, D.W. Nitrogen/Carbon-Coated Zero-Valent Copper as Highly Efficient Co-catalysts for $\mathrm{TiO}_{2}$ Applied in Photocatalytic and Photoelectrocatalytic Hydrogen Production. ACS Appl. Mater. Interfaces 2020, 12, 30365-30380. [CrossRef]

52. DeSario, P.A.; Pietron, J.J.; Brintlinger, T.H.; McEntee, M.; Parker, J.F.; Baturina, O.; Stroud, R.M.; Rolison, D.R. Oxidation-stable plasmonic copper nanoparticles in photocatalytic $\mathrm{TiO}_{2}$ nanoarchitectures. Nanoscale 2017, 9, 11720-11729. [CrossRef] [PubMed]

53. Asahi, R.; Morikawa, T.; Ohwaki, T.; Aoki, K.; Taga, Y. Visible-light photocatalysis in nitrogen-doped titanium oxides. Science 2001, 293, 269-271. [CrossRef]

54. Ohno, T.; Mitsui, T.; Matsumura, M. Photocatalytic activity of S-doped $\mathrm{TiO}_{2}$ photocatalyst under visible light. Chem. Lett. 2003, 32, 364-365. [CrossRef]

55. Reszczynska, J.; Grzyb, T.; Wei, Z.S.; Klein, M.; Kowalska, E.; Ohtani, B.; Zaleska-Medynska, A. Photocatalytic activity and luminescence properties of $\mathrm{RE}^{3+}-\mathrm{TiO}_{2}$ nanocrystals prepared by sol-gel and hydrothermal methods. Appl. Catal. B Environ. 2016, 181, 825-837. [CrossRef]

56. Luna, A.L.; Novoseltceva, E.; Louran, E.; Beaunier, P.; Kowalska, E.; Ohtani, B.; Valenzuela, M.A.; Remita, H.; Colbeau-Justin, C. Synergetic effect of $\mathrm{Ni}$ and Au nanoparticles synthesized on titania particles for efficient photocatalytic hydrogen production. Appl. Catal. B Environ. 2016, 191, 18-28. [CrossRef]

57. Wang, K.; Bielan, Z.; Endo-Kimura, M.; Janczarek, M.; Zhang, D.; Kowalski, D.; Zielińska-Jurek, A.; Markowska-Szczupak, A.; Ohtani, B.; Kowalska, E. On the mechanism of photocatalytic reactions on $\mathrm{Cu}_{\mathrm{x}} \mathrm{O} @ \mathrm{TiO}_{2}$ core-shell photocatalysts. J. Mat. Chem. A 2021, 9, 10135-10145. [CrossRef] 
58. Tian, Y.; Tatsuma, T. Mechanisms and Applications of Plasmon-Induced Charge Separation at $\mathrm{TiO}_{2}$ Films Loaded with Gold Nanoparticles. J. Am. Chem. Soc. 2005, 127, 7632-7637. [CrossRef]

59. Kowalska, E.; Abe, R.; Ohtani, B. Visible light-induced photocatalytic reaction of gold-modified titanium(IV) oxide particles: Action spectrum analysis. Chem. Commun. 2009, 241-243. [CrossRef]

60. Ueno, K.; Misawa, H. Surface plasmon-enhanced photochemical reactions. J. Photoch. Photobio. C 2013, 15, 31-52. [CrossRef]

61. Verbruggen, S.W. $\mathrm{TiO}_{2}$ photocatalysis for the degradation of pollutants in gas phase: From morphological design to plasmonic enhancement. J. Photoch. Photobio. C Photochem. Rev. 2015, 24, 64-82. [CrossRef]

62. Wei, Z.; Janczarek, M.; Wang, K.; Zheng, S.; Kowalska, E. Morphology-governed performance of plasmonic photocatalysts. Catalysts 2020, 10, 1070. [CrossRef]

63. Malankowska, A.; Kobylanski, M.P.; Mikolajczyk, A.; Cavdar, O.; Nowaczyk, G.; Jarek, M.; Lisowski, W.; Michalska, M.; Kowalska, E.; Ohtani, B.; et al. $\mathrm{TiO}_{2}$ and $\mathrm{NaTaO}_{3}$ Decorated by Trimetallic $\mathrm{Au} / \mathrm{Pd} / \mathrm{Pt}$ Core-Shell Nanoparticles as Efficient Photocatalysts: Experimental and Computational Studies. ACS Sustain. Chem. Eng. 2018, 6, 16665-16682. [CrossRef]

64. Kowalska, E.; Yoshiiri, K.; Wei, Z.; Zheng, S.; Kastl, E.; Remita, H.; Ohtani, B.; Rau, S. Hybrid photocatalysts composed of titania modified with plasmonic nanoparticles and ruthenium complexes for decomposition of organic compounds. Appl. Catal. B Environ. 2015, 178, 133-143. [CrossRef]

65. Mendez-Medrano, M.G.; Kowalska, E.; Lehoux, A.; Herissan, A.; Ohtani, B.; Rau, S.; Colbeau-Justin, C.; Rodriguez-Lopez, J.L.; Remita, H. Surface Modification of $\mathrm{TiO}_{2}$ with $\mathrm{Au}$ Nanoclusters for Efficient Water Treatment and Hydrogen Generation under Visible Light. J. Phys. Chem. C 2016, 120, 25010-25022. [CrossRef]

66. Bian, Z.F.; Tachikawa, T.; Zhang, P.; Fujitsuka, M.; Majima, T. Au/TiO 2 Superstructure-Based Plasmonic Photocatalysts Exhibiting Efficient Charge Separation and Unprecedented Activity. J. Am. Chem. Soc. 2014, 136, 458-465. [CrossRef]

67. Bian, Z.F.; Tachikawa, T.; Zhang, P.; Fujitsuka, M.; Majima, T. A nanocomposite superstructure of metal oxides with effective charge transfer interfaces. Nat. Commun. 2014, 5, 3038. [CrossRef]

68. Yu, S.; Han, B.; Lou, Y.; Liu, Z.; Qian, G.; Wang, Z. Rational design and fabrication of $\mathrm{TiO}_{2}$ nano heterostructure with multijunctions for efficient photocatalysis. Int. J. Hydrogen Energy 2020, 45, 28640-28650. [CrossRef]

69. Janczarek, M.; Kowalska, E. Defective Dopant-Free $\mathrm{TiO}_{2}$ as an Efficient Visible Light-Active Photocatalyst. Catalysts 2021, 11, 978. [CrossRef]

70. Luna, A.L.; Dragoe, D.; Wang, K.L.; Beaunier, P.; Kowalska, E.; Ohtani, B.; Uribe, D.B.; Valenzuela, M.A.; Remita, H.; ColbeauJustin, C. Photocatalytic Hydrogen Evolution Using Ni-Pd/ $\mathrm{TiO}_{2}$ : Correlation of Light Absorption, Charge-Carrier Dynamics, and Quantum Efficiency. J. Phys. Chem. C 2017, 121, 14302-14311. [CrossRef]

71. Huang, H.; Lin, J.; Fan, L.; Wang, X.; Fu, X.; Long, J. Heteroatomic Ni, Sn Clusters-Grafted Anatase TiO 2 Photocatalysts: Structure, Electron Delocalization, and Synergy for Solar Hydrogen Production. J. Phys. Chem. C 2015, 119, 10478-10492. [CrossRef]

72. Amano, F.; Yasumoto, T.; Prieto-Mahaney, O.O.; Uchida, S.; Shibayama, T.; Ohtani, B. Photocatalytic activity of octahedral single-crystalline mesoparticles of anatase titanium(IV) oxide. Chem. Commun. 2009, 2311-2313. [CrossRef]

73. Wei, Z.; Kowalska, E.; Verrett, J.; Colbeau-Justin, C.; Remita, H.; Ohtani, B. Morphology-dependent photocatalytic activity of octahedral anatase particles prepared by ultrasonication-hydrothermal reaction of titanates. Nanoscale 2015, 7, 12392-12404. [CrossRef]

74. Amano, F.; Prieto-Mahaney, O.O.; Terada, Y.; Yasumoto, T.; Shibayama, T.; Ohtani, B. Decahedral single-crystalline particles of anatase titanium(IV) oxide with high photocatalytic activity. Chem. Mater. 2009, 21, 2601-2603. [CrossRef]

75. Janczarek, M.; Kowalska, E.; Ohtani, B. Decahedral-shaped anatase titania photocatalyst particles: Synthesis in a newly developed coaxial-flow gas-phase reactor. Chem. Eng. J. 2016, 289, 502-512. [CrossRef]

76. Wei, Z.; Janczarek, M.; Endo, M.; Colbeau-Justin, C.; Ohtani, B.; Kowalska, E. Silver-modified octahedral anatase particles as plasmonic photocatalyst. Catal. Today 2018, 310, 19-25. [CrossRef] [PubMed]

77. Wei, Z.; Rosa, L.; Wang, K.; Endo, M.; Juodkazi, S.; Ohtani, B.; Kowalska, E. Size-controlled gold nanoparticles on octahedral anatase particles as efficient plasmonic photocatalyst. Appl. Catal. B Environ. 2017, 206, 393-405. [CrossRef]

78. Amoli, V.; Sibi, M.G.; Banerjee, B.; Anand, M.; Maurya, A.; Farooqui, S.A.; Bhaumik, A.; Sinha, A.K. Faceted Titania Nanocrystals Doped with Indium Oxide Nanoclusters As a Superior Candidate for Sacrificial Hydrogen Evolution without Any Noble-Metal Cocatalyst under Solar Irradiation. ACS Appl. Mater. Interfaces 2015, 7, 810-822. [CrossRef]

79. Li, W.; Elzatahry, A.; Aldhayan, D.; Zhao, D. Core-shell structured titanium dioxide nanomaterials for solar energy utilization. Chem. Soc. Rev. 2018, 47, 8203-8237. [CrossRef] [PubMed]

80. Ghosh Chaudhuri, R.; Paria, S. Core/Shell Nanoparticles: Classes, Properties, Synthesis Mechanisms, Characterization, and Applications. Chem. Rev. 2012, 112, 2373-2433. [CrossRef] [PubMed]

81. Bielan, Z.; Sulowska, A.; Dudziak, S.; Siuzdak, K.; Ryl, J.; Zielinska-Jurek, A. Defective $\mathrm{TiO}_{2}$ core-shell magnetic photocatalyst modified with plasmonic nanoparticles for visible light-induced photocatalytic activity. Catalysts 2020, 10, 672. [CrossRef]

82. Zielinska-Jurek, A.; Bielan, Z.; Wysocka, I.; Strychalska, J.; Janczarek, M.; Klimczuk, T. Magnetic semiconductor photocatalysts for the degradation of recalcitrant chemicals from flow back water. J. Environ. Manag. 2017, 195, 157-165. [CrossRef]

83. Bielan, Z.; Kowalska, E.; Dudziak, S.; Wang, K.; Ohtani, B.; Zielinska-Jurek, A. Mono- and bimetallic (Pt/Cu) titanium(IV) oxide core-shell photocatalysts with UV/Vis light activity and magnetic separability. Catal. Today 2021, 361, 198-209. [CrossRef]

84. Janczarek, M.; Kowalska, E. On the Origin of Enhanced Photocatalytic Activity of Copper-Modified Titania in the Oxidative Reaction Systems. Catalysts 2017, 7, 317. [CrossRef] 
85. Endo-Kimura, M.; Janczarek, M.; Bielan, Z.; Zhang, D.; Wang, K.; Markowska-Szczupak, A.; Kowalska, E. Photocatalytic and antimicrobial properties of $\mathrm{Ag}_{2} \mathrm{O} / \mathrm{TiO}_{2}$ heterojunction. ChemEngineering 2019, 3, 3. [CrossRef]

86. Janczarek, M.; Endo, M.; Zhang, D.; Wang, K.; Kowalska, E. Enhanced photocatalytic and antimicrobial prformance of cuprous oxide/titania: The effect of titania matrix. Materials. 2018, 11, 2069. [CrossRef]

87. Mendez-Medrano, M.G.; Kowalska, E.; Ohtani, B.; Uribe, D.B.; Colbeau-Justin, C.; Rau, S.; Rodriguez-Lopez, J.L.; Remita, H. Heterojunction of $\mathrm{CuO}$ nanoclusters with $\mathrm{TiO}_{2}$ for photo-oxidation of organic compounds and for hydrogen production. J. Chem. Phys. 2020, 153, 034705. [CrossRef]

88. Zubair, M.; Svenum, I.-H.; Rønning, M.; Yang, J. Facile synthesis approach for core-shell $\mathrm{TiO}_{2}-\mathrm{CdS}$ nanoparticles for enhanced photocatalytic $\mathrm{H}_{2}$ generation from water. Catal. Today 2019, 328, 15-20. [CrossRef]

89. Paszkiewicz-Gawron, M.; Kowalska, E.; Endo-Kimura, M.; Zwara, J.; Pancielejko, A.; Wang, K.; Lisowski, W.; Łuczak, J.; ZaleskaMedynska, A.; Grabowska-Musiał, E. Stannates, titanates and tantalates modified with carbon and graphene quantum dots for enhancement of visible-light photocatalytic activity. Appl. Surf. Sci. 2021, 541, 148425. [CrossRef]

90. Dong, Y.; Han, Q.; Hu, Q.; Xu, C.; Dong, C.; Peng, Y.; Ding, Y.; Lan, Y. Carbon quantum dots enriching molecular nickel polyoxometalate over CdS semiconductor for photocatalytic water splitting. Appl. Catal. B Environ. 2021, 293, 120214. [CrossRef]

91. Zhang, P.; Zeng, G.; Song, T.; Huang, S.; Wang, T.; Zeng, H. Synthesis of a plasmonic CuNi bimetal modified with carbon quantum dots as a non-semiconductor-driven photocatalyst for effective water splitting. J. Catal. 2019, 369, 267-275. [CrossRef]

92. Campuzano, S.; Yáñez-Sedeño, P.; Pingarrón, J.M. Carbon Dots and Graphene Quantum Dots in Electrochemical Biosensing. Nanomaterials 2019, 9, 634. [CrossRef]

93. Giovannetti, R.; Rommozzi, E.; Zannotti, M.; D'Amato, C.A. Recent Advances in Graphene Based TiO $2 \mathrm{Nanocomposites}$ $\left(\mathrm{GTiO}_{2} \mathrm{Ns}\right)$ for Photocatalytic Degradation of Synthetic Dyes. Catalysts 2017, 7, 305. [CrossRef]

94. Wang, K.L.; Endo-Kimura, M.; Belchi, R.; Zhang, D.; Habert, A.; Boucle, J.; Ohtani, B.; Kowalska, E.; Herlin-Boime, N. Carbon/graphene-modified titania with enhanced photocatalytic activity under UV and vis irradiation. Materials. 2019, 12, 4158. [CrossRef] [PubMed]

95. Zou, J.-P.; Wang, L.-C.; Luo, J.; Nie, Y.-C.; Xing, Q.-J.; Luo, X.-B.; Du, H.-M.; Luo, S.-L.; Suib, S.L. Synthesis and efficient visible light photocatalytic $\mathrm{H}_{2}$ evolution of a metal-free $\mathrm{g}-\mathrm{C}_{3} \mathrm{~N}_{4}$ /graphene quantum dots hybrid photocatalyst. Appl. Catal. B Environ. 2016, 193, 103-109. [CrossRef]

96. Yan, M.; Hua, Y.; Zhu, F.; Sun, L.; Gu, W.; Shi, W. Constructing nitrogen doped graphene quantum dots- $\mathrm{ZnNb}_{2} \mathrm{O}_{6} / g-\mathrm{C}_{3} \mathrm{~N}_{4}$ catalysts for hydrogen production under visible light. Appl. Catal. B Environ. 2017, 206, 531-537. [CrossRef]

97. Qian, J.; Chen, Z.; Chen, F.; Wang, Y.; Wu, Z.; Zhang, W.; Wu, Z.; Li, P. Exploration of $\mathrm{CeO}_{2}-\mathrm{CuO}$ Quantum Dots in Situ Grown on Graphene under Hypha Assistance for Highly Efficient Solar-Driven Hydrogen Production. Inorg. Chem. 2018, 57, 14532-14541. [CrossRef] [PubMed]

98. Lee, S.; Lee, K.; Kim, W.D.; Lee, S.; Shin, D.J.; Lee, D.C. Thin Amorphous $\mathrm{TiO}_{2}$ Shell on CdSe Nanocrystal Quantum Dots Enhances Photocatalysis of Hydrogen Evolution from Water. J. Phys. Chem. C 2014, 118, 23627-23634. [CrossRef]

99. Ohtani, B.; Ogawa, Y.; Nishimoto, S.I. Photocatalytic Activity of Amorphous-Anatase Mixture of Titanium(IV) Oxide Particles Suspended in Aqueous Solutions. J. Phys. Chem. B 1997, 101, 3746-3752. [CrossRef]

100. Gong, D.; Grimes, C.A.; Varghese, O.K.; Hu, W.; Singh, R.S.; Chen, Z.; Dickey, E.C. Titanium oxide nanotube arrays prepared by anodic oxidation. J. Mater. Res. 2001, 16, 3331-3334. [CrossRef]

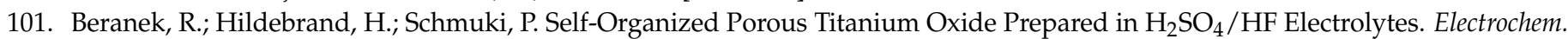
Solid State Lett. 2003, 6, B12-B14. [CrossRef]

102. Kowalski, D.; Kim, D.; Schmuki, P. $\mathrm{TiO}_{2}$ nanotubes, nanochannels and mesosponge: Self-organized formation and applications. Nano Today 2013, 8, 235-264. [CrossRef]

103. Mor, G.K.; Varghese, O.K.; Paulose, M.; Shankar, K.; Grimes, C.A. A review on highly ordered, vertically oriented TiO 2 nanotube arrays: Fabrication, material properties, and solar energy applications. Sol. Energy Mater. Sol. 2006, 90, 2011-2075. [CrossRef]

104. Mor, G.K.; Shankar, K.; Paulose, M.; Varghese, O.K.; Grimes, C.A. Use of Highly-Ordered $\mathrm{TiO}_{2} \mathrm{Nanotube}$ Arrays in Dye-Sensitized Solar Cells. Nano Lett. 2006, 6, 215-218. [CrossRef] [PubMed]

105. Kowalski, D.; Schmuki, P. Polypyrrole self-organized nanopore arrays formed by controlled electropolymerization in $\mathrm{TiO}_{2}$ nanotube template. Chem. Commun. 2010, 46, 8585-8587. [CrossRef] [PubMed]

106. Kowalski, D.; Mallet, J.; Thomas, S.; Nemaga, A.W.; Michel, J.; Guery, C.; Molinari, M.; Morcrette, M. Electrochemical synthesis of $1 \mathrm{D}$ core-shell $\mathrm{Si} / \mathrm{TiO}_{2}$ nanotubes for lithium ion batteries. J. Power Sources 2017, 361, 243-248. [CrossRef]

107. Kowalski, D.; Mallet, J.; Thomas, S.; Rysz, J.; Bercu, B.; Michel, J.; Molinari, M. Self-organization of TiO 2 nanotubes in mono-, diand tri-ethylene glycol electrolytes. Electrochim. Acta 2016, 204, 287-293. [CrossRef]

108. Nischk, M.; Mazierski, P.; Wei, Z.S.; Siuzdak, K.; Kouame, N.A.; Kowalska, E.; Remita, H.; Zaleska-Medynska, A. Enhanced photocatalytic, electrochemical and photoelectrochemical properties of $\mathrm{TiO}_{2}$ nanotubes arrays modified with $\mathrm{Cu}, \mathrm{AgCu}$ and $\mathrm{Bi}$ nanoparticles obtained via radiolytic reduction. Appl. Surf. Sci. 2016, 387, 89-102. [CrossRef] [PubMed]

109. Mazierski, P.; Malankowska, A.; Kobylanski, M.; Diak, M.; Kozak, M.; Winiarski, M.J.; Klimczuk, T.; Lisowski, W.; Nowaczyk, G.; Zaleska-Medynska, A. Photocatalytically Active $\mathrm{TiO}_{2} / \mathrm{Ag}_{2} \mathrm{O}$ Nanotube Arrays Interlaced with Silver Nanoparticles Obtained from the One-Step Anodic Oxidation of Ti-Ag Alloys. ACS Catal. 2017, 7, 2753-2764. [CrossRef] 
110. Wang, G.M.; Feng, H.Q.; Hu, L.S.; Jin, W.H.; Hao, Q.; Gao, A.; Peng, X.; Li, W.; Wong, K.Y.; Wang, H.Y.; et al. An antibacterial platform based on capacitive carbon-doped $\mathrm{TiO}_{2}$ nanotubes after direct or alternating current charging. Nat. Commun. 2018, 9, 2055. [CrossRef]

111. Zhao, Y.; Hoivik, N.; Wang, K.Y. Recent advance on engineering titanium dioxide nanotubes for photochemical and photoelectrochemical water splitting. Nano Energy 2016, 30, 728-744. [CrossRef]

112. Chu, J.; Sun, Y.; Han, X.; Zhang, B.; Du, Y.; Song, B.; Xu, P. Mixed Titanium Oxide Strategy for Enhanced Photocatalytic Hydrogen Evolution. ACS Appl. Mater. Interfaces 2019, 11, 18475-18482. [CrossRef]

113. Yang, W.; Li, M.; Pan, K.; Guo, L.; Wu, J.; Li, Z.; Yang, F.; Lin, K.; Zhou, W. Surface engineering of mesoporous anatase titanium dioxide nanotubes for rapid spatial charge separation on horizontal-vertical dimensions and efficient solar-driven photocatalytic hydrogen evolution. J. Colloid Interface Sci. 2021, 586, 75-83. [CrossRef]

114. Liu, N.; Schneider, C.; Freitag, D.; Hartmann, M.; Venkatesan, U.; Müller, J.; Spiecker, E.; Schmuki, P. Black TiO 2 Nanotubes: Cocatalyst-Free Open-Circuit Hydrogen Generation. Nano Lett. 2014, 14, 3309-3313. [CrossRef] [PubMed]

115. Wang, Y.; Zhu, L.; Ba, N.; Gao, F.; Xie, H. Effects of $\mathrm{NH}_{4} \mathrm{~F}$ quantity on N-doping level, photodegradation and photocatalytic $\mathrm{H}_{2}$ production activities of $\mathrm{N}$-doped $\mathrm{TiO}_{2}$ nanotube array films. Mater. Res. Bull. 2017, 86, 268-276. [CrossRef]

116. Chen, W.-T.; Dosado, A.G.; Chan, A.; Sun-Waterhouse, D.; Waterhouse, G.I.N. Highly reactive anatase nanorod photocatalysts synthesized by calcination of hydrogen titanate nanotubes: Effect of calcination conditions on photocatalytic performance for aqueous dye degradation and $\mathrm{H}_{2}$ production in alcohol-water mixtures. Appl. Catal. A Gen. 2018, 565, 98-118. [CrossRef]

117. Galdámez-Martínez, A.; Bai, Y.; Santana, G.; Sprick, R.S.; Dutt, A. Photocatalytic hydrogen production performance of 1-D ZnO nanostructures: Role of structural properties. Int. J. Hydrogen Energy 2020, 45, 31942-31951. [CrossRef]

118. Yu, X.; Li, W.; Li, Z.; Liu, J.; Hu, P. Defect engineered $\mathrm{Ta}_{2} \mathrm{O}_{5}$ nanorod: One-pot synthesis, visible-light driven hydrogen generation and mechanism. Appl. Catal. B Environ. 2017, 217, 48-56. [CrossRef]

119. Wang, Z.; Hu, T.; He, H.; Fu, Y.; Zhang, X.; Sun, J.; Xing, L.; Liu, B.; Zhang, Y.; Xue, X. Enhanced $\mathrm{H}_{2} \mathrm{Production}_{\text {of TiO }} / \mathrm{ZnO}$ Nanowires Co-Using Solar and Mechanical Energy through Piezo-Photocatalytic Effect. ACS Sustain. Chem. Eng. 2018, 6, 10162-10172. [CrossRef]

120. Tso, S.; Li, W.-S.; Wu, B.-H.; Chen, L.-J. Enhanced $\mathrm{H}_{2}$ production in water splitting with CdS-ZnO core-shell nanowires. Nano Energy 2018, 43, 270-277. [CrossRef]

121. Hsu, M.-H.; Chang, C.-J.; Weng, H.-T. Efficient $\mathrm{H}_{2}$ Production Using $\mathrm{Ag}_{2} \mathrm{~S}$-Coupled ZnO@ZnS Core-Shell Nanorods Decorated Metal Wire Mesh as an Immobilized Hierarchical Photocatalyst. ACS Sustain. Chem. Eng. 2016, 4, 1381-1391. [CrossRef]

122. Hu, S.; Qiao, P.; Zhang, L.; Jiang, B.; Gao, Y.; Hou, F.; Wu, B.; Li, Q.; Jiang, Y.; Tian, C.; et al. Assembly of TiO ${ }_{2}$ ultrathin nanosheets with surface lattice distortion for solar-light-driven photocatalytic hydrogen evolution. Appl. Catal. B Environ. 2018, 239, 317-323. [CrossRef]

123. Liu, Y.; Wang, M.; Li, D.; Fang, F.; Huang, W. Engineering self-doped surface defects of anatase $\mathrm{TiO}_{2}$ nanosheets for enhanced photocatalytic efficiency. Appl. Surf. Sci. 2021, 540, 148330. [CrossRef]

124. Liu, X.; Hua, R.; Niu, J.; Zhang, Z.; Zhang, J. $\mathrm{N}_{2}$ plasma treatment $\mathrm{TiO}_{2}$ nanosheets for enhanced visible light-driven photocatalysis. J. Alloys Compd. 2021, 881, 160509. [CrossRef]

125. Hu, X.; Song, J.; Luo, J.; Zhang, H.; Sun, Z.; Li, C.; Zheng, S.; Liu, Q. Single-atomic Pt sites anchored on defective TiO 2 nanosheets as a superior photocatalyst for hydrogen evolution. J. Energy Chem. 2021, 62, 1-10. [CrossRef]

126. Yu, X.; Liu, G.; Li, W.; An, L.; Li, Z.; Liu, J.; Hu, P. Mesocrystalline $\mathrm{Ta}_{2} \mathrm{O}_{5}$ nanosheets supported PdPt nanoparticles for efficient photocatalytic hydrogen production. Int. J. Hydrogen Energy 2018, 43, 8232-8242. [CrossRef]

127. Wu, X.; Zuo, S.; Qiu, M.; Li, Y.; Zhang, Y.; An, P.; Zhang, J.; Zhang, H.; Zhang, J. Atomically defined Co on two-dimensional TiO 2 nanosheet for photocatalytic hydrogen evolution. Chem. Eng. J. 2021, 420, 127681. [CrossRef]

128. Wu, Y.; Li, Y.; Hu, H.; Zeng, G.; Li, C. Recovering Hydrogen Energy from Photocatalytic Treatment of PharmaceuticalContaminated Water Using $\mathrm{Co}_{3} \mathrm{O}_{4}$ Modified $\{001\} /\{101\}-\mathrm{TiO}_{2}$ Nanosheets. ACS EST Eng. 2021, 1, 603-611. [CrossRef]

129. Feng, J.; An, C.; Dai, L.; Liu, J.; Wei, G.; Bai, S.; Zhang, J.; Xiong, Y. Long-term production of $\mathrm{H}_{2}$ over Pt/CdS nanoplates under sunlight illumination. Chem. Eng. J. 2016, 283, 351-357. [CrossRef]

130. Su, Y.; Zhang, L.; Wang, W. Internal polar field enhanced $\mathrm{H}_{2}$ evolution of $\mathrm{BiOIO}_{3}$ nanoplates. Int. J. Hydrogen Energy 2016, 41, 10170-10177. [CrossRef]

131. Yu, S.; Webster, R.D.; Zhou, Y.; Yan, X. Ultrathin $\mathrm{g}-\mathrm{C}_{3} \mathrm{~N}_{4}$ nanosheets with hexagonal CuS nanoplates as a novel composite photocatalyst under solar light irradiation for $\mathrm{H}_{2}$ production. Catal. Sci. Technol. 2017, 7, 2050-2056. [CrossRef]

132. Zhang, S.; Chen, S.; Liu, D.; Zhang, J.; Peng, T. Layered $\mathrm{WS}_{2} / \mathrm{WO}_{3}$ Z-scheme photocatalyst constructed via an in situ sulfurization of hydrous $\mathrm{WO}_{3}$ nanoplates for efficient $\mathrm{H}_{2}$ generation. Appl. Surf. Sci. 2020, 529, 147013. [CrossRef]

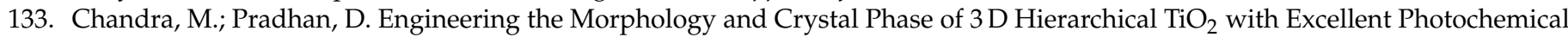
and Photoelectrochemical Solar Water Splitting. ChemSusChem 2020, 13, 3005-3016. [CrossRef]

134. Zhang, W.; Zhang, H.; Xu, J.; Zhuang, H.; Long, J. 3D flower-like heterostructured $\mathrm{TiO}_{2} @ \mathrm{Ni}(\mathrm{OH})_{2}$ microspheres for solar photocatalytic hydrogen production. Chin. J. Catal. 2019, 40, 320-325. [CrossRef]

135. Liu, X.; Xing, Z.; Zhang, Y.; Li, Z.; Wu, X.; Tan, S.; Yu, X.; Zhu, Q.; Zhou, W. Fabrication of 3D flower-like black N-TiO ${ }_{2}-\mathrm{x}_{\mathrm{M}} \mathrm{MoS}_{2}$ for unprecedented-high visible-light-driven photocatalytic performance. Appl. Catal. B Environ. 2017, 201, 119-127. [CrossRef]

136. Lv, T.; Xu, Z.; Hong, W.; Li, G.; Li, Y.; Jia, L. Graphene oxide mediated self-sacrificial synthesis of $\mathrm{LaCO}_{3} \mathrm{OH}-\mathrm{Ni}(\mathrm{OH})_{2} @ g r a p h e n e$ hierarchical composite for photocatalytic $\mathrm{H}_{2}$ evolution and supercapacitor. Chem. Eng. J. 2020, 382, 123021-123032. [CrossRef] 
137. Chao, P.-Y.; Chang, C.-J.; Lin, K.-S.; Wang, C.F. Synergistic effects of morphology control and calcination on the activity of flower-like $\mathrm{Bi}_{2} \mathrm{WO}_{6}-\mathrm{Bi}_{2} \mathrm{O}_{3}$ photocatalysts prepared by an ionic liquid-assisted solvothermal method. J. Alloys Compd. 2021, 883, 160920-160930. [CrossRef]

138. Sun, L.; Xiao, H.; Cong, S.; Hao, Y.; Xue, M.; Kang, S.-Z. Fabrication of flower-like $\mathrm{Sn}_{3} \mathrm{O}_{4}$ hierarchical nanostructure and its photocatalytic activity for $\mathrm{H}_{2}$ evolution from water. Inorg. Chem. Commun. 2019, 106, 116-119. [CrossRef]

139. Di, T.; Cheng, B.; Ho, W.; Yu, J.; Tang, H. Hierarchically CdS- $\mathrm{Ag}_{2} \mathrm{~S}$ nanocomposites for efficient photocatalytic H2 production. Appl. Surf. Sci. 2019, 470, 196-204. [CrossRef]

140. Zhang, W.; He, H.; Tian, Y.; Li, H.; Lan, K.; Zu, L.; Xia, Y.; Duan, L.; Li, W.; Zhao, D. Defect-engineering of mesoporous TiO 2 microspheres with phase junctions for efficient visible-light driven fuel production. Nano Energy 2019, 66, 104113. [CrossRef]

141. Zhang, W.; He, H.L.; Tian, Y.; Lan, K.; Liu, Q.; Wang, C.Y.; Liu, Y.; Elzatahry, A.; Che, R.C.; Li, W.; et al. Synthesis of uniform ordered mesoporous $\mathrm{TiO}_{2}$ microspheres with controllable phase junctions for efficient solar water splitting. Chem. Sci. 2019, 10, 1664-1670. [CrossRef]

142. Lv, S.; Wang, Y.; Zhou, Y.; Liu, Q.; Song, C.; Wang, D. Oxygen vacancy stimulated direct Z-scheme of mesoporous $\mathrm{Cu}_{2} \mathrm{O} / \mathrm{TiO}_{2}$ for enhanced photocatalytic hydrogen production from water and seawater. J. Alloys Compd. 2021, 868, 159144. [CrossRef]

143. Zou, X.; Yang, Y.; Chen, H.; Shi, X.-L.; Song, S.; Chen, Z.-G. Hierarchical meso/macro-porous $\mathrm{TiO}_{2} /$ graphitic carbon nitride nanofibers with enhanced hydrogen evolution. Mater. Des. 2021, 202, 109542. [CrossRef]

144. Meng, A.; Zhu, B.; Zhong, B.; Zhang, L.; Cheng, B. Direct Z-scheme $\mathrm{TiO}_{2} / \mathrm{CdS}$ hierarchical photocatalyst for enhanced photocatalytic $\mathrm{H}_{2}$-production activity. Appl. Surf. Sci. 2017, 422, 518-527. [CrossRef]

145. Lv, B.; Lu, L.; Feng, X.; Wu, X.; Wang, X.; Zou, X.; Zhang, F. Efficient photocatalytic hydrogen production using an $\mathrm{NH}_{4} \mathrm{TiOF}_{3} / \mathrm{TiO}_{2} / \mathrm{g}-\mathrm{C}_{3} \mathrm{~N}_{4}$ composite with a 3D camellia-like Z-scheme heterojunction structure. Ceram. Int. 2020, 46, 26689-26697. [CrossRef]

146. Zhang, J.; Huang, Y.; Nie, T.; Wang, R.; He, B.; Han, B.; Wang, H.; Tian, Y.; Gong, Y. Enhanced visible-light photocatalytic $\mathrm{H}_{2}$ production of hierarchical g- $\mathrm{C}_{3} \mathrm{~N}_{4}$ hexagon by one-step self-assembly strategy. Appl. Surf. Sci. 2020, 499, 143942. [CrossRef]

147. Gultom, N.S.; Abdullah, H.; Kuo, D.-H.; Ke, W.-C. Oriented p-n Heterojunction $\mathrm{Ag}_{2} \mathrm{O} / \mathrm{Zn}(\mathrm{O}, \mathrm{S})$ Nanodiodes on Mesoporous SiO2 for Photocatalytic Hydrogen Production. ACS Appl. Energy Mat. 2019, 2, 3228-3236. [CrossRef]

148. Zhang, C.; Zhou, Y.; Bao, J.; Sheng, X.; Fang, J.; Zhao, S.; Zhang, Y.; Chen, W. Hierarchical Honeycomb Br-, N-Codoped TiO 2 with Enhanced Visible-Light Photocatalytic $\mathrm{H}_{2}$ Production. ACS Appl. Mater. Interfaces 2018, 10, 18796-18804. [CrossRef]

149. Yablonovitch, E. Photonic Band-Gap Structures. J. Opt. Soc. Am. B 1993, 10, 283-295. [CrossRef]

150. Lopez, C. Materials aspects of photonic crystals. Adv. Mater. 2003, 15, 1679-1704. [CrossRef]

151. Jovic, V.; Idriss, H.; Waterhouse, G.I.N. Slow photon amplification of gas-phase ethanol photo-oxidation in titania inverse opal photonic crystals. Chem. Phys. 2016, 479, 109-121. [CrossRef]

152. Curti, M.; Mendive, C.B.; Grela, M.A.; Bahnemann, D.W. Stopband tuning of $\mathrm{TiO}_{2}$ inverse opals for slow photon absorption. Mater. Res. Bull. 2017, 91, 155-165. [CrossRef]

153. Wan, Y.; Wang, J.; Wang, X.; Xu, H.; Yuan, S.; Zhang, Q.; Zhang, M. Preparation of inverse opal titanium dioxide for photocatalytic performance research. Optic. Mater. 2019, 96, 109287. [CrossRef]

154. Chiarello, G.L.; Zuliani, A.; Ceresoli, D.; Martinazzo, R.; Selli, E. Exploiting the Photonic Crystal Properties of TiO $2 \mathrm{Nanotube}$ Arrays To Enhance Photocatalytic Hydrogen Production. ACS Catal. 2016, 6, 1345-1353. [CrossRef]

155. Kim, W.T.; Choi, W.Y. Fabrication of $\mathrm{TiO}_{2}$ photonic crystal by anodic oxidation and their optical sensing properties. Sens. Actuators A Phys. 2017, 260, 178-184. [CrossRef]

156. Cheng, C.W.; Karuturi, S.K.; Liu, L.J.; Liu, J.P.; Li, H.X.; Su, L.T.; Tok, A.I.Y.; Fan, H.J. Quantum-dot-sensitized TiO 2 inverse opals for photoelectrochemical hydrogen generation. Small 2012, 8, 37-42. [CrossRef]

157. Liu, J.; Liu, G.; Li, M.; Shen, W.; Liu, Z.; Wang, J.; Zhao, J.; Jiang, L.; Song, Y. Enhancement of photochemical hydrogen evolution over Pt-loaded hierarchical titania photonic crystal. Energy Environ. Sci. 2010, 3, 1503-1506. [CrossRef]

158. Waterhouse, G.I.N.; Wahab, A.K.; Al-Oufi, M.; Jovic, V.; Anjum, D.H.; Sun-Waterhouse, D.; Llorca, J.; Idriss, H. Hydrogen production by tuning the photonic band gap with the electronic band gap of $\mathrm{TiO}_{2}$. Sci. Rep. 2013, 3, 2849. [CrossRef] [PubMed]

159. Raja-Mogan, T.; Ohtani, B.; Kowalska, E. Photonic crystals for plasmonic photocatalysis. Catalysts 2020, 10, 827. [CrossRef]

160. Zhang, X.; Liu, Y.; Lee, S.T.; Yang, S.H.; Kang, Z.H. Coupling surface plasmon resonance of gold nanoparticles with slow-photoneffect of $\mathrm{TiO}_{2}$ photonic crystals for synergistically enhanced photoelectrochemical water splitting. Energ. Environ. Sci. 2014, 7, 1409-1419. [CrossRef]

161. Zhang, L.W.; Lin, C.Y.; Valev, V.K.; Reisner, E.; Steiner, U.; Baumberg, J.J. Plasmonic enhancement in BiVO 4 photonic crystals for efficient water splitting. Small 2014, 10, 3970-3978. [CrossRef]

162. Raja-Mogan, T.; Lehoux, A.; Takashima, M.; Kowalska, E.; Ohtani, B. Slow photon-induced enhancement of photocatalytic activity of gold nanoparticle-incorporated titania in-verse opal. Chem. Lett. 2021, 50, 711-713. [CrossRef]

163. Cui, X.; Wang, Y.; Jiang, G.; Zhao, Z.; Xu, C.; Wei, Y.; Duan, A.; Liu, J.; Gao, J. A photonic crystal-based CdS-Au-WO 3 heterostructure for efficient visible-light photocatalytic hydrogen and oxygen evolution. RSC Adv. 2014, 4, 15689-15694. [CrossRef]

164. Sordello, F.; Duca, C.; Maurino, V.; Minero, C. Photocatalytic metamaterials: $\mathrm{TiO}_{2}$ inverse opals. Chem. Commun. 2011, 47, 6147-6149. [CrossRef] 
165. Zhao, H.; Hu, Z.Y.; Liu, J.; Li, Y.; Wu, M.; Van Tendeloo, G.; Su, B.L. Blue-edge slow photons promoting visible-light hydrogen production on gradient ternary $3 \mathrm{DOM} \mathrm{TiO}_{2}-\mathrm{Au}-\mathrm{CdS}$ photonic crystals. Nano Energy 2018, 47, 266-274. [CrossRef]

166. Zhang, S.S.; Peng, B.Y.; Yang, S.Y.; Wang, H.G.; Yu, H.; Fang, Y.P.; Peng, F. Non-noble metal copper nanoparticles-decorated TiO 2 nanotube arrays with plasmon-enhanced photocatalytic hydrogen evolution under visible light. Int. J. Hydrogen Energy 2015, 40, 303-310. [CrossRef]

167. Rahul, T.K.; Sandhyarani, N. In situ gold-loaded fluorinated titania inverse opal photocatalysts for enhanced solar-light-driven hydrogen production. ChemNanoMat 2017, 3, 503-510. [CrossRef]

168. Fiorenza, R.; Bellardita, M.; Scirè, S.; Palmisano, L. Photocatalytic $\mathrm{H}_{2}$ production over inverse opal TiO 2 catalysts. Catal. Today 2019, 321-322, 113-119. [CrossRef]

169. Rahul, T.K.; Mohan, M.; Sandhyarani, N. Enhanced solar hydrogen evolution over in situ gold-platinum bimetallic nanoparticleloaded $\mathrm{Ti}^{3+}$ self-doped titania photocatalysts. ACS Sustain. Chem. Eng. 2018, 6, 3049-3059. [CrossRef]

170. Zhang, R.; Wang, C.; Chen, H.; Zhao, H.; Liu, J.; Li, Y.; Su, B. Cadmium Sulfide Inverse Opal for Photocatalytic Hydrogen Production. Acta Phys. -Chim. Sin. 2020, 36, 1803014. [CrossRef]

171. Zhang, Z.H.; Yang, X.L.; Hedhili, M.N.; Ahmed, E.; Shi, L.; Wang, P. Microwave-Assisted Self-Doping of TiO $2 \mathrm{Photonic} \mathrm{Crystals}$ for Efficient Photoelectrochemical Water Splitting. ACS Appl. Mater. Inter. 2014, 6, 691-696. [CrossRef]

172. <monospace>Chen, Y.; Li, L.; Xu, Q.; Düren, T.; Fan, J.; Ma, D. Controllable Synthesis of g- ${ }_{3} \mathrm{~N}_{4}$ Inverse Opal Photocatalysts for Superior Hydrogen Evolution. Acta Phys.-Chim. Sin. 2021, 37, 2009080.

173. Temerov, F.; Pham, K.; Juuti, P.; Mäkelä, J.M.; Grachova, E.V.; Kumar, S.; Eslava, S.; Saarinen, J.J. Silver-Decorated TiO 2 Inverse Opal Structure for Visible Light-Induced Photocatalytic Degradation of Organic Pollutants and Hydrogen Evolution. ACS Appl. Mater. Interfaces 2020, 12, 41200-41210. [CrossRef] [PubMed]

174. Zhang, D.; Mao, B.; Li, D.; Liu, Y.; Li, F.; Dong, W.; Jiang, T.; Shi, W. 0D/2D Z-scheme heterojunctions of Zn-AgIn $\mathrm{ZS}_{8}$ QDs / $\alpha$-Fe ${ }_{2} \mathrm{O}_{3}$ nanosheets for efficient visible-light-driven hydrogen production. Chem. Eng. J. 2021, 417, 128275-128284. [CrossRef]

175. Liu, Q.; Huang, J.; Tang, H.; Yu, X.; Shen, J. Construction $0 \mathrm{D} \mathrm{TiO}_{2}$ nanoparticles $/ 2 \mathrm{D}$ CoP nanosheets heterojunctions for enhanced photocatalytic $\mathrm{H}_{2}$ evolution activity. J. Mater. Sci. Technol. 2020, 56, 196-205. [CrossRef]

176. Wang, J.; Wang, G.; Wang, X.; Wu, Y.; Su, Y.; Tang, H. 3D/2D direct Z-scheme heterojunctions of hierarchical TiO 2 microflowers/g$\mathrm{C}_{3} \mathrm{~N}_{4}$ nanosheets with enhanced charge carrier separation for photocatalytic $\mathrm{H}_{2}$ evolution. Carbon 2019, 149, 618-626. [CrossRef]

177. Wu, L.; Zhang, Y.; Li, X.; Cen, C. CdS nanorod arrays with $\mathrm{TiO}_{2}$ nano-coating for improved photostability and photocatalytic activity. Phys. Chem. Chem. Phys. 2014, 16, 15339-15345. [CrossRef] [PubMed]

178. Yu, J.C.; Wu, L.; Lin, J.; Li, P.; Li, Q. Microemulsion-mediated solvothermal synthesis of nanosized CdS-sensitized TiO 2 crystalline photocatalyst. Chem. Commun. 2003, 1552-1553. [CrossRef]

179. Peter, L.M.; Riley, D.J.; Tull, E.J.; Wijayantha, K.G.U. Photosensitization of nanocrystalline $\mathrm{TiO}_{2}$ by self-assembled layers of CdS quantum dots. Chem. Commun. 2002, 1030-1031. [CrossRef]

180. Tan, P.; Liu, Y.; Zhu, A.; Zeng, W.; Cui, H.; Pan, J. Rational Design of Z-Scheme System Based on 3D Hierarchical CdS Supported 0D Co $\mathrm{S}_{8}$ Nanoparticles for Superior Photocatalytic $\mathrm{H}_{2}$ Generation. ACS Sustain. Chem. Eng. 2018, 6, 10385-10394. [CrossRef]

181. Wang, J.; Wang, Z.; Qu, P.; Xu, Q.; Zheng, J.; Jia, S.; Chen, J.; Zhu, Z. A 2D/1D TiO 2 nanosheet/CdS nanorods heterostructure with enhanced photocatalytic water splitting performance for $\mathrm{H}_{2}$ evolution. Int. J. Hydrogen Energy 2018, 43, 7388-7396. [CrossRef]

182. Chava, R.K.; Do, J.Y.; Kang, M. Hydrothermal growth of two dimensional hierarchical $\mathrm{MoS}_{2}$ nanospheres on one dimensional $\mathrm{CdS}$ nanorods for high performance and stable visible photocatalytic $\mathrm{H}_{2}$ evolution. Appl. Surf. Sci. 2018, 433, 240-248. [CrossRef]

183. Wang, H.-Y.; Hu, R.; Lei, Y.-J.; Jia, Z.-Y.; Hu, G.-L.; Li, C.-B.; Gu, Q. Highly efficient and selective photocatalytic $\mathrm{CO}_{2}$ reduction based on water-soluble CdS QDs modified by the mixed ligands in one pot. Catal. Sci. Technol. 2020, 10, 2821-2829. [CrossRef]

184. Zhou, Q.; Fu, M.-L.; Yuan, B.-L.; Cui, H.-J.; Shi, J.-W. Assembly, characterization, and photocatalytic activities of TiO 2 nanotubes/CdS quantum dots nanocomposites. J. Nanoparticle Res. 2011, 13, 6661-6672. [CrossRef]

185. Bajorowicz, B.; Kowalska, E.; Nadolna, J.; Wei, Z.S.; Endo, M.; Ohtani, B.; Zaleska-Medynska, A. Preparation of CdS and Bi $2 \mathrm{~S}_{3}$ quantum dots co-decorated perovskite-type $\mathrm{KNbO} 3$ ternary heterostructure with improved visible light photocatalytic activity and stability for phenol degradation. Dalton Trans. 2018, 47, 15232-15245. [CrossRef]

186. Yang, M.; Qian, Y.; Du, J.; Yuan, S.; Wang, S.; Zhu, X.; Lin, X.; Li, K.; Li, S.; Kang, D.J. Controlled synthesis of nanoplate, nanoprism and nanopyramid-shaped CdSe decorated on porous $\mathrm{TiO}_{2}$ photocatalysts for visible-light-driven hydrogen evolution. Ceram. Int. 2018, 44, 12555-12563. [CrossRef]

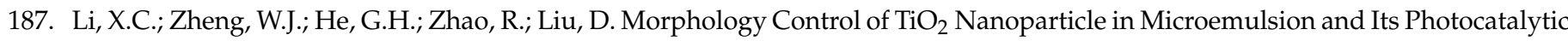
Property. ACS Sustain. Chem. Eng. 2014, 2, 288-295. [CrossRef]

188. Li, S.Y.; Yang, Y.L.; Su, Q.; Liu, X.Y.; Zhao, H.P.; Zhao, Z.X.; Li, J.; Jin, C. Synthesis and photocatalytic activity of transition metal and rare earth element co-doped $\mathrm{TiO}_{2}$ nano particles. Mater Lett. 2019, 252, 123-125. [CrossRef]

189. El-Shamy, A.G. New carbon quantum dots nano-particles decorated zinc peroxide (C-dots $\left./ \mathrm{ZnO}_{2}\right)$ nano-composite with superior photocatalytic efficiency for removal of different dyes under UV-A light. Synthetic Met. 2020, 267, 116472. [CrossRef]

190. Zhou, W.J.; Liu, H.; Boughton, R.I.; Du, G.J.; Lin, J.J.; Wang, J.Y.; Liu, D. One-dimensional single-crystalline Ti-O based nanostructures: Properties, synthesis, modifications and applications. J. Mater. Chem. 2010, 20, 5993-6008. [CrossRef]

191. Kulathunga, K.M.S.D.B.; Yan, C.F.; Bandara, J. Photocatalytic removal of airborne indoor pollutants by IR illuminated silver coated $\mathrm{TiO}_{2}$ catalyst: Advantage of one-dimensional $\mathrm{TiO}_{2}$ nanostructures in IR active photocatalysis. Colloid. Surface A 2020, 590, 124509. [CrossRef] 
192. Butler, S.Z.; Hollen, S.M.; Cao, L.Y.; Cui, Y.; Gupta, J.A.; Gutierrez, H.R.; Heinz, T.F.; Hong, S.S.; Huang, J.X.; Ismach, A.F.; et al. Progress, Challenges, and Opportunities in Two-Dimensional Materials Beyond Graphene. ACS Nano 2013, 7, $2898-2926$. [CrossRef]

193. Xu, M.S.; Liang, T.; Shi, M.M.; Chen, H.Z. Graphene-Like Two-Dimensional Materials. Chem. Rev. 2013, 113, 3766-3798. [CrossRef] [PubMed]

194. Zhou, Y.S.; Cai, T.M.; Liu, S.; Liu, Y.Y.; Chen, H.J.; Li, Z.T.; Du, J.; Lei, Z.Q.; Peng, H.L. N-doped magnetic three-dimensional carbon microspheres@ $\mathrm{TiO}_{2}$ with a porous architecture for enhanced degradation of tetracycline and methyl orange via adsorption/photocatalysis synergy. Chem. Eng. J. 2021, 411, 128615. [CrossRef]

195. Zhou, Q.L.; Li, L.; Zhang, X.Y.; Yang, H.P.; Cheng, Y.J.; Che, H.T.; Wang, L.; Cao, Y.Z. Construction of heterojunction and homojunction to improve the photocatalytic performance of $\mathrm{ZnO}$ quantum dots sensitization three-dimensional ordered hollow sphere $\mathrm{ZrO}_{2}-\mathrm{TiO}_{2}$ arrays. Int. J. Hydrogen Energy 2020, 45, 31812-31824. [CrossRef]

196. Ko, Y.H.; Leem, J.W.; Yu, J.S. Controllable synthesis of periodic flower-like ZnO nanostructures on Si subwavelength grating structures. Nanotechnology 2011, 22, 205604. [CrossRef] 